University of Louisville

ThinkIR: The University of Louisville's Institutional Repository

Electronic Theses and Dissertations

7-2012

\title{
Effect of flow on human endothelial cell and dermal cell growth rates supplemented with drug infused media.
}

Daniel Baumann

University of Louisville

Follow this and additional works at: https://ir.library.louisville.edu/etd

\section{Recommended Citation}

Baumann, Daniel, "Effect of flow on human endothelial cell and dermal cell growth rates supplemented with drug infused media." (2012). Electronic Theses and Dissertations. Paper 84.

https://doi.org/10.18297/etd/84

This Master's Thesis is brought to you for free and open access by ThinkIR: The University of Louisville's Institutional Repository. It has been accepted for inclusion in Electronic Theses and Dissertations by an authorized administrator of ThinkIR: The University of Louisville's Institutional Repository. This title appears here courtesy of the author, who has retained all other copyrights. For more information, please contact thinkir@louisville.edu. 
Effect of Flow on Human Endothelial Cell and Dermal Cell Growth Rates

Supplemented With Drug Infused Media

By

Daniel Baumann

B.Eng., University of Louisville, 2012

\author{
A Thesis \\ Submitted to the Faculty of the \\ University of Louisville \\ J. B. Speed School of Engineering \\ As Partial Fulfillment of the Requirements \\ For the Professional Degree
}

\title{
MASTER OF ENGINEERING
}

Department of Bioengineering

July $20^{\text {th }}, 2012$ 
Effect of Flow on Human Endothelial Cell and Dermal Cell Growth Rates

Supplemented With Drug Infused Media

Submitted by:

Daniel Joseph Baumann

A Thesis Approved On

(Date)

By the Following Reading and Examination Committee:

Dr. William Ehringer, Thesis Director

Dr. Palaniappan Sethu, Committee Member

Dr. Andre Gobin, Committee Member

Dr. Shamus McNamara, Committee Member 


\section{Acknowledgements:}

Thank you to all who provided expertise and guidance for the duration of the project.

Thank you to Dr. Gobin and Dr. Sethu who helped guide and direct testing protocol development, as well as for their time and effort as committee members. A big thank you to Dr. McNamara who helped establish the testing flow rates through his knowledge of the continuous flow drug delivery device as well as for his time in weekly meeting where data and results were discussed. A very special thank you to Dr. Ehringer for lending his expertise on the ATP infused lipid vesicles used in this experimentation, his constant support throughout research, as well as providing the facilities used in this experimentation. 


\begin{abstract}
:
Wounds care and management is one of the most basic needs in the medical setting. Burn wounds, trauma wounds, pressure ulcers and bedsores are just some of the many types of wounds that need to be treated quickly and efficiently. Take for instance pressure ulcers, there at least 3 million reported cases of chronic ulcers and bedsores reported in the U.S. each year alone. Each ulcer can takes weeks to months to fully heal, leading to extended hospital stays and decreased quality of life in patients. Current treatment seeks to protect and keep the wound clean, manage cellular exudates, and in general reduce wound area. This is done by packing antibiotic gels into the wound bed, which have a bolus drug release profile, and covering the area with commercially available bandages. There are many studies documenting bolus drug release profiles and their effects on wounds, but what is distinctly absent are studies which investigate the effects of continuous drug delivery on wound healing.
\end{abstract}

Here it is hypothesized that applying a continuous flow of fresh drugs into the wound bed will speed up the often lengthy wound healing process. To examine this hypothesis, human umbilical vein endothelial cells (HUVEC) and adult human dermal fibroblasts (HDFa) cell culture models were used to mimic the wound healing process. Results were characterized by the rate of cell migration and proliferation (wound closure) into a simulated wound channel created in the middle of nearly confluent HUVEC and HDFa cell culture models. Both cell types were exposed to static or continuous flow conditions with and without drug infused media. For the HUVEC cells testing indicates a significant difference between the average rate of closure for flow versus no flow conditions $(0.0628$ versus 0.0232 percent closure per minute, $\mathrm{p}=0.00165)$. For the HDFa cells testing indicates a significant difference between the average rate of closure 
for flow versus no flow conditions $(0.0595$ versus 0.0392 percent closure per minute, $\mathrm{p}=$ 0.01606). The research suggests that positive growth rate occurs in HDF and HUVEC when continuous low flow conditions are applied to the cells. 
Table of Contents:

$\underline{\text { Page }}$

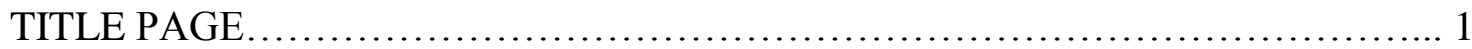

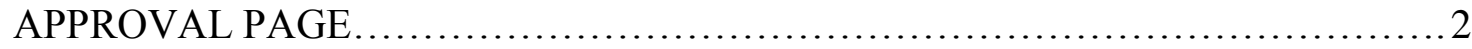

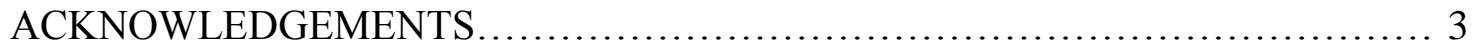

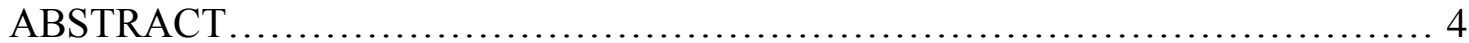

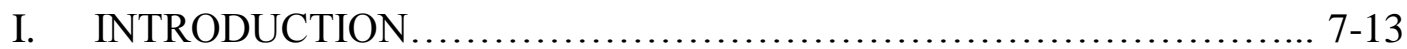

Wound Healing Process of Chronic Wounds........................ 7

Current Techniques to Treat Chronic Wounds.......................8

Continuous Drug Delivery with Novel Knudsen Pump..............9

Known Flow Effects on Cells........................................9

Known Effects of VitaSol on Cells................................10

Purpose of Research............................................11

Discussion of Model Used........................................ 12

Hypotheses................................................... 12

II. INSTUMENTATION .............................................. 13

III. PROCEDURE.................................................. 14-24

Making the VitaSol............................................... 14

Vesicle Binding by Native Media Proteins.......................... 16

Flow Field Verification...........................................19

Wound Closure Rate Experiments...............................19

Setting up the Microincubation System......................20

Preparing and Testing the Samples..........................20

MTT Assay of Cells After Imaging...........................23

IV. RESULTS ................................................... 25-39

Vesicle Binding by Native Media Proteins..........................25

Flow Field Verification.........................................26

Wound Closure Rate........................................27

Cellular Model of Wound Closure Data......................28

MTT Mitochondrial Activity Assay...........................35

V. DISCUSSION .............................................. $40-43$

Wound Closure Rate Data.....................................40

MTT Assay Data..............................................41

Closure Mechanism Analysis....................................42

VI. RECOMMENDATIONS ......................................... 44-45

VII. CONCLUSIONS ............................................... 46

VIII. REFERENCES................................................47

APPENDIX I. EXPERIMENTAL SETUP PHOTOS ...........................51

APPENDIX II. ADDITIONAL DATA AND STATISTICS ....................57

APPENDIX III. REPRESENTATIVE PHOTOS FROM TESTING GROUPS......86

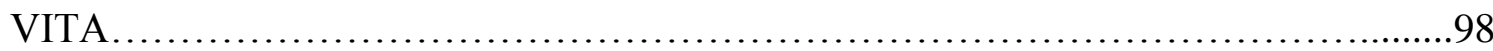




\section{Introduction:}

\section{Wound Healing Process of Chronic Wounds:}

Over 3 million Americans are afflicted with pressure ulcers, bedsores, and other related wounds each year. They are classified on a scale from 1 to 4 , where 1 is redness of skin with some pain on contact and 4 is full thickness tissue loss down to the bone $[1,2]$. The healing process for these types of wounds can often take weeks, and can be very labor intensive for staff to treat. The wound healing process in general is composed of five steps hemostasis, inflammation, migration, proliferation, and remodeling. The hemostasis phase occurs immediately after the initial wound and is indicated by the clotting cascade causing the bleeding to stop [3]. Fibrinogen elicits the clotting mechanism and in conjunction with the establishment of the fibrin network, resulting in the formation of the clot [4]. The inflammatory phase occurs nearly simultaneously with the hemostasis phase and primarily includes the congregation of neutrophils at the site of the wound. Also present during this phase is the vasodilation of surrounding vessels in an attempt to get blood to the site of the wound. The migration and proliferation phases are of the most interest to the wound healing process because they are the most easily altered to speed up the wound healing process [3].

The migration phase is characterized by the movement of epithelial cells and fibroblasts to the wound bed in an attempt to replace damaged or destroyed tissue. Proliferation is initiated by the further filling of the wound bed by growing and dividing new cells. Granulation tissue is formed as blood and lymph vessels are reestablished. This phase is also characterized by thickening of the epithelial layer [5]. These two phases can take anywhere from a few days to weeks to complete, which is why shortening these two phases is very important in managing the 
wound healing process. The final phase is the remodeling phase where connective tissue is formed to strengthen the new epithelium. This final phase can take anywhere from a month to a year to complete depending on the effectiveness of the administered treatments early on [3].

\section{Current Techniques to Treat Chronic Wounds:}

The techniques used to treat chronic wounds all seek to accomplish a few things. These goals are to manage exudates [6], debridement of the wound [7], protecting the wound from infection, and be low maintenance $[8,9]$. Clinically there are a few methods used to treat chronic ulcers or bedsores, most include a combination of wound dressings and topical gels. The wound is typically cleaned with an isotonic saline solution to remove foreign contaminants. Depending on the type of wound a variety of pharmaceutical therapies can be administered. These include silver nitrate [10], a silver sulpha-diazine [11, 12], antibiotics, antimycotics [3], or drugs that

promote angiogenesis and granular tissue growth (e.g., Regranex ${ }^{\mathrm{TM}}$ ) [13]. These different treatment modalities require several treatments/day, which can lead to variations in the amount of therapeutic used $[14,15]$. Another mechanism of treatment used for extreme cases is a tissue graft transplant to fill in the affected area [16, 17]. Apligraf is one such example of a skin substitute which contains living cells and structural proteins to act as a scaffold for new tissue regeneration. One thing all these methods have in common is that when a drug is applied, it has a bolus release profile that in no way maintains a constant concentration of the drug being delivered to the wound $[3,18]$. A more recent method of treatment for wounds is vacuum or negative pressure therapy. Vacuum therapy works by pulling exudates out of the wound rather than allowing them to merely seep out of the wound resulting in a faster mechanism of action. The vacuum therapy also results in a mechanical tension on the underlying tissue which results 
in dilated arterioles and an increased blood supply to the wound $[19,20]$. Vacuum therapy treatment is the closest to being called a continuous flow treatment that is currently available. The fact that so much research is being thrust into vacuum therapy lends credence to the idea that continuous flow will greatly benefit wounds and should be explored.

\section{Continuous Drug Delivery with Novel Knudsen Pump}

Currently being developed is a pump which is capable of providing continuous circulation of fluids without power, using only thermal gradients. Since it doesn't need a power supply, it is able to be made small and would be perfectly suited for wound healing especially when incorporated into a bandage or other wound dressing. Theoretically, this pump is able to produce flow rate between 0.01 and $0.25 \mathrm{~mL} / \mathrm{min}$ in a constant fashion based on the thermal gradient generated between the skin and the ambient air temperature. The development of this device and the introduction of it into the field of medical devices poses new questions about the effects of flow on wound healing. Very little research has been conducted into low flow effects on healing wounds as well as continuous perfusion of a drug into the wound. The creation of this novel device is partially what prompted this investigation. The flow parameters used in testing were restricted to those flow rates capable of being generated by the device.

\section{Known Flow Effects on Cells:}

Some recent experimentation has been conducted to look at the effects of shear stress on simulated wound HUVEC cell culture models [21]. One such experiment presheared the cells for 18 hours at $12 \mathrm{dyn} / \mathrm{cm}^{2}$ to obtain alignment of the cells in the direction of the flow field. After which they sheared the cells at values of 3,12 , and $20 \mathrm{dyn} / \mathrm{cm}^{2}$. Results of testing showed increased wound closure at all levels of shear stress over the static conditions. In addition they 
found that the lower shear stress value $3 \mathrm{dyn} / \mathrm{cm}^{2}$ produced a significant effect on wound healing over the higher shear stress values [22, 23]. It is important to note that these levels of shear stress are radically higher than those capable of being produced by the continuous flow pump described above. Another such investigation examined at what levels of shear HUVEC cells began to display different cellular adhesion molecules. They found that at shear levels around $8 \mathrm{dyn} / \mathrm{cm}^{2}$ there is a significant upregulation of ICAM-1 and E-selectin, two cellular adhesion molecules $[24,25,26]$. At shear stress levels lower than $8 \mathrm{dyn} / \mathrm{cm}^{2}$, these effects were not significantly altered. This information provides a shear stress threshold at which the HUVEC cells can be expected to begin differentiation. There is little to no data regarding flow effects with shear stress lower than $3 \mathrm{dyn} / \mathrm{cm}^{2}$ on HUVEC cells and there is no data investigating this effect on HDFa cells. It would be beneficial to explore the relationship between shear stress lower than 3 $\mathrm{dyn} / \mathrm{cm}^{2}$ and the resulting cellular growth rates.

\section{Known Effects of VitaSol on Cells:}

The effect of VitaSol, an ATP lipid vesicle formulation, on cells has been extensively reported in the literature. In one example, VitaSol was tested in a nude mouse wound healing model. A small incision was made on the head and covered with a protective bandage soaked with the ATP lipid vesicles. When compared to the control treatment it was shown that that VitaSol significantly reduced wound area and healed the wound faster. The VitaSol also had a marked positive effect on the reepithelialization and granular tissue shown in histological studies as well as a significant increase in a produced revascularization growth factor, VEGF [27, 28]. Another study used VitaSol in an attempt to speed the wound closure rates in an ischemic rabbit ear model. For this investigation the VitaSol was again applied as a drug soaked bandage. The 
results of this experimentation concluded similar results to the first, in terms of wound closure rates the VitaSol significantly reduced to number of days until full healing when compared to a saline control $[29,30]$. It is important to note the delivery mechanism of the VitaSol treatment. For each conducted investigation the delivery method was a bolus profile. A drug soaked bandage was applied to the wound and was changed daily. This means a higher concentration of the drug will be released initially which will eventually tapper off. It is unknown how the drug will behave when applied to a wound at a constant concentration through continuous flow. It is expected that the displayed effects would be even greater than those demonstrated by these articles. These are just two examples of studies conducted using ATP infused lipid vesicles and the effects they are capable of. Intracellular absorption of ATP has also been shown to upregulate certain growth factors suspected to assist in the wound healing process [31].

\section{Purpose of Research:}

The goal of this research investigation is to characterize the effect of flow conditions on several types of cell culture models and assess the potential it has to overcome the previously mentioned drawbacks to current wound therapies. Some research has been done to study the effects of flow on HUVEC cell culture models as it pertains to wound healing rates, however, all research that has been conducted dealt with extremely high flow rates and shear stresses, well outside the realm of what the continuous flow device being developed is capable of. Currently published research also does not investigate what effects, if any, flow has on HDFa cells. In the field of research there is a need to characterize the effects of low flow on HUVEC and HDFa cells as it applies to the wound healing process, which is what this investigation seeks to accomplish. 


\section{Discussion of Model Used:}

For this investigation HUVEC and HDFa cells were chosen to model the behavior of a healing wound. During the wound healing process it is known that fibroblasts play a key role in filling the wound bed. This filling of the wound plays a crucial role in the overall recovery time as it protects the wound from infections which, if the wound becomes septic slows the wound healing substantially. Another crucial aspect of the wound healing process is the revascularization and angiogenesis of new blood vessels in to wound area to replace the vessels that were destroyed or damaged at the time of the initial wound creation. Reestablishing blood flow and a fresh nutrient supply to the wound bed ensures that cells have all the supplements they need for optimal growth rates. Reforming this complex network of blood vessels faster should in turn allow the rest of the cells to close the wound faster. It is widely accepted that HUVEC cells are a suitable cell line to model revascularization which is why they too were chosen for this investigation.

\section{Hypotheses:}

It is hypothesized that an application of continuous flowing media over the cells will increase the observed growth rate of HUVEC and HDFa cells over no flow media conditions. It is further hypothesized that the flow of media will increase metabolic rates and mitochondrial activity in HUVEC and HDFa culture models. Finally, it is hypothesized that adding ATP infused lipid vesicles will substantially increase not only the observed growth rates of the cell cultures but also have a marked effect on the mitochondrial activity obtained through the MTT assay. 


\section{Instrumentation:}

This section contains specific information regarding the instrumentation used throughout the duration of this experimentation.

\section{Fluorescence Spectrometer:}

Fluorescent readings were taken using a LS 50B Fluorescence Spectrometer (Perkin Elmer, Waltham, MA) using a cuvette with optical path length of $10 \mathrm{~mm}$. Slits for excitation and emission beam were set to 15 and 20 , respectively.

\section{Dynamic Light Scattering Detector:}

DLS measurements used to measure vesicles radius were taken using a Protein Solutions DynaPro Titan with Temperature Controlled MicroSampler (Wyatt Technology, Santa Barbara, CA) using a cuvette with $10 \mathrm{~mm}$ optical path length. Scans were performed at temperatures $37^{\circ} \mathrm{C}$ with a scattering angle of $90^{\circ}$. DI water was used as a standard.

\section{Spectrophotometer:}

Absorption scans to measure protein and MTT assays were taken using GENESYS 10S UV-Vis spectrophotometer (Thermo Scientific, Pittsburgh, PA) using a cuvette with $10 \mathrm{~mm}$ optical path length. Scans were performed at the correct wavelength depending on the experiment. 


\section{Procedure:}

Before conducting the primary wound closure rate experiment, smaller verification experiments had to be conducted to ensure the proper criteria were met for the main design. Each of these verification steps is detailed in the subsections below with a description of the materials required to complete the task.

\section{Making the VitaSol:}

For the purposes of this experimentation, two of the testing groups will be given a dosage of ATP such that the cells experience a $0.1 \mathrm{mg} / \mathrm{mL}$ working concentration of the drug with a 5 mmol ATP concentration in HBSS. To make the drug according to these specifications the following steps were conducted. To make VitaSol: mix soy phosphatidylcholine 95\% (SOYPC, Avanti Polar Lipids, Alabaster, Alabama) in solid form and 1, 2-dioleyol-3-trimethylammonium-propane (DOTAP, Avanti Polar Lipids, Alabaster, Alabama) dissolved in chloroform in a weight ratio of 50:1 respectively.

The lipids were weighed out and mixed together in a $50 \mathrm{~mL}$ plastic test tube. Once mixed it is necessary to dry off the chloroform from the mixture. To do this nitrogen gas is blown over the lipids while gently rotating the test tube to speed up the drying process. Once the lipids appear dry the test tube is placed into a vacuum chamber overnight to further remove any traces of chloroform.

The next day the lipids were rehydrated using a stock solution composed of DI water, ATP magnesium salt (5 mM, Avanti Polar Lipids, Alabaster, Alabama), Trizma Base (25 mM, Sigma-Aldrich, St. Louis, Missouri), and hanks balance salt solution (HBSS) (9.5 g/L, Sigma- 
Aldrich, St. Louis, Missouri). To make the stock solution the three solid components were weighed out in the proper quantities, added to the correct volume of DI water, and mixed thoroughly.

Once the stock solution had been created it was added to the lipids along with several glass beads. The resulting solution was then vortexed to fully rehydrate the lipids in the stock solution. This rehydration process may take anywhere from 20 minutes for small batches to 2 hours for larger batches of VitaSol. It is important to try to keep the solution at room temperature and covered with aluminum foil to limit any light interactions that may occur which can degrade the lipid vesicles.

After rehydration it was necessary to sonicate the sample to reduce aggregation of the lipid vesicles and bring down the average hydrodynamic radius of the particle. Samples were sonicated for 10 minutes at a 50\% duty cycle (Branson Sonifer, VWR Scientific, Radnor, Pennsylvania). The VitaSol solution was then centrifuged for 10 minutes at $2000 \mathrm{~g}$ to remove any titanium contaminants that flaked off from the sonicator probe.

After centrifugation the VitaSol was extruded through a $0.1 \mu \mathrm{m}$ filter using a nitrogen cavitation bomb (Parr Instruments, Moline, Illinois). This further refines the average size of the. The extrusion process is completed by pressuring a reservoir containing the VitaSol to around 300 to $600 \mathrm{psi}$ at $40^{\circ} \mathrm{C}$ using a water jacket or circulating water bath. After the extrusion the resulting VitaSol solution was ready for use in experimentation, although the size and $\mathrm{pH}$ were verified first. 
The $\mathrm{pH}$ was checked to be around 7.4 since this is physiologic conditions. The $\mathrm{pH}$ was tested by using a calibrated $\mathrm{pH}$ probe (Oakton $\mathrm{pH}$ Tutor, Cole-Parmer, Vernon Hills, Illinois) immersed in the VitaSol solution. To measure the hydrodynamic radius of the lipid vesicles of VitaSol, a $50 \mu \mathrm{L}$ sample was placed in a $450 \mu \mathrm{L}$ of sample buffer and equilibrated to room temperature. The VitaSol solution was measured using a Protein Solutions Dyna Pro Dynamic Light Scattering device. Roughly 60 to 100 unique measurements, taken at a count rate of 5000 per measurement, were taken from the sample to ensure that the size was around $100-120 \mathrm{~nm}$ in radius with a fairly low poly dispersity index. The sample is considered usable as long as the average size is kept less than $150 \mathrm{~nm}$ in radius. This is how all VitaSol testing solutions were created for the duration of these experiments.

\section{Vesicle Binding By Native Media Proteins:}

It is known that the proteins in the culture media can have a binding affinity for certain substances introduced into the media. In terms of this experimentation the ratio of injected ATP lipid vesicles bound by the native media proteins was unknown and needed to be quantified so the proper dosage of VitaSol could be given to the cells. This binding ratio was determined through a column separation technique.

The lipid vesicles were labeled with Nile red (Molecular Probes-Invitrogen, Eugene, Oregon) dissolved in a solution of 25\% dimethyl sulfoxide (DMSO) $75 \%$ deionized water, such that a final working concentration of $1 \mathrm{mg} / \mathrm{mL}$ was achieved $[32,33]$. The Nile red stock solution was then added to the VitaSol solution in a ratio of 1:50 respectively and allowed to sit in a $4^{\circ} \mathrm{C}$ 
environment for 1 hour. This resulted in Nile red dye becoming trapped in the lipid bilayer due to hydrophobic interactions between the Nile red molecule and the inner bilayer space.

The labeled vesicle solution was added to the culture media in a 1:1 ratio. Since two cell culture types are going to be used, each required a binding profile to be established. The media being tested is the EGM-2 media (Lonza-Clonetics, Basel, Switzerland) for the HUVEC cells and M-106 media (Gibco-Cascade Biologics, Eugene, Oregon) for the HDFa cells. Once combined the testing sample was placed in the incubator at $37^{\circ} \mathrm{C}$ and left to sit overnight (at least 12 hours). In order to separate the unbound lipids from the media proteins, a Sepharose-2B (Sigma-Aldrich, St. Louis, Missouri) packing agent was used in a column length of $40 \mathrm{~cm}$ [34]. When pouring the column the Sepharose gel was diluted in a small amount of the running buffer in a ratio of 4:1 respectively [35]. A depiction of the setup is shown in Appendix I Photo 1. In order to test the media samples, $1 \mathrm{~mL}$ of the lipid vesicle/media combination was taken and loaded into the gel column. As the sample began to flush through the column, collection samples were collected in $1 \mathrm{~mL}$ intervals for further analysis. Collection of the samples was stopped 5 $\mathrm{mL}$ after the media band was no longer visible which made sure the entire sample had been collected. Throughout the duration of the experiment roughly $25 \mathrm{~mL}$ of samples was collected for the EGM-2 media and $30 \mathrm{~mL}$ of samples was collected for the M-106 media. It was decided that an $\mathrm{N}=3$ would be required to generate an accurate assessment of the ratio of bound lipid vesicles, so for each media type three unique media sample were run.

Once these samples were collected it was necessary to run both a fluorescence measurement and a BCA assay measurement on them. Fluorescence measurements were 
obtained using a luminescent spectrometer (Perkin-Elmer, Model\# LS50B) and reading the fluorescence measurement at an excitation wavelength of $533 \mathrm{~nm}$ and an emission wavelength of $544 \mathrm{~nm}$. The BCA assay was conducted using the test tube method. The test tube method required $0.1 \mathrm{~mL}$ of each unknown sample to be pipetted into individual glass test tubes. $2 \mathrm{~mL}$ of the working reagent was then added to each sample. The working reagent was created by mixing together in a 50:1 ratio reagent A to reagent B respectively. Once the working reagent had been added to the test sample, each of the glass test tubes were covered and placed in the incubator at $37^{\circ} \mathrm{C}$ for 30 minutes. Each sample, after incubation, was read by a spectrophotometer (ThermoScientific, Model\# Genesys 10-S) at a wavelength of $562 \mathrm{~nm}$.

With this information known one can now estimate the sum of the area under the lipid fluorescence curve and compare that to the sum of the area under the protein bound lipid curves. Since the exact equation of the curve is unknown a trapezoidal approximation was conducted to get as close to the actual area as possible. The trapezoidal approximation for each of the media samples can be found in Appendix II Chart 1 for the EGM-2 media and Chart 2 for the M-106 media. Looking at the results it is clear that in both media conditions a little over half of the injected lipid vesicles are bound by the native proteins, meaning that for the desired $0.1 \mathrm{mg} / \mathrm{mL}$ working concentration to be attained $0.2 \mathrm{mg} / \mathrm{mL}$ must be injected into the culture media. This number the guidance for how much of the lipid vesicle mixture should be added to the media in future experiments in order to achieve the correct working concentration. 


\section{Flow Field Verification:}

Since the primary observation of these experiments is the rate change as it pertains to flow, needless to say the flow characteristics the cells are experiencing are quite important. Flow rate, shear stress, and type of flow all needed to be defined and were determined via dye injection analysis [36]. For this verification dye was injected into the DI water being pumped through the system. The trajectory of the dye particles was observed under the microscope and caught on the camera system by taking video. The video was then analyzed in slow motion to obtain the flow velocity of the particles moving through the system. Knowing the velocity the shear stress could then be calculated as well as the Reynolds number to determine the type of flow. Also in the video the particles were tracked to see if any types of vortexing or swirling were present which would tend to indicate a more turbulent flow. Example photographs of how this verification were conducted are shown below in Appendix I Photo 6-8

\section{Wound Closure Rate Experiments:}

HUVEC and HDFa Culture and Passage

For this experimentation all cellular samples needed to complete the testing sets were cultured prior to testing and frozen back in cryopreservation. To do this $1^{\circ} \mathrm{HUVEC}$ and $1^{\circ} \mathrm{HDFa}$ cells

(Lonza, Walkersville, Maryland) were clonally expanded to achieve the desired passage number $\left(4^{\circ}\right)$. Once the cells reached the desired passage number they were divided out into individual vials containing the exact number of cells required to plate the specialized RC-40 glass bottom dishes (Wilco Wells, Amsterdam, Netherlands) used with the DH-40i microincubation system (Warner Instruments, Hamden, Connecticut) used during testing. A depiction of the incubation 
system can be found in Appendix I Photo 2. Each dish should be optimally plated with 50,000 cells so this was the number chosen to cryopreserve the cells at. This meant that all testing samples were kept at the exact same passage number, and from the same cultured cell line.

\section{Setting Up the Microincubation System:}

The microincubation system was specifically designed to culture cells under continuous view from a microscope. For this reason thermal controls and heating elements as well as media pumping lines all had to be condensed to fit on a standard microscope stage. The DH-40i system has flow ports built in so it was easy enough to connect sterile tubing lines to the incubation system, run them through a dual peristaltic pump, one capable of both pumping in fluid and pulling it back out, and finally connect the tubing to a sterile media reservoir. The heating elements are also built into the incubation system and are designed to be able to maintain the ideal temperature of $37^{\circ} \mathrm{C}$ needed to culture the cells. This ability to maintain the temperature of the system was verified using a handheld IR thermometer as well as a thermocouple. This verification step is displayed in Appendix I Photo 3. Prior to each experiment the tubing transporting the media as well as the cover dish on the microincubation system were autoclaved to cut down on the risk of infection. A photo of the final setup can be found in Appendix I Photo 4.

\section{Preparing and Testing Samples:}

Once the culturing system was functional, testing could begin, however, since the culture dishes were all glass bottom dishes it was necessary to gelatinize the dishes prior to plating the cells in order to initiate adhesion sites. This was done by allowing the glass bottom dishes to 
incubate overnight with a $0.1 \%$ gelatin coating. The $0.1 \%$ gelatin solution was created by taking $0.1 \mathrm{~g}$ of the gelatin powder (Sigma Aldrich, St. Louis, MO) and adding that to $100 \mathrm{~mL}$ of DI water. The solution was then sterile filtered under the laminar flow hood, aliquoted into sterile test tubes, and stored in the $4{ }^{\circ} \mathrm{C}$ refrigerator throughout the duration of experimentation until it was needed for each sample. Each culture dish was prepped with this gelatin solution before being plated with either the HUVEC of HDFa cells.

Once plated the cells were allowed to become nearly confluent at which time a $1 \mathrm{ml}$ sterile pipette tip was used to scratch a simulated wound channel directly in the middle of the wound culture dish. The resultant wound channel should be roughly $1.5 \mathrm{~mm}$ to $2 \mathrm{~mm}$ in width with clearly defined borders. Once the channel had been created, the culture dish was placed inside the microincubation system in a sterile environment under the laminar flow hood, after which the chamber was sealed to preserve the sterile environment. Once sealed, the setup was taken to the microscope and connected to both the peristaltic pump and the DC power supply. To maintain physiologic $\mathrm{pH}$, a $5 \mathrm{mM}$ concentration of HEPES was added to the culture media for each sample. Once fully connected, initial measurements of the wound channel were taken and subsequent photos were taken every 15 minutes to track the closure of the wound. Samples were allowed to run for approximately 15 hours, giving plenty of data to track wound closure rates over time. After each sample had been tested the culture dish was removed, sterilized, and disposed of. In addition the microincubation system was cleaned and prepared for the next test run, at which time the process repeats itself. 
Roughly five samples needed to be run in each of the four testing groups in order to determine significance. The static flow testing group with regular media and the static flow testing group with VitaSol doped media were batch processed to speed up the data collection rate. This means that all five of the samples were run at the same time while taking photos at discrete measurements manually. The samples in the flow testing group with regular media and the flow testing group with VitaSol doped media were tested individually using the camera system and the microincubation stage described above. It is important to note that five samples in each of the testing groups were run for both the HUVEC and the fibroblast cell culture models. This is how samples were run to obtain the rate of wound closure measurements.

Data was obtained through a Nikon D90 camera mounted to the microscope imaging the cells at 10x magnification. This way the cells could be monitored and their growth progress tracked over time. As mentioned earlier the static flow cells were batch processed, meaning that six samples were grown and imaged at the same time. The cell chambers were each marked so that the same location in the wound bed could be imaged each and every time ensuring that the data is accurate. For the static flow conditions, images were taken every 6-8 hours excluding overnight. During imaging, two unique locations in each cell culturing dish were photographed, which made sure that an average wound distance could be obtained for each sample. For the flow conditions, each sample had to run individually since it had to be placed in the special remote culturing stage. For this reason only one unique location could be imaged for each sample since the sample couldn't be moved once placed in the culturing stage. However, unlike the static flow conditions, the images could be taken at a much closer interval, in this case every 15 minutes 
essentially creating a video as the cells fill in the wound bed. In all cases, no matter how the photos were taken, all photos were analyzed the same way.

Using the ImageJ software, freely downloaded from the NIH website, the wound bed gap distance was measured and recorded in an excel spreadsheet. Before using the ImageJ software the scale first had to be calibrated before measurements could be obtained. To calibrate the scale, a photo of a $2 \mathrm{~mm}$ scale bar, shown below in Appendix I Photo 5, taken at the same magnification of the cells in the experiment (10x) was used. Once the scale had been calibrated the images were analyzed. For each image three unique distance measurements were obtained, one on the far left, one in the center, and one on the far right. The wound boundary on each side was identified as best as possible and this became the start and the finish of the distance measurements. A depiction of how these three measurements were taken is shown below in Appendix I Photo 9. After obtaining the distance measurements, they were all converted into a percent representing the closure when compared to the original wound channel distance. By converting these measurements to a percent it eliminates any bias caused by different initial wound channel lengths which greatly reduces the expressed standard deviation.

\section{MTT Assay of Cells After Imaging:}

After the imaging sequence had been completed an MTT assay was run on a select number of samples from each testing group. While an MTT assay is normally used to determine the number of metabolically active cells in a culture dish, it can also be used to assess the degree 
of mitochondrial activity exhibited by the sample if the amount of cells remains constant from sample to sample.

To conduct the MTT assay the reagent solutions were created according to the Vybrant recommended protocol [37]. A $12 \mathrm{mM}$ MTT stock solution was created by adding $1 \mathrm{~mL}$ of sterile PBS to one $5 \mathrm{mg}$ vial of MTT Component A (Invitrogen-Molecular Probes, Eugene, Oregon). A second reagent solution is created by adding $10 \mathrm{~mL}$ of $0.01 \mathrm{M} \mathrm{HCl}$ to one tube containing $1 \mathrm{~g}$ of SDS Component B (Invitrogen-Molecular Probes, Eugene, Oregon) contained in the same kit as the MTT component.

Since the culture dished used in this experimentation differ in surface area from the ones used in the Vybrant MTT assay protocol the amounts of each reagent used had to be scaled accordingly. It was determined that a scaling factor of 9 should be used on all values discussed in the Vybrant protocol. This means that to begin the MTT assay all media was removed from the culture dishes and was replaced with $900 \mu \mathrm{L}$ of fresh media. At this point $90 \mu \mathrm{L}$ of the MTT reagent solution to each culture dish and were placed in the incubator at $37^{\circ} \mathrm{C}$ for 4 hours. After the incubation period was complete the samples were removed and $900 \mu \mathrm{L}$ of the SDS reagent solution was added to them and mixed thoroughly with a pipette. After mixing the samples were placed back in the incubator at $37^{\circ} \mathrm{C}$ for another 4 hours. After this final incubation period the samples were removed, mixed again, and tested for absorbance measurements at $570 \mathrm{~nm}$ using a spectrometer. This is how the MTT assay was conducted for all samples in this investigation. 


\section{Results:}

\section{Vesicle Binding by Native Media Proteins:}

With this information generated from this experiment one can now estimate the sum of the area under the lipid fluorescence curve and compare that to the sum of the area under the protein bound lipid curves. Since the exact equation of the curve is unknown, a trapezoidal approximation was conducted to get as close to the actual area as possible. The trapezoidal approximation for each of the media samples can be found in Appendix II Chart 1 for the EGM2 media and Chart 2 for the M-106 media. A summarized chart of this data is shown below.

\begin{tabular}{|c|c|c|c|c|c|}
\hline & EGM-2 & & & M-106 & \\
\hline & Percent & Percent & & Percent & Percent \\
\hline & Vesicle & Vesicle & & Vesicle & Vesicle \\
\hline Sample & Bound & Free & Sample & Bound & Free \\
\hline 1 & $59.03 \%$ & $40.97 \%$ & 1 & $58.16 \%$ & $41.84 \%$ \\
\hline 2 & $57.63 \%$ & $42.37 \%$ & 2 & $63.79 \%$ & $36.21 \%$ \\
\hline 3 & $54.60 \%$ & $45.40 \%$ & 3 & $60.13 \%$ & $39.87 \%$ \\
\hline Avg & $57.08 \%$ & $42.92 \%$ & Avg & $60.69 \%$ & $39.31 \%$ \\
\hline STDEV & $2.26 \%$ & $2.26 \%$ & STDEV & $2.85 \%$ & $2.85 \%$ \\
\hline
\end{tabular}

Chart 7: Averages and standard deviations for the ratio of lipid vesicles bound to media proteins for each media type.

Looking at the results it is clear that in both media conditions a little over half of the injected lipid vesicles are bound by the native proteins, meaning that for the desired $0.1 \mathrm{mg} / \mathrm{mL}$ working concentration to be attained, $0.244 \mathrm{mg} / \mathrm{mL}$ must be injected into the EGM-2 culture media and $0.254 \mathrm{mg} / \mathrm{mL}$ must be injected into the M-106 culture media. This number the guidance for how much of the lipid vesicle mixture should be added to the media in future experiments in order to achieve the correct working concentration. 


\section{Flow Field Verification:}

Analyzing the video in slow motion produced a flow velocity of $\mathrm{v}=2.97 \times 10^{-4} \mathrm{~m} / \mathrm{s}$, a rate consistent with the theoretical output of the continuous flow drug delivery device. Using the equation:

$$
\mathrm{Q}=\mathrm{vbh}
$$

where $\mathrm{v}$ is the flow velocity and $\mathrm{b}$ and $\mathrm{h}$ are the dimensions of the culture dish, one can calculate the flow rate of the system. This turns out to be $\mathrm{Q}=0.267 \mathrm{~mL} / \mathrm{min}$, again consistent with the theoretical output of the drug delivery device. Using this flow rate one can plug it into the equation for shear stress:

$$
\mathrm{T}=(6 \mathrm{Qu}) /\left(\mathrm{bh}^{2}\right)
$$

where $\mathrm{u}$ is the viscosity of the culture media. Plugging all terms into this equation yields a shear stress, which the cells experience, of $5.9 \times 10^{-4} \mathrm{~N} / \mathrm{m}^{2}$, which is well below the target shear stress of $0.3 \mathrm{~N} / \mathrm{m}^{2}$ meaning that these conditions won't influence differentiation of the HUVEC cells. One final bit of validation was to determine the Reynolds number with regards to the type of flow. The equation used in this case is:

\section{$\operatorname{Re}=\rho v l / u$}

where $\rho$ is the density of the media, $v$ is the velocity, and $\mathrm{u}$ is the viscosity over the respective length 1. Substituting these values gives a Reynolds number of 1.612. A Reynolds number of less than 2300 tends to indicate laminar flow. In this case laminar flow makes sense because the media is flowing so slowly there is nothing to disturb the fluid layers and cause turbulent flow. 


\section{Wound Closure Rate:}

It is important to note that this system required many iterations in order to integrate all the many functional components of the experimental system. For example, the media reservoir required a specially designed heating system to keep the cells exposed to $37^{\circ} \mathrm{C}$ media. Other challenges included modifications to the height adjustments to the flow inlet or outlet to prevent loss of culture media, random software crashes due to the massive amounts of data accumulated/experiments, and issues with microscope failure where the bulb burned out from prolonged use.

Results from the cellular model of wound closure are expressed as a rate measurement of the changes in area over time. In addition an MTT assay on a portion of the samples in each of the testing groups was analyzed to measure cell proliferation and mitochondrial activity. In addition to these quantitative measurements, the photo sets were carefully inspected in an attempt to gage the mechanism of cellular wound closure. In this case the goal was to determine if cell proliferation, migration, or a combination of both was the primary mode of closure. No physical numbers were generated in closure mechanism analysis; instead it was more of a subjective investigation to see if there was a difference. In analyzing the data, a significant difference in values between the sets was determined if the p-value from the student's t test was less than 0.05 . Before the student's t test was conducted an $\mathrm{f}$ test first had to be conducted to determine if the data sets had equal or unequal variance, which determines the type of test to run. 


\section{Cellular Model of Wound Closure Data:}

Looking at the data generated from the Image $\mathrm{J}$ measurements and averaging them together generates the graphs shown in Figures 13-15 for the HUVEC cells and Figures 16-18 for the HDFA cells.



Figure 13: Comparison between HUVEC Flow and No Flow conditions. HUVEC Flow showed significantly faster closure rates than HUVEC No Flow $(\mathrm{p}=0.00165)$.

To prove the first hypothesis whether low flow influences cellular wound closure rates, the data was examined between the HUVEC Flow and No Flow conditions. It was shown that HUVEC Flow had an average rate of closure of 0.0628 percent per minute whereas the HUVEC No Flow had an average rate of closure of 0.0232 . This resulted in a significant difference 
$(\mathrm{p}=0.00165)$ between Flow and No Flow conditions thus proving the initial hypothesis that low flow rate can accelerate wound closure at least in the HUVEC cell culture model.

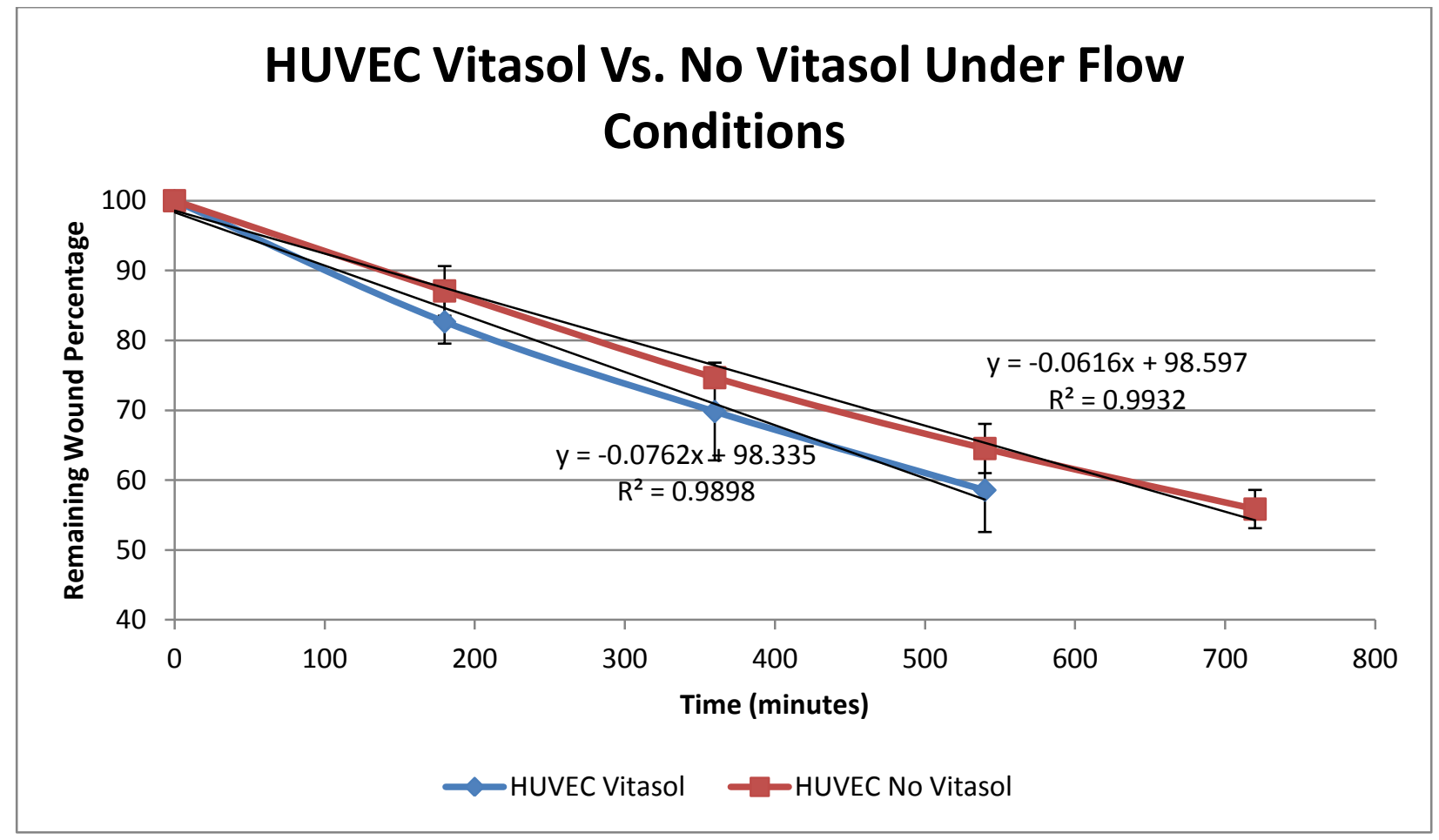

Figure 14: Comparison between HUVEC VitaSol and No VitaSol conditions when subjected to a flow environment. There was no observed difference between the closure rates for the HUVEC VitaSol and No VitaSol testing groups $(\mathrm{p}=0.3566)$.

To prove the secondary hypothesis whether VitaSol influences the wound closure rate, the data was examined between the HUVEC VitaSol and No VitaSol conditions when subjected to a flow environment. It was shown that HUVEC VitaSol had an average rate of closure of 0.0730 percent per minute whereas the HUVEC No VitaSol had an average rate of closure of 0.0628. This did not result in a significant difference $(\mathrm{p}=0.3566)$ between VitaSol and No 
VitaSol conditions thus suggesting that the secondary hypothesis, that adding VitaSol can accelerate wound closure, may not be true.

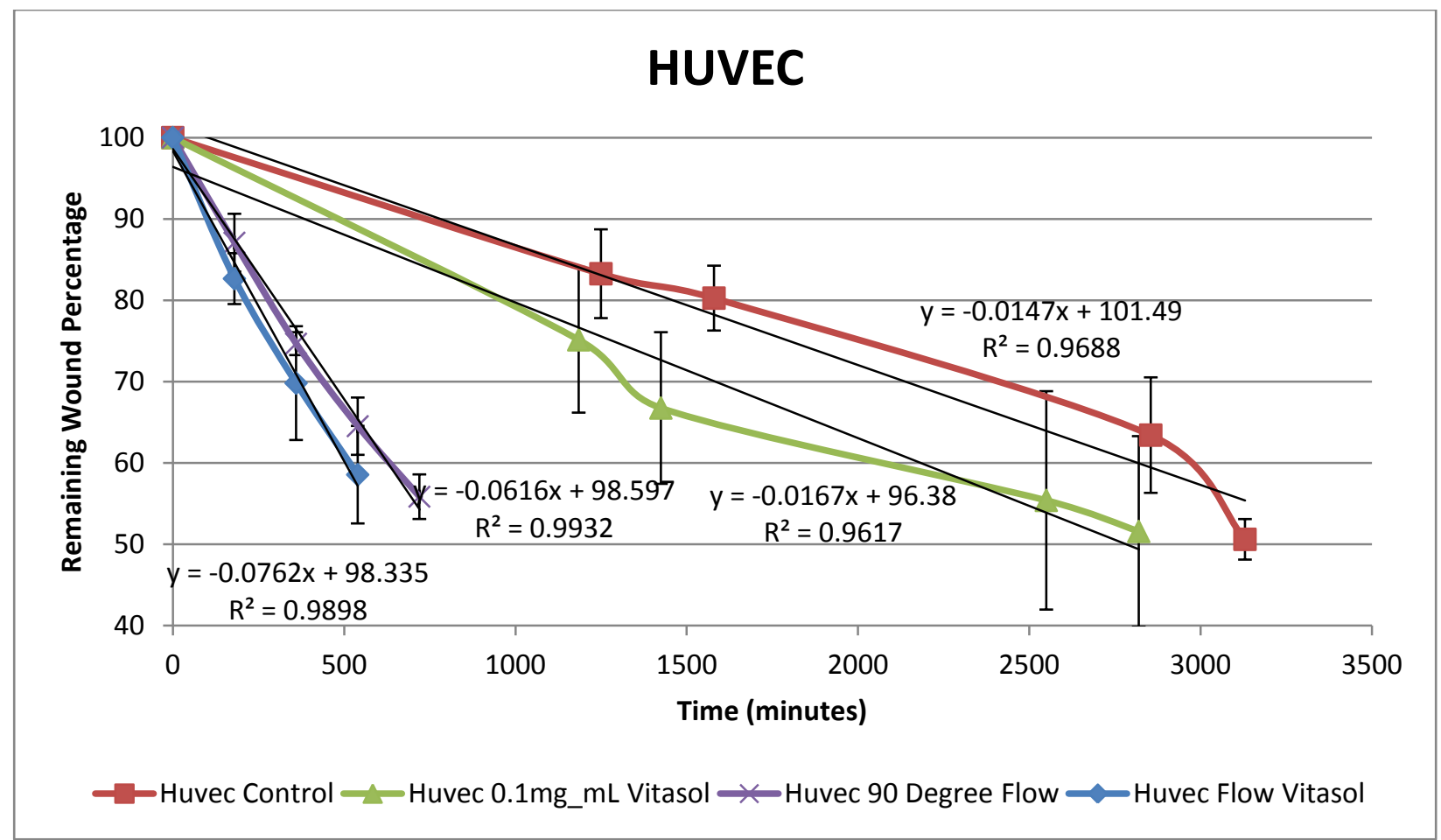

Figure 15: Comparison between all HUVEC testing groups. There was no observed difference between any of the VitaSol testing groups ( $\mathrm{p}=0.3566$ and 0.4080 for Flow and No Flow conditions respectively). There was a significant difference between the Flow and No Flow testing groups ( $\mathrm{p}=0.00165$ and 0.00980 with and without VitaSol respectively).

The raw data used to generate these graphs can be found in Appendix II Chart 3 for the HUVEC cells. Taking the closure measurements one can calculate the rate of closure between each step. Doing so yields the data found in Appendix II Chart 5 for the HUVEC cells. The summarized averages and standard deviations for each of the testing groups are shown in the tables below. 


$\begin{array}{cccc} & \text { Number of Samples } & \begin{array}{c}\text { Average Rate } \\ \text { Percent/min }\end{array} & \begin{array}{c}\text { Average } \\ \text { STDEV }\end{array} \\ \text { Huvec Control } & 6 & 0.0232 & 0.0122 \\ \text { Huvec } 0.1 \mathrm{mg} / \mathrm{mL} \text { VitaSol } & 6 & 0.0170 & 0.0105 \\ \text { Huvec 90 Degree Flow } & 5 & 0.0628 & 0.0168 \\ \text { Huvec Flow 0.1mg/mL } & 4 & 0.0730 & 0.0225 \\ \text { VitaSol } & & & \end{array}$

$\begin{array}{cccc} & \text { Huvec } & \text { Huvec } 0.1 \mathrm{mg} / \mathrm{mL} & \text { Huvec } 90 \text { Degree } \\ & \text { Control } & \text { VitaSol } & \text { Flow } \\ \text { Huvec Control } & - & - & - \\ \text { Huvec } 0.1 \mathrm{mg} / \mathrm{mL} \text { VitaSol } & 0.4080 & - & - \\ \text { Huvec } 90 \text { Degree Flow } & 0.0016 & 1.024 \mathrm{E}-06 & - \\ \text { Huvec Flow 0.1mg/mL } & 0.0012 & 0.0098 & 0.3566 \\ \text { VitaSol } & 0.006\end{array}$

Chart 8: Averages and standard deviations for HUVEC cell rate of closure as well as p-values between testing groups. 


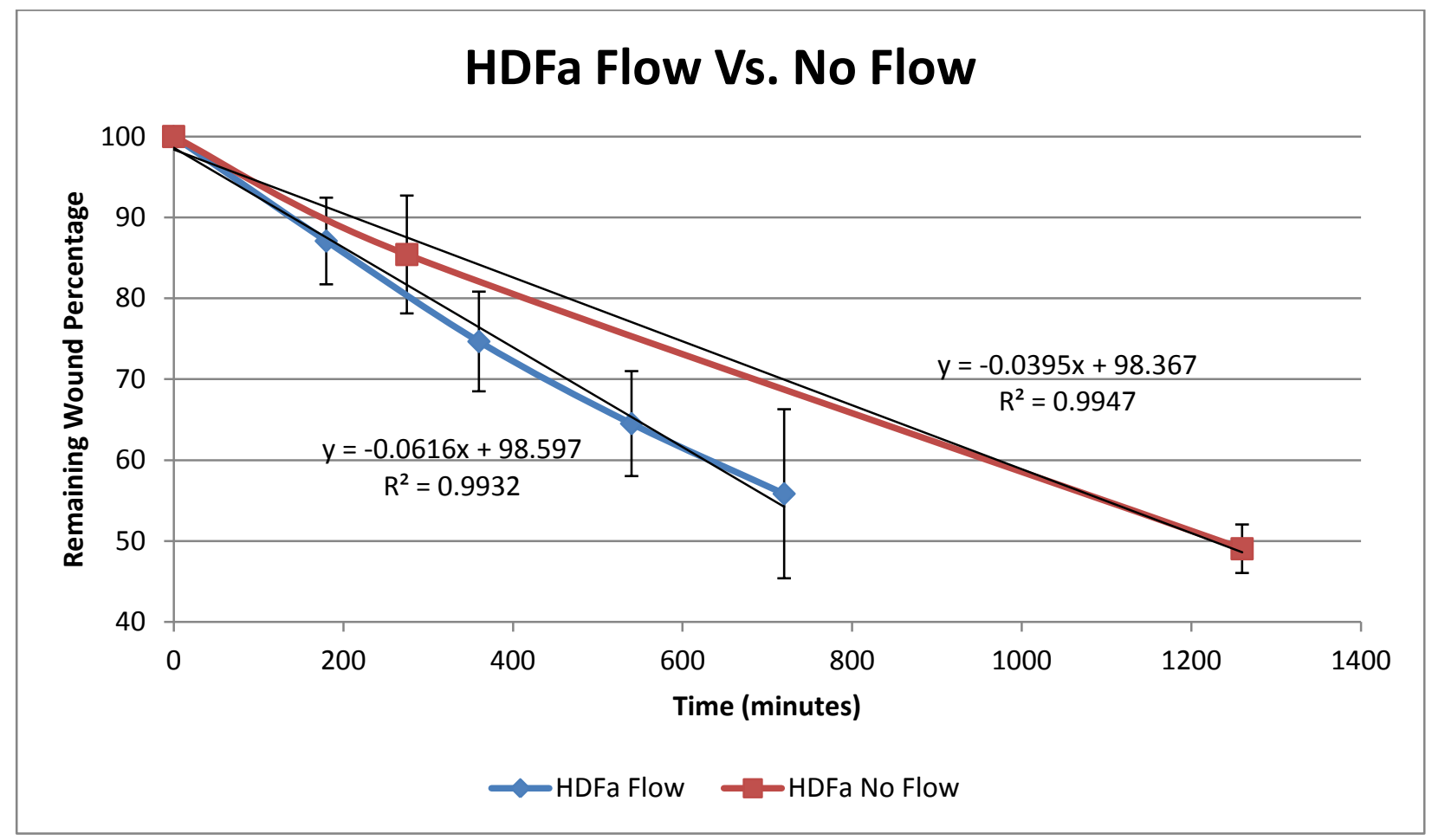

Figure 16: Comparison between HDFa Flow and No Flow conditions. HDFa Flow showed significantly faster closure rates than HDFa No Flow ( $\mathrm{p}=0.01606)$.

To prove the first hypothesis whether low flow influences cellular wound closure rates, the data was examined between the HDFa Flow and No Flow conditions. It was shown that HDFa Flow had an average rate of closure of 0.0595 percent per minute whereas the HUVEC No Flow had an average rate of closure of 0.0392. This resulted in a significant difference $(p=0.01606)$ between Flow and No Flow conditions thus conclusively proving the initial hypothesis that low flow rate can accelerate wound closure in both the HUVEC and HDFa cell culture models. 


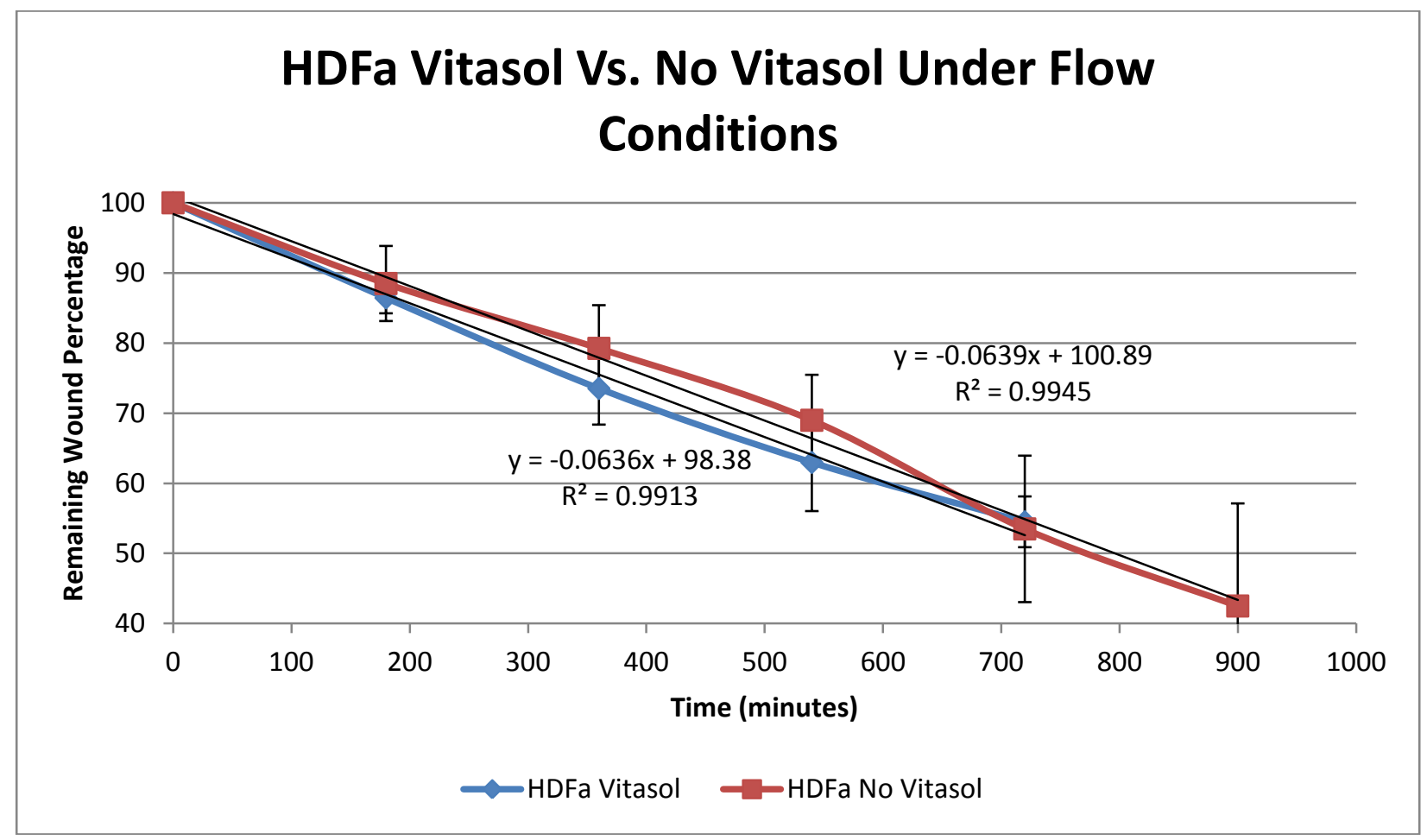

Figure 17: Comparison between HDFa VitaSol and No VitaSol conditions when subjected to a

flow environment. There was no observed difference between the closure rates for the HDFa VitaSol and No VitaSol testing groups $(\mathrm{p}=0.3314)$.

To prove the secondary hypothesis whether VitaSol influences the wound closure rate, the data was examined between the HDFa VitaSol and No VitaSol conditions when subjected to a flow environment. It was shown that HDFa VitaSol had an average rate of closure of 0.0661 percent per minute whereas the HDFa No VitaSol had an average rate of closure of 0.0595 . This did not result in a significant difference $(\mathrm{p}=0.3314)$ between VitaSol and No VitaSol conditions further suggesting that the secondary hypothesis, that adding VitaSol can accelerate wound closure, may not be true since this was the case in both HUVEC and HDFa culture models. 


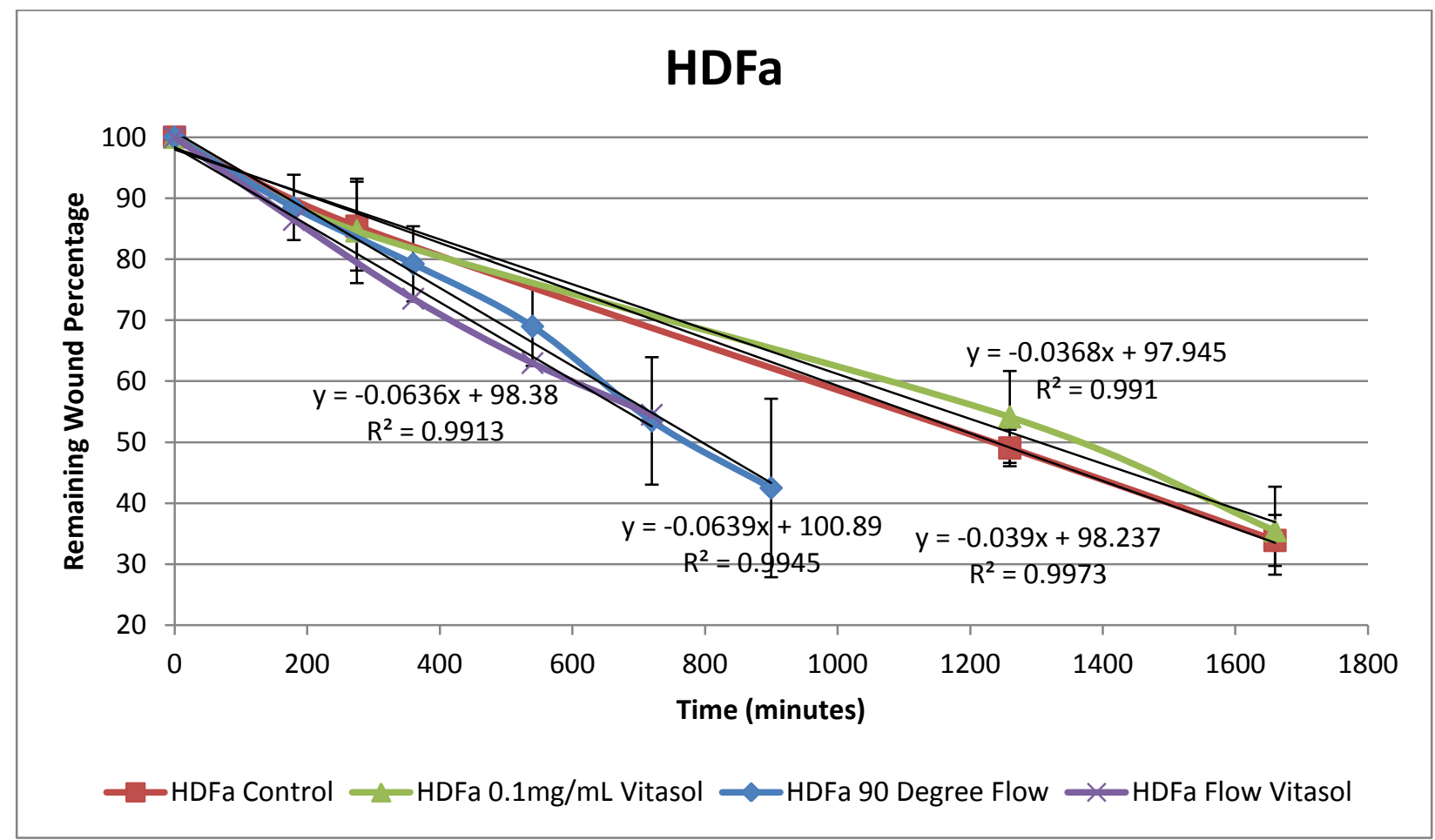

Figure 18: Comparison between all HDFa testing groups. There was no observed difference between any of the VitaSol testing groups ( $\mathrm{p}=0.0794$ and 0.3314 for Flow and No Flow conditions respectively). There was a significant difference between the Flow and No Flow testing groups ( $\mathrm{p}=0.01606$ and 0.00386 with and without VitaSol respectively).

The raw data used to generate these graphs can be found in Appendix II Chart 4 for the HDFa cells. Taking the closure measurements one can calculate the rate of closure between each step. Doing so yields the data found in Appendix II Chart 6 for the HDFa cells. The summarized averages and standard deviations for each of the testing groups are shown in the tables below. 


$\begin{array}{cccc} & \text { Number of Samples } & \begin{array}{c}\text { Average Rate } \\ \text { Percent/min }\end{array} & \begin{array}{c}\text { Average } \\ \text { STDEV }\end{array} \\ \text { HDFa Control } & 5 & 0.0392 & 0.0118 \\ \text { HDFa 0.1mg/mL VitaSol } & 6 & 0.0156 & 0.0579 \\ \text { HDFa 90 Degree Flow } & 5 & 0.0595 & 0.0210 \\ \text { HDFa Flow 0.1mg/mL } & 5 & 0.0661 & 0.0244 \\ \text { VitaSol } & & & \end{array}$

$\begin{array}{cccc} & \text { HDFa } & \text { HDFa 0.1mg/mL } & \text { HDFa 90 Degree } \\ \text { Control } & \text { VitaSol } & \text { Flow } \\ \text { HDFa Control } & - & - & - \\ \text { HDFa 0.1mg/mL VitaSol } & 0.0794 & - & - \\ \text { HDFa 90 Degree Flow } & 0.0160 & 0.0035 & - \\ \begin{array}{c}\text { HDFa Flow 0.1 mg/mL } \\ \text { VitaSol }\end{array} & 0.0058 & 0.0038 & 0.3314\end{array}$

Chart 9: Averages and standard deviations for HDFa cell rate of closure as well as p-values between testing groups.

To check for statistical significance an f test first had to be run comparing each of the test groups to one another. The $\mathrm{f}$ test determines if the variance between the groups is equal or unequal and based on this result, the proper $t$ test can be chosen. Running the appropriate $t$ test for each comparison yields the full statistical tables seen in Appendix 2 Tables 1 through 12 . Representative photos of each of the testing groups can be found in Appendix III.

\section{MTT Mitochondrial Activity Assay:}

As mentioned previously an MTT assay was attempted on select samples within each of the testing groups in order to try to gauge the level of mitochondrial activity displayed between each set. The results of this analysis are shown in the table below as well as a graphical representation. 


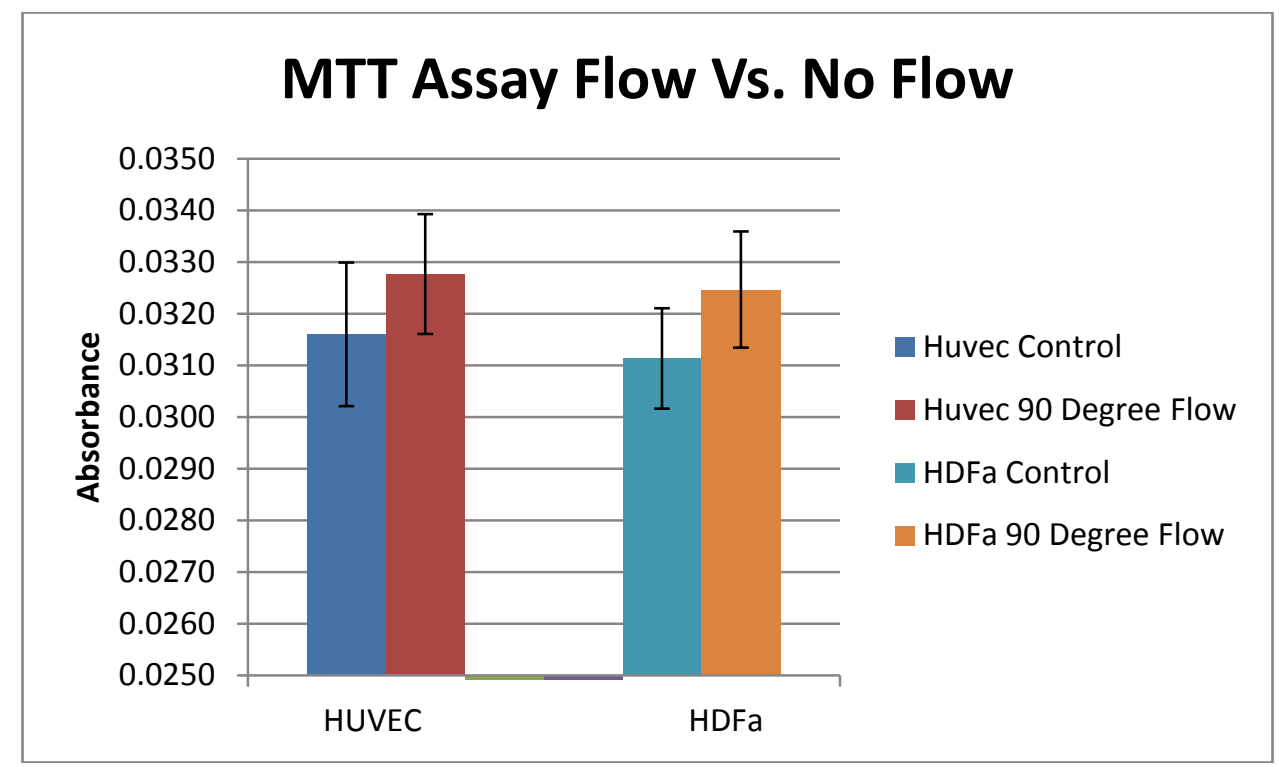

Figure 19: MTT Assay comparison between Flow and No Flow conditions. No significant difference was observed between Flow and No Flow for both HUVEC and HDFa culture models $(\mathrm{p}=0.3265$ and 0.1950 respectively).

To prove the tertiary hypothesis, whether low flow rates induce higher mitochondrial activity, the data was examined between the HUVEC and HDFa Flow and No Flow conditions. It was shown that HUVEC Flow had an average absorbance 0.0328 whereas the HUVEC No Flow had an average absorbance of 0.0316 . The HDFA Flow had an average absorbance 0.0325 whereas the HDFa No Flow had an average absorbance of 0.0311 . This did not result in a significant difference $(\mathrm{p}=0.3265$ and 0.1950$)$ in mitochondrial activity for either HUVEC of HDFa cultures respectively, as it pertains to flow. This suggests that the tertiary hypothesis may not be true since this was the case in both HUVEC and HDFa culture models. 


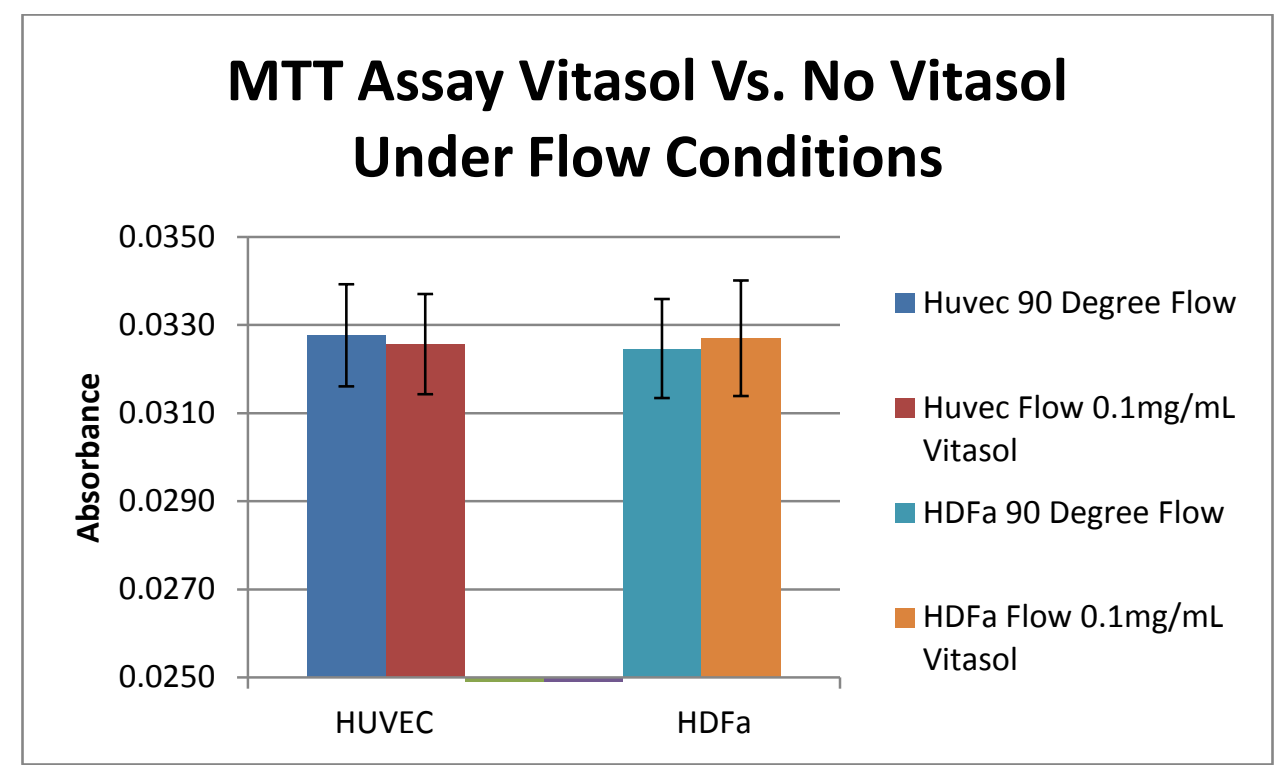

Figure 20: MTT Assay comparison between VitaSol and No VitaSol conditions. No significant difference was observed between VitaSol and No VitaSol for both HUVEC and HDFa culture models ( $\mathrm{p}=0.5947$ and 0.4156 respectively).

To prove the tertiary hypothesis, whether the addition of VitaSol induces higher mitochondrial activity, the data was examined between the HUVEC and HDFa VitaSol and No VitaSol conditions. It was shown that HUVEC VitaSol had an average absorbance 0.0326 whereas the HUVEC No VitaSol had an average absorbance of 0.0328 . The HDFA VitaSol had an average absorbance 0.0327 whereas the HDFa No VitaSol had an average absorbance of 0.0325. This did not result in a significant difference $(\mathrm{p}=0.5947$ and 0.4156$)$ in mitochondrial activity for either HUVEC of HDFa cultures respectively, as it pertains to the addition of VitaSol. This suggests that the tertiary hypothesis may not be true since this was the case in both HUVEC and HDFa culture models. 


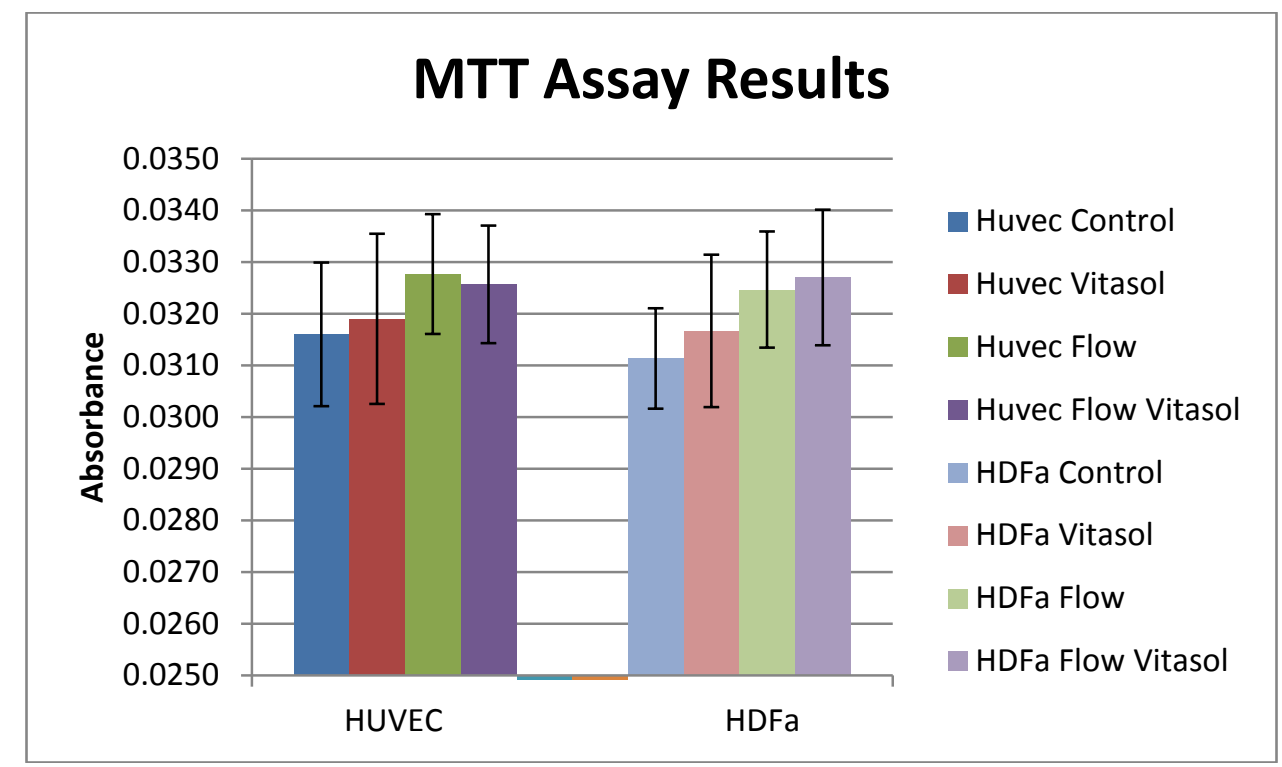

Figure 21: MTT Assay comparison between all testing groups for both HUVEC and HDFa

culture models. There was no observed difference between any of the testing groups on any level for either the HUVEC of HDFa cultures.

To check for statistical significance an $\mathrm{f}$ test first had to be run comparing each of the test groups to one another. The $\mathrm{f}$ test determines if the variance between the groups is equal or unequal and based on this result, the proper $t$ test can be chosen. Running the appropriate $t$ test for each comparison yields the full statistical tables seen in Appendix 2 Tables 13 through 24. A summarized table of p-values is shown below.

$\begin{array}{cccc} & \text { Huvec } & \text { Huvec } 0.1 \mathrm{mg} / \mathrm{mL} & \text { Huvec 90 Degree } \\ & \text { Control } & \text { VitaSol } & \text { Flow } \\ \text { Huvec Control } & - & - & - \\ \text { Huvec } 0.1 \mathrm{mg} / \mathrm{mL} \text { VitaSol } & 0.8212 & - & - \\ \text { Huvec 90 Degree Flow } & 0.3265 & 0.4973 & - \\ \text { Huvec Flow 0.1mg/mL } & 0.4038 & 0.5947 & 0.8414 \\ \text { VitaSol } & & \end{array}$




$\begin{array}{cccc} & \text { HDFa } & \text { HDFa 0.1mg/mL } & \text { HDFa 90 Degree } \\ & \text { Control } & \text { VitaSol } & \text { Flow } \\ \text { HDFa Control } & - & - & - \\ \text { HDFa 0.1mg/mL VitaSol } & 0.6284 & - & - \\ \text { HDFa 90 Degree Flow } & 0.1950 & 0.4963 & - \\ \text { HDFa Flow 0.1mg/mL } & 0.1716 & 0.4156 & 0.8264 \\ \text { VitaSol } & & & \end{array}$

Chart 10: Summarized table of p-values for HUVEC and HDFa cellular MTT assay. 


\section{Discussion:}

\section{Wound Closure Rate Data:}

Looking at the data generated from the wound closure experiments a few things became evident. First and foremost, it seems that the primary hypothesis was proven true. A continuous flow of media over the cells does promote higher rates of growth and closure of the wound. This is demonstrated by the $\mathrm{p}$ values less than 0.05 for all comparisons between the flow test groups and the static test groups. Comparing the results of this experimentation to the known flow effects on cells the data seems to coincide. While previous experiments used higher flow rates than those used in this experimentation it appears that the same effects, accelerated growth rates, are prevalent in both cases [22]. This means that when such a device is created, capable of sustaining the flow of a drug, such as VitaSol, over a wound bed, it is expected that full closure and healing of the wound would be expedited. By speeding up the wound healing process for chronic ulcers or bedsores, which often take weeks of recuperation in a hospital, one could expect to shorten these lengthy often uncomfortable stays, thus enhancing the quality of life for many patients.

The secondary hypothesis in this investigation was far less definitive after all the results had come in. The original intent was to demonstrate that by adding a drug to the circulating media, this too will have a positive effect on the growth rate of the cells in culture. What was seen from the data was that the VitaSol had no effect whatsoever on either of the cell culture models. Comparing these results to the known effects of VitaSol on the cells they do not match up. Previous experimentation saw profound effects on cellular growth rates when VitaSol was added whereas in this experimentation no difference was observed. The reason for this lack of 
effect can't be definitively proven, but after a reexamination of the model used in this testing method the likely reason is that the cells were grown under normal oxygen conditions. This is further backed up by the fact that previous testing by other labs did in fact culture the cells under hypoxic conditions whereas for this experimentation the cells were cultured under normoxia conditions [27]. Under normal oxygen conditions the cells will produce adequate amounts of ATP required for sustained growth. Since ATP is the functional aspect of the VitaSol treatment given to the cells it would be treated as excess and disposed of by the cells. The result of this being that the overall growth rates between the cells given the VitaSol infused media and those given the standard media remains the same. Given the proper model a difference might be able to be gleaned from the data. Clinically it is expected that VitaSol will accelerate healing rates since this aspect has been definitively proven in bolus therapy just not yet so in continuously applied therapy.

\section{MTT Assay Data:}

The data generated from the MTT assay was less conclusive. While the data itself is reliable and accurate it doesn't show any statistically significant differences in mitochondrial activity between the testing groups. The simple explanation for this lack of significance is the shortage of cells being tested with each run of the MTT assay. When creating the calibration curve for the number of cells and the absorbance measurements they generate, one of the lowest values of cells used is 50,000 while one of the upper values is 1,000,000 cells. The number of cells able to be grown in micro incubation dishes used in the experimentation is roughly 100,000 cells at a max. The actual amount of cells contained in these dishes during experimentation was roughly 75,000 based on cell counts using a hemocytometer. This 75,000 falls at the very low 
end of the calibration curve And could have contributed to the lack of differences noted here. It is suggested that future experimentation in this area use greater than 75,000 used hereto potentially detect significant differences between groups. It seems that the cells experiencing flow tended to have higher absorbance measurements than the static conditions, 0.0328 compared to 0.0316 for the HUVEC cells and 0.0325 compared to 0.0311 for the HDFa cells,

\section{Closure Mechanism Analysis:}

This method of analysis, as mentioned earlier was purely subjective. Looking at the static flow samples the primary wound closure mechanism was proliferation of the cells into the simulated wound channel. While there was some migration of the cells, as they do naturally, the migration that was seen was parallel to the wound channel and not into the wound. An example of this is shown in Figure 7 below. With the low flow samples the primary wound closure mechanism was a combination of proliferation and migration into the wound channel. It seems that the flow directed the movement of the cells into the channel where they then began to proliferate. An example of this is shown in Figure 8 below. In terms of wound healing in vivo, migration of HUVEC cells into the wound could play an important role in their role in neovascularization of the wound, which could speed the healing process. Migration of fibroblasts into the wound is very important in laying down, extracellular matrix, increasing cellular proliferation, and filling the wound are to prevent infection. In conclusion migration of the cells, guided by the flow conditions expected to be produced from this device, will expedite the wound healing process. 


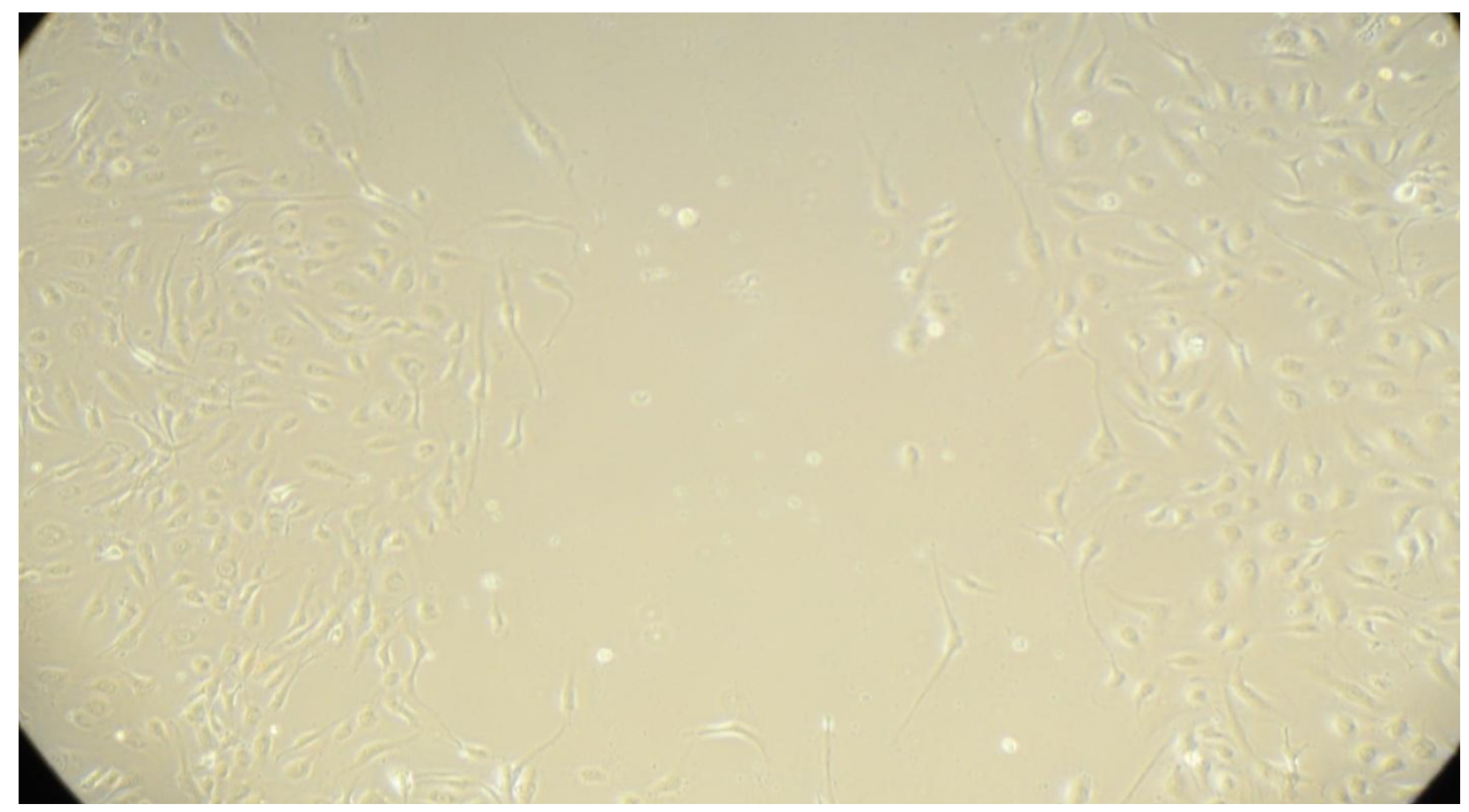

Figure 7: HUVEC cells in static conditions. Note high cell density on wound borders with some lone migratory cells in the wound channel.

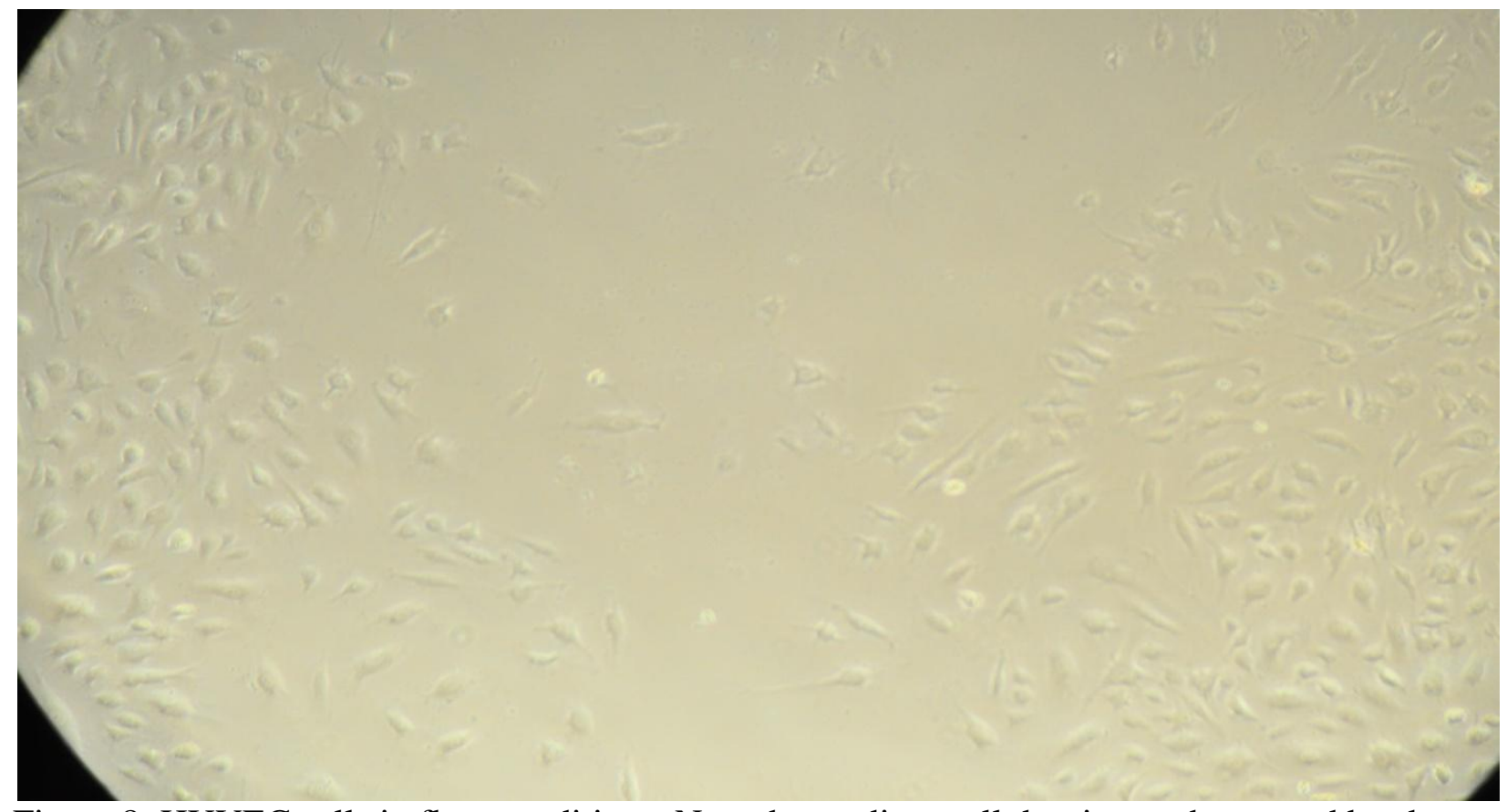

Figure 8: HUVEC cells in flow conditions. Note the medium cell density on the wound borders with many lone migratory cells in the wound channel. 


\section{Recommendations:}

After spending time conducting these experiments it is evident that there is additional experimentation which can be conducted to further enhance the conclusions drawn from this experimental investigation. The first and foremost is modifying the model in order to show a difference between the cells given the VitaSol supplemented media and those given the standard media formulation. As mentioned briefly above in the discussion section, there was no significant difference between the drug loaded media and the no drug loaded media when there probably should have been. After much deliberation, this is thought to be the cause of the normal oxygen conditions the cells were introduced to. In a normal oxygen environment the cells are able to produce as much ATP as they need, which is the primary active molecule in the VitaSol. Therefore any ATP delivered as a result of the VitaSol would be treated as excess by the cells and would be discarded from the cells if it is even absorbed at all. It is therefore the recommendation to repeat these experiments in a hypoxic environment where the cells are ATP deprived, if this is the case then there should be a displayed difference between the VitaSol samples and the regular media samples. Retesting the samples under hypoxic conditions would probably also more accurately mimic in vivo conditions in a wound, which is often oxygen deprived.

A second recommendation would be to retest the flow samples at different flow rates. While this experimentation did show that flow has a significant effect in the rate of wound closure it is unknown if the flow used in this investigation optimizes the rate of closure. For this reason it would be desirable to attempt to maximize the rate of wound healing by testing at a flow rate higher and lower than the one used in this experimentation and see if this makes a 
difference. It is fairly well documented that high flow rates accompanied with relatively higher shear stresses enhances HUVEC cell growth rates especially when the cells are exposed to shear stress prior to testing. There is very little documentation regarding what happens to the cells at low flow rates with nearly negligible shear stresses, which is why further research into this area is recommended.

A final recommendation would be to test whether flow directionality has a significant impact on the rates of wound closure. For this experimentation a perpendicular flow to the channel was chosen because that is what the literature precedent used, however, considering the nature of a wound bed which is more radial it would be more realistic to test a variety of angles of flow. It is theorized that a parallel angle of flow in comparison to the wound channel wouldn't direct the cells into the wound channel to the extent that the perpendicular flow did thus reducing the rate of closure. However, since there is still the constant circulating of fresh media with the removal of metabolytes would still lead to a significant difference in the rate of growth over the static flow conditions. 


\section{Conclusion:}

Based on the results from the previously discussed experiments a few things can be concluded. One such thing was that a flow rate, even a very low rate, such as the one used in this experimentation, promotes cellular growth rates in both the HUVEC and the HDFa cell culture models. This enhanced rate should translate to faster filling of the wound bed as well as the faster revascularization of the wound bed. Another thing concluded from this round of experimentation is that the VitaSol did not have any effect on the growth rate, although likely for the reasons discussed above. In a similar fashion the MTT assay also could not display statistically significant results because the number of cells used in the assay was too low to display a difference in the metabolic rates. Overall, even with some aspects of this investigation being inconclusive, the experimentation was still a success as it proved the primary hypothesis. Despite the setbacks exhibited during this investigation, the results can still be used as a reliable predicate comparison for future experimentation in this area. 


\section{References:}

1) Lazarus, G.S., Cooper, D.M., Knighton, D.R., Margolis, D.J., Percoraro, E.R., Rodeheaver, G., Robson, M.C. (1994). Definitions and guidelines for assessment of wounds and evaluation of healing. Arch Dermatol.; 130: 489-493

2) Wound Care Education Institute. (2007). Pressure Ulcer Staging Guide. National Pressure Advisory Panel

3) Advanced Wound Management: Healing and Restoring Lives. (2006). Advanced Medical Technology Association

4) Harding, K.G., Morris, H.L., Patel, G.K. (2002). Science, medicine and the future: healing chronic wounds. BMJ; 324: 160-163

5) Ettenson, D.S., Gotlieb, A.I. (1994). Endothelial wounds with disruption in cell migration repair primarily by cell proliferation. Microvasc. Res.; 48: 328-337

6) Thomas, S. (1997). Assessment and management of wound exudates. J. Wound Care; 6: $327-330$

7) Sibbald, G.R., Orsted, H., Schultz, G.S., Coutts, P., Keast, D. (2003). Preparing the wound bed: Focus on infection and inflammation. Ostomy Wound Manag.; 49: 24-51

8) Falabella, A.F. (2006). Debridement and wound bed preparation. Dermatol. Ther.; 19: 317325

9) Moore, K., McCallion, R., Searle, R.J., Stacey, M.C., Harding, K.G. (2006). Prediction and monitoring the therapeutic response of chronic dermal wounds. Int. Wound J.; 3: 89-96

10) Liao, Z.J., Huan, J.N., Lv, G.Z., Shou, Y.M., Wang, Z.Y. (2006). Multi-centre clinical study of the effect of silver nitrate ointment on the partial thickness burn wounds. Zhonghua Shao Shang Za Zhi; 22: 359-361 
11) Cho, Y.S., Lee, J.W., Lee, J.S., Lee, J.H., Yoon, T.R., Kuroyanagi, Y., Park, M.H., Pyun, D.G., Kim, H.J. (2002). Hyaluronic acid and silver sulfadiazine-impregnated polyurethane foams for wound dressing application. J. Mater. Sci. Mater. Med.; 13: 861-865

12) Lee, A.R.C., Leem, H., Jaegwan, L., Park, K.C. (2005). Reversal of silver sulfadiadineimpaired wound healing by epidermal growth factor. Biomaterials; 26: 4670-4676

13) http://www.ncbi.nlm.nih.gov/pubmedhealth/PMH0001057/. Becaplermin Topical (Regranex). NIH

14) Boateng, J.S., Matthews, K.H., Stevens, H.N.E., Eccleston, G.M. (2008). Wound Healing Dressings and Drug Delivery Systems: A Review. Journal of Pharmaceutical Sciences; 97(8): 2892-2923

15) Hinchliffe, R.J., Valk, G.D., Apelqvist, J., et al. (2008). A systematic review of the effectiveness of interventions to enhance the healing of chronic ulcers of the foot in diabetes. Diabetes/metabolism research and reviews; 24(Suppl 1): S119-44

16) Hanft, J.R., Surprenant, M.S. (2002). Healing of chronic foot ulcers in diabetic patients treated with a human fibroblast derived dermis. Journal of Foot and Ankle Surgery; 5: 1-9

17) Shakespeare, P. (2001). Burn wound healing and skin substitutes. Burns; 27: 517-522

18) Gender, A. (2008). Pressure Ulcer Prevention and Management. ARN Network

19) Connelly, N. (2009). The Journey to Zero: Eliminating Nosocomial Pressure Ulcers. RCM\&D Healthcare Group

20) Kaufman, M.W., Pahl, D.W. (2003). Vacuum Assisted Closure Therapy: Wound Care and Nursing Implications. Dermatology Nursing; 15(4): 317-325

21) Wechezak, A.R., Viggers, R.F., Sauvage, L.R. (1985). Fibronectin and F-actin redistribution in cultured endothelial cells exposed to shear stress. Lab Invest.; 53: 639 
22) Ballermann, B.J., Ott, M.J. (1995). Adhesion and differentiation of endothelial cells by exposure to chronic shear stress: a vasculargraft model. Blood Purif.; 13: 125-134

23) Dewey, C.F., Bussolari, S.R., Gimbrone, M.A., Davies, P.F. (1981). The dynamic response of vascular endothelial cells to fluid shear stress. J. Biomech. Eng.; 103: 177

24) Albuquerque, M.L.C., Waters, C.M., Savla, U., Schnaper, H.W., Flozak, A.S. (2000). Am. J. Physiol. Heart Circ. Physiol. 279(H): 293-302

25) Arslan, N., Isik, S., Uykan, O. (2010). Steady and Disturbed Flow Effects on Human Umbilical Vein Endothelial Cells in Vascular System: An Experimental Study. Acta of Bioengineering and Biomechanics; 12(4): 3-9

26) Morigi, M., Zoja, C., Figliuzzi, M., Foppolo, M., Micheletti, G., Bontempelli, M., Saronni, M., Remuzzi, G., Remuzzi, A. (1995). Fluid Shear Stress Modulates Surface Expression of Adhesion Molecules by Endothelial Cells. Blood; 85(7): 1696-1703

27) Chiang, B., Essick, E., Ehringer, W., Murphree, S., Hauck, M. A., Li, M., Chien, S. (2007). Enhancing Skin Wound Healing By Direct Intracellular ATP Delivery. Am. J. Surg.; 193(2): 213-218

28) Chien S. (2009). Intracellular ATP delivery using highly fusogenic liposomes. Methods in molecular biology; In Press

29) Wang, J., Wan, R., Mo, Y., Li, M., Zhang, Q., Chien, S. (2010) Intracellular Delivery of ATP Enhanced Healing Process in Full Thickness Skin Wounds in Diabetic Rabbits. Am. J. Surg.; 199(6): 823-832

30) Wang, J., Zhang, Q., Wan, R., et al. (2009). Intracellular ATP delivery enhanced skin wound healing in rabbits. Annals of Plastic Surgery; 62: 180-186 
31) Mo, Y., Wan, R., Wang, J., et al. (2009). Intracellular ATP delivery accelerates skin wound healing through upregulation cytokines and vascular endothelial growth factors expressions. Wound Rep. Reg.; 17: A11

32) Chen W., Zhang C.W., Song L.R., Sommerfeld M., Hu Q. (2009). A high throughput Nile red method for quantitative measurement of neutral lipids in microalgae. Journal of Microbiological Methods; 77: 41-47

33) Huang, G.H., Chen G., Chen F. (2009). Rapid screening method for lipid production in alga based on Nile red fluorescence. Biomass and Bioenergy; 33: 1386-1392

34) Gel Filtration: Principles and Methods. (2002). Amersham Biosciences. Article: 18-1022-18

35) Sepharose and Sepharose CL Instructions. (2005). Amersham Biosciences. Article: 71-709800

36) http://web.mit.edu/fluids-modules/www/exper_techniques/2.Dye_Injection.pdf. Dye Injection Technique. MIT

37) Vybrant MTT Cell Proliferation Assay Instructions. (2002). Molecular Probes. Article MP 13154 


\section{Appendices:}

\section{Appendix I: Experimental Setup Photos}

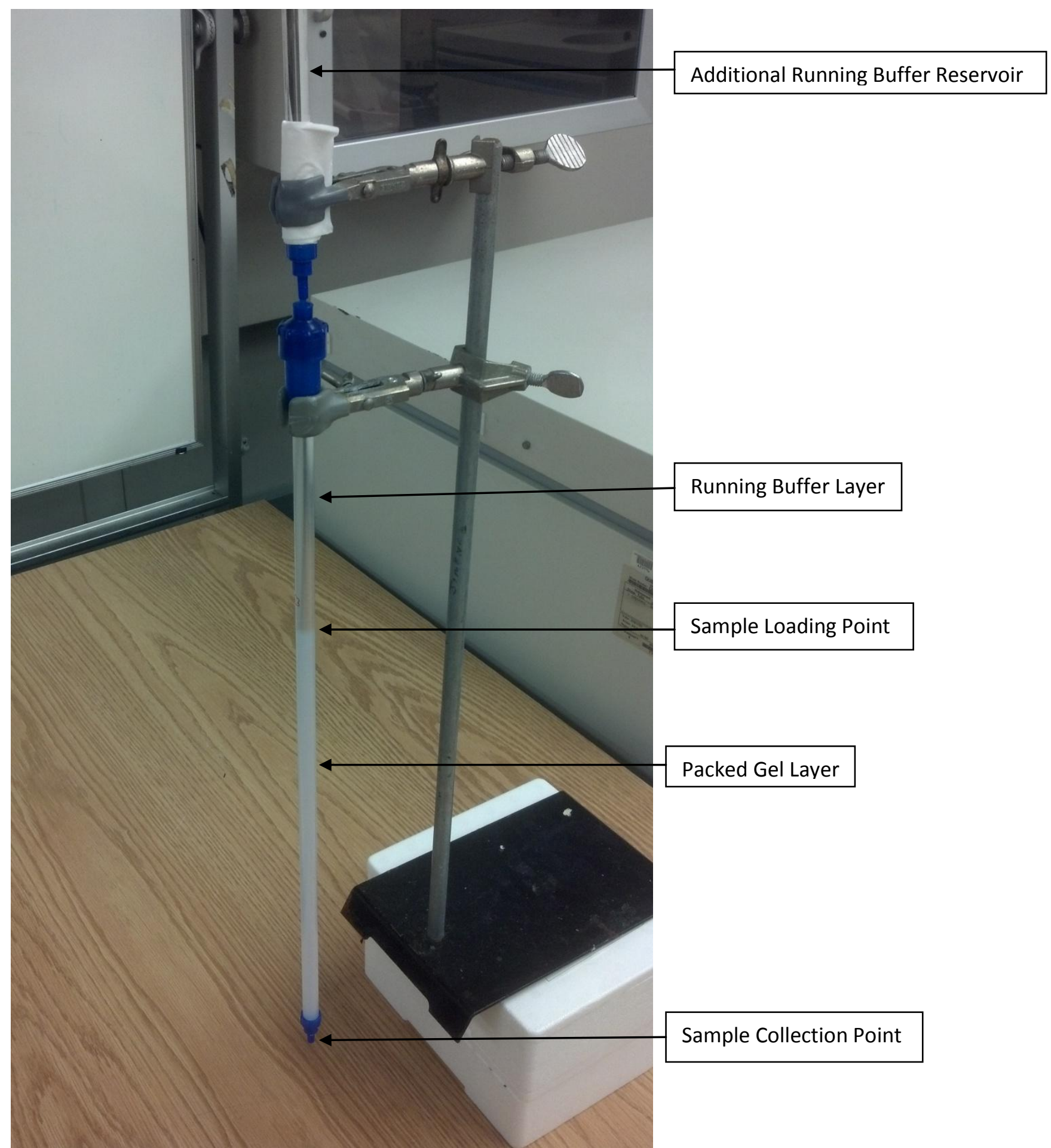

Photo 1: Gel Filtration Column Setup with Extra Running Buffer Reservoir Attached 


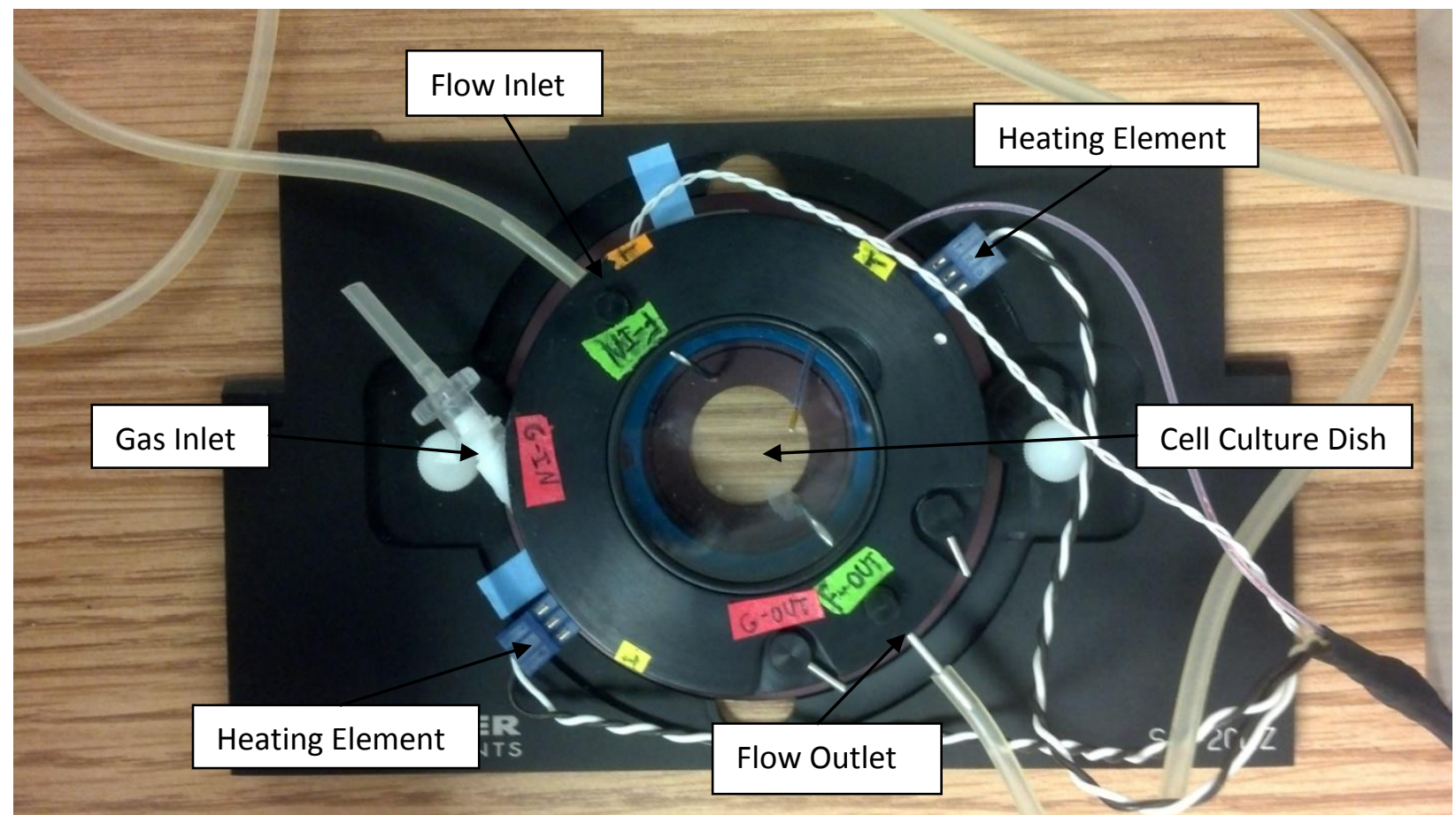

Photo 2: DH-40i Microincubation System with labeled flow inlets and outlets designed to supply media to the cell culture and heating elements, powered by DC current, designed to maintain $37^{\circ} \mathrm{C}$. 


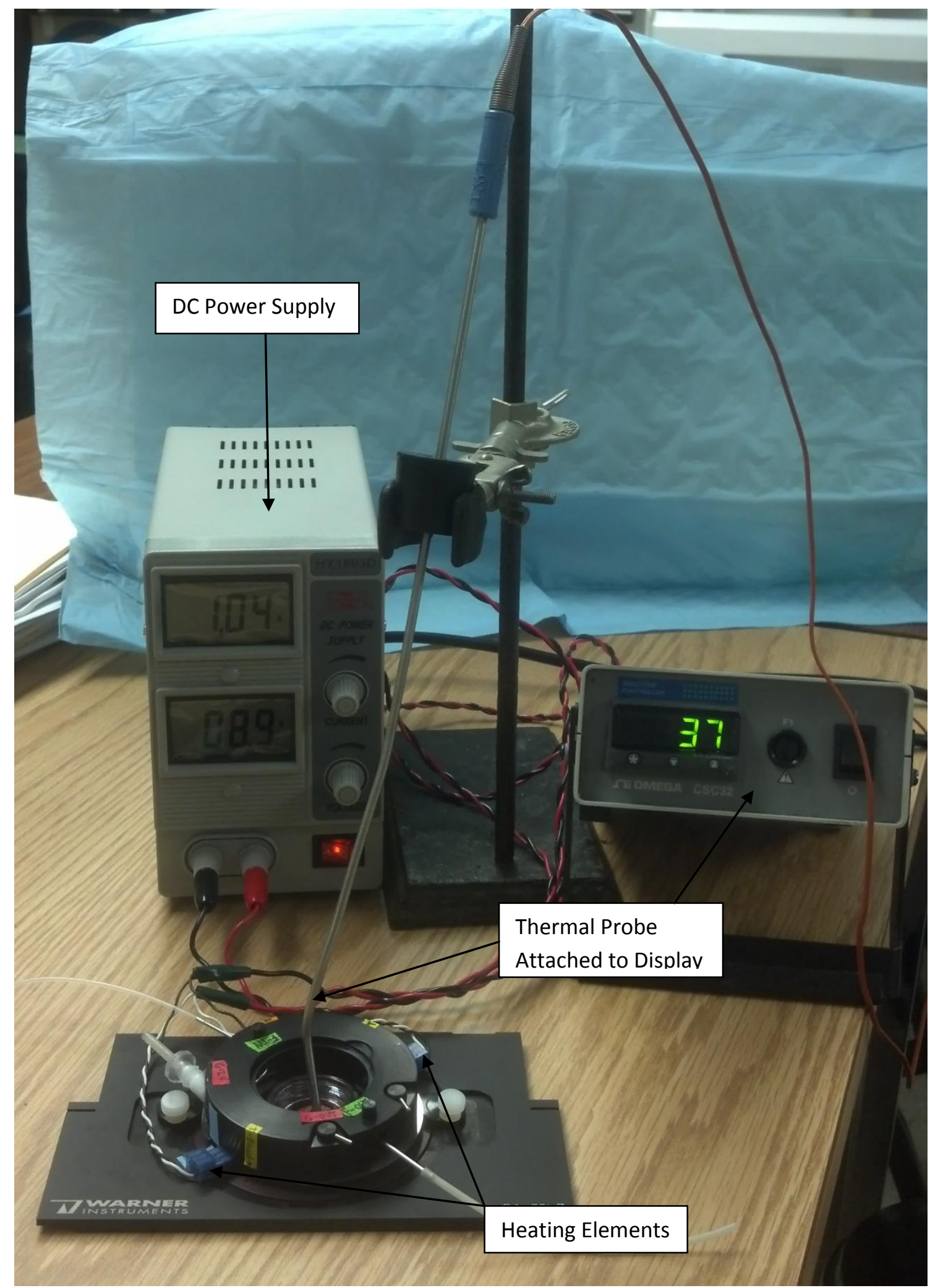

Photo 3: Temperature Verification Using the DC Power Supply set to maintain $37^{\circ} \mathrm{C}$. 


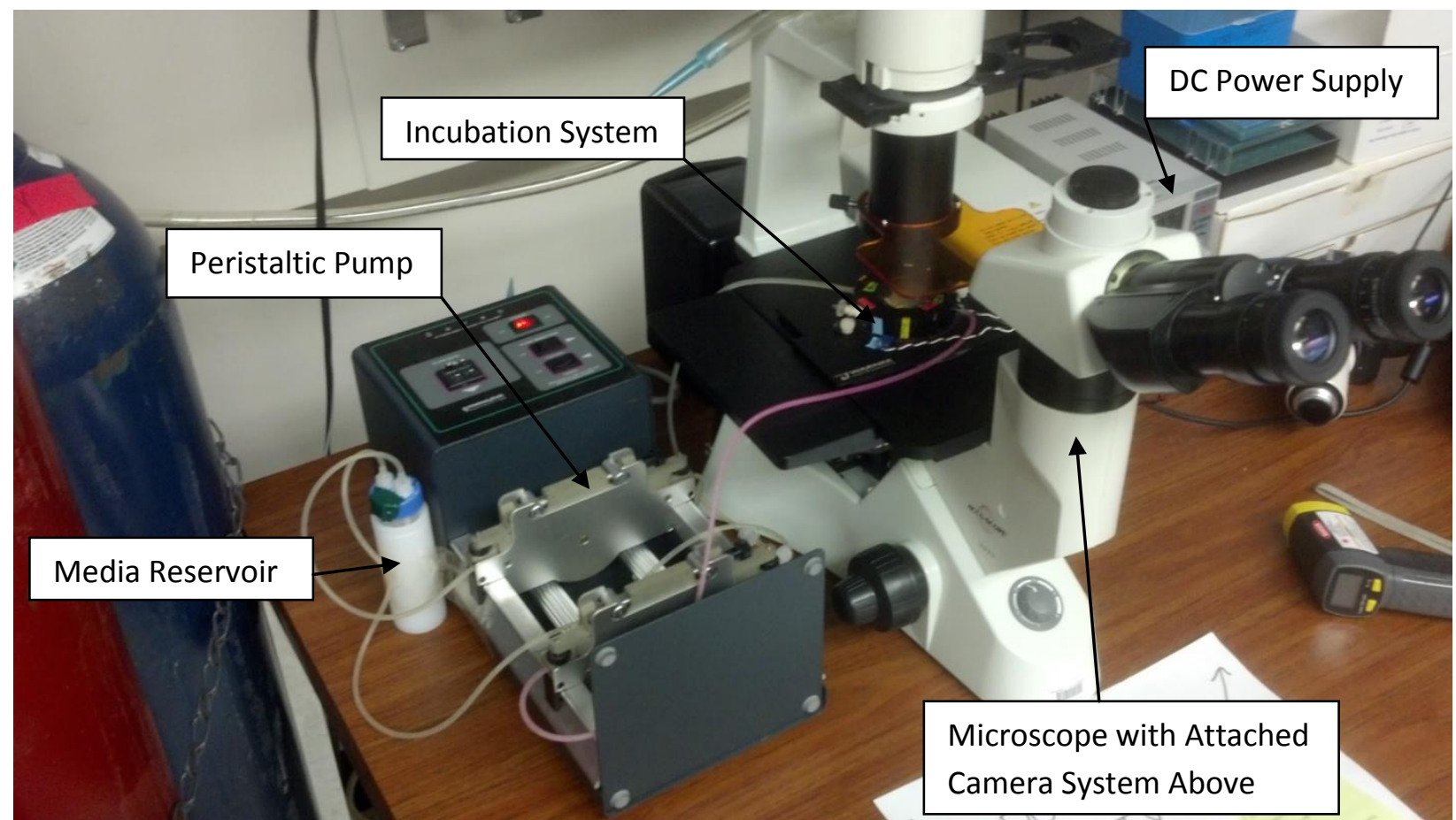

Photo 4: Complete Cell Culturing System with attached peristaltic pump facilitating the flow of

media, DC Power supply to maintain physiologic growing temperatures, and attached camera system for data collection.



Photo 5: 2mm Scale Bar Imaged at 10x used to calibrate the ImageJ software. 
Photo 8: Image of Particle Tracking Time 3

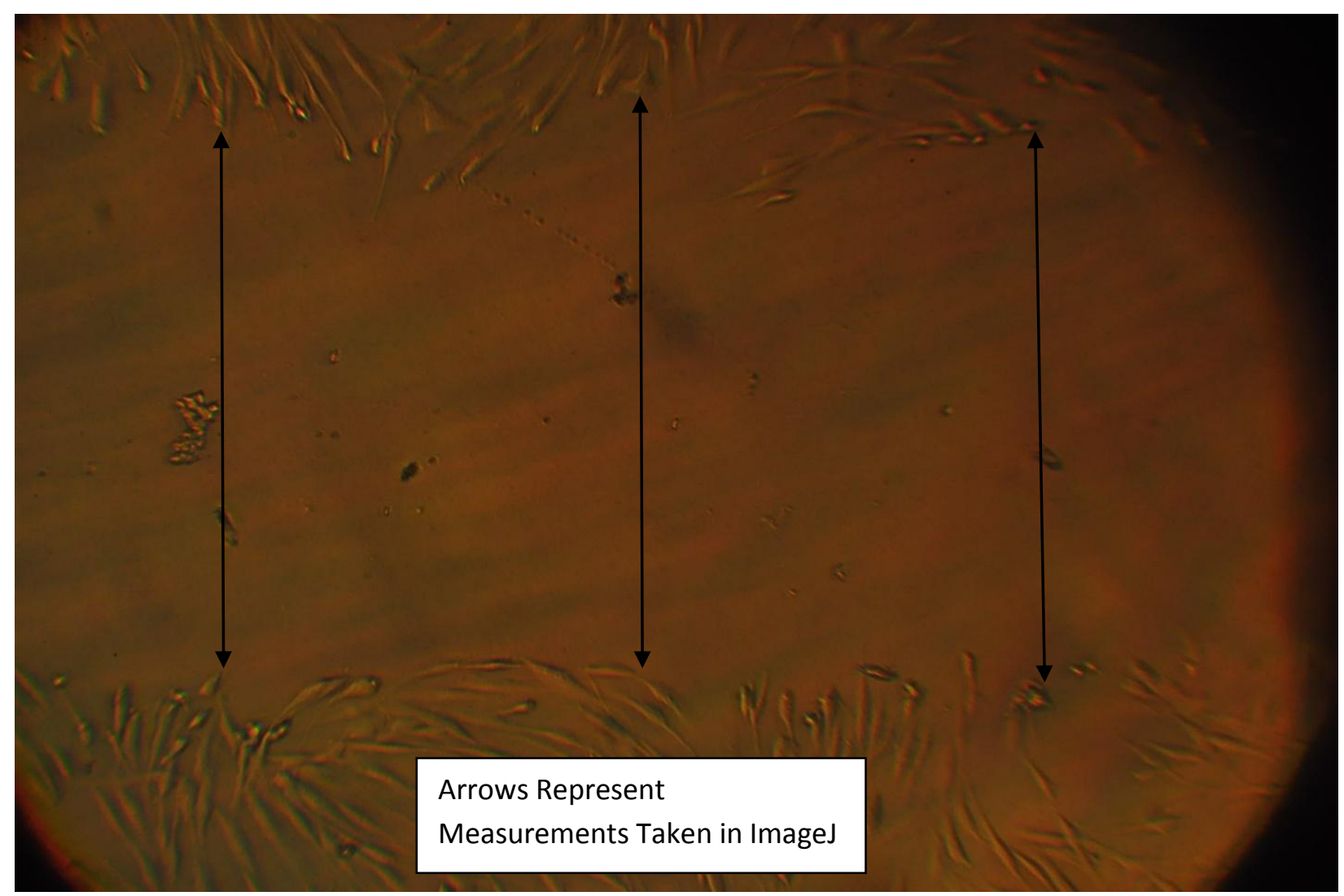

Photo 9: Depiction of how the distance measurements were taken from each photo. 
Appendix II: Additional Data and Statistics

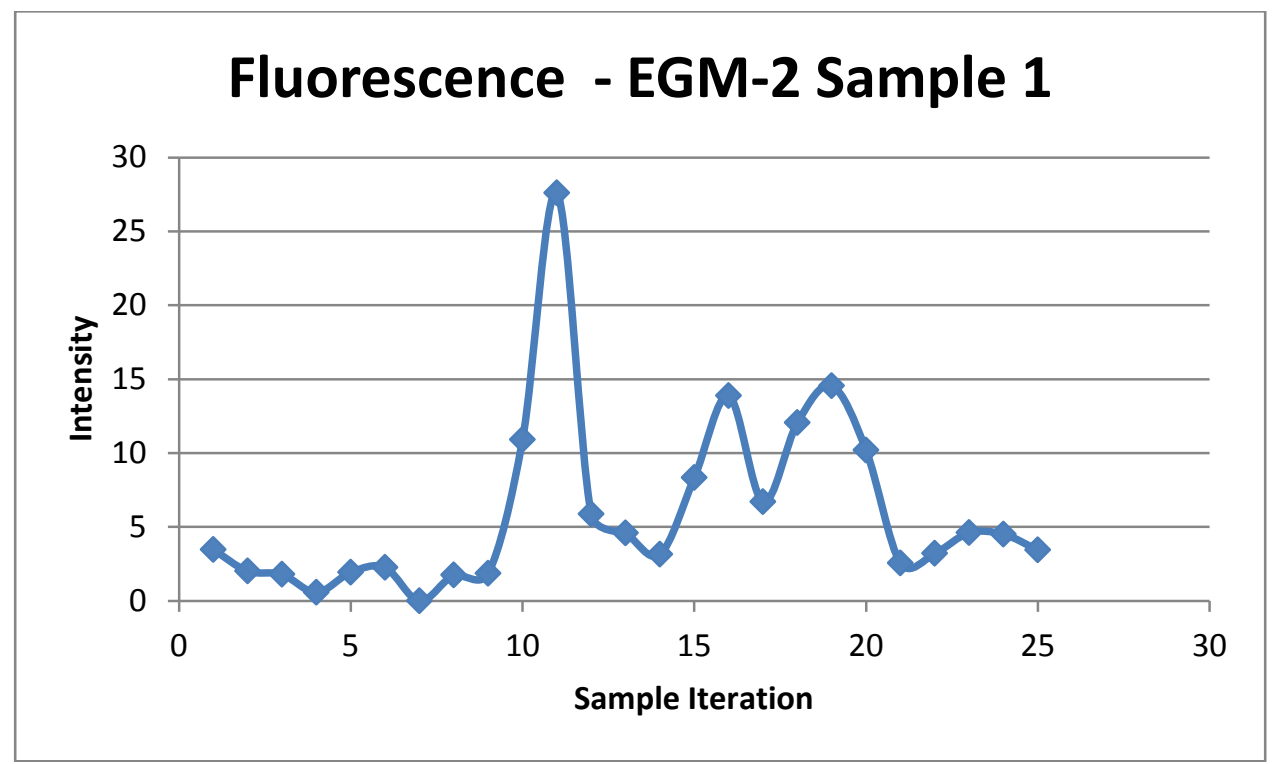

Figure 1: EGM-2 Media Sample 1 Fluorescence Curve

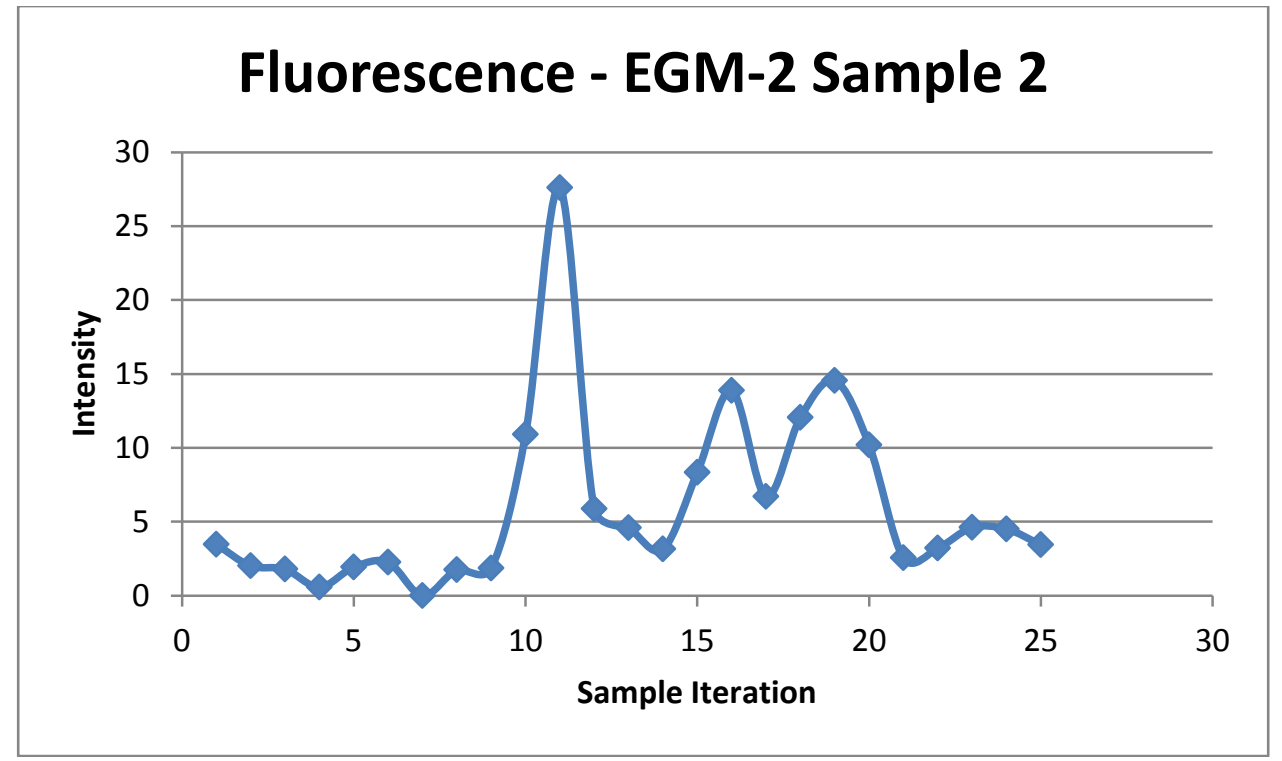

Figure 2: EGM-2 Media Sample 2 Fluorescence Curve 




Figure 3: EGM-2 Media Sample 3 Fluorescence Curve

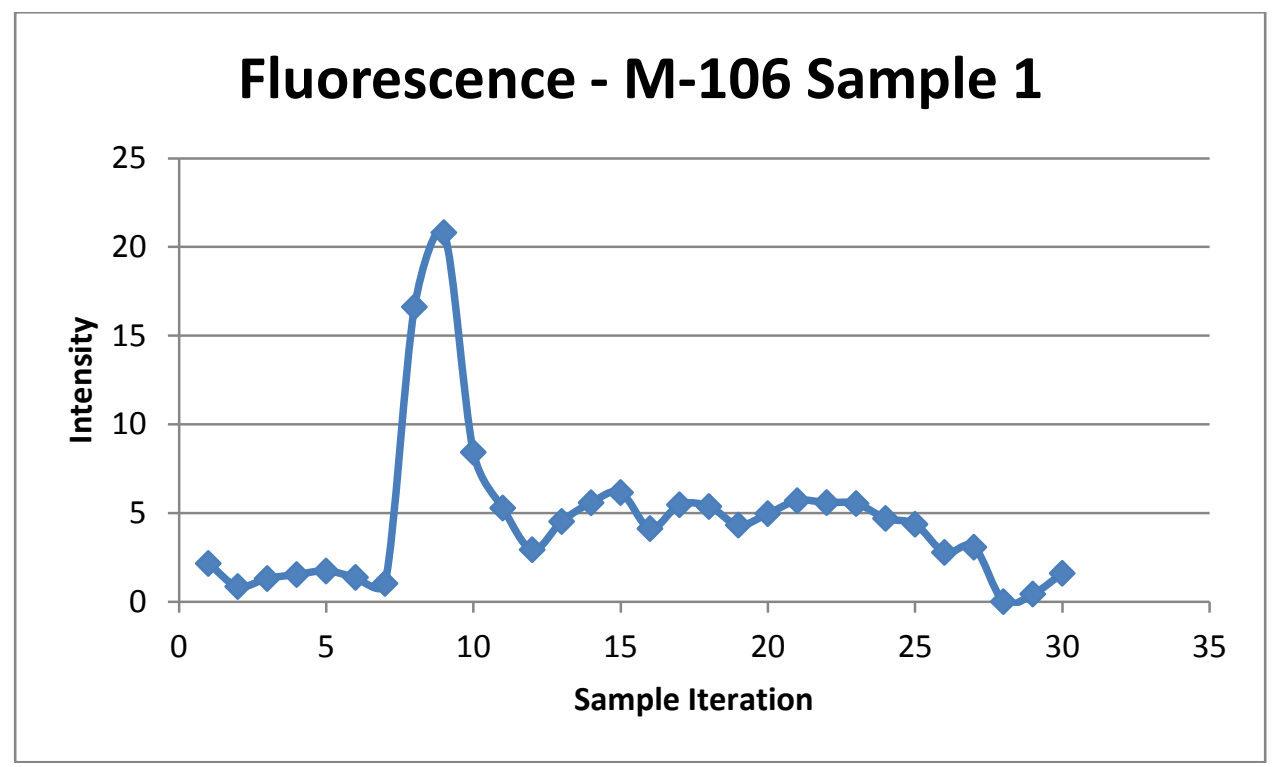

Figure 4: M-106 Media Sample 1 Fluorescence Curve 




Figure 5: M-106 Media Sample 2 Fluorescence Curve

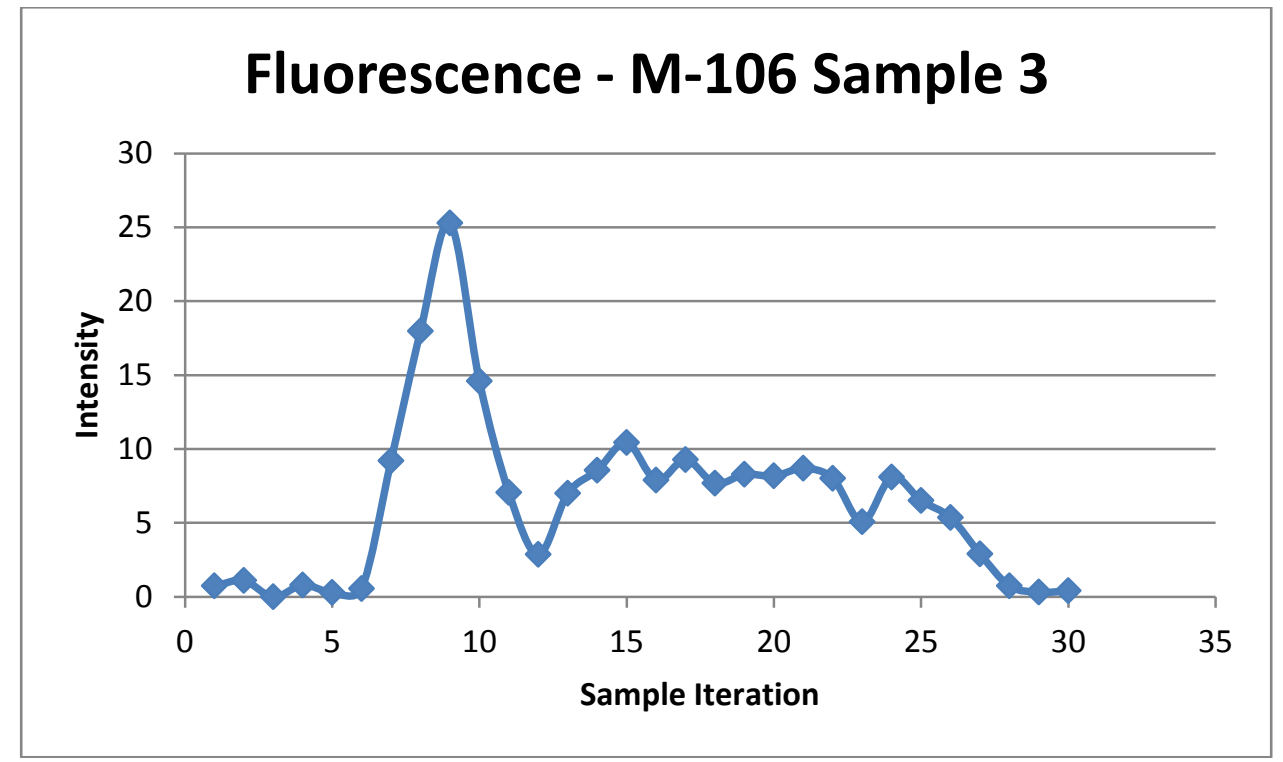

Figure 6: M-106 Media Sample 3 Fluorescence Curve 


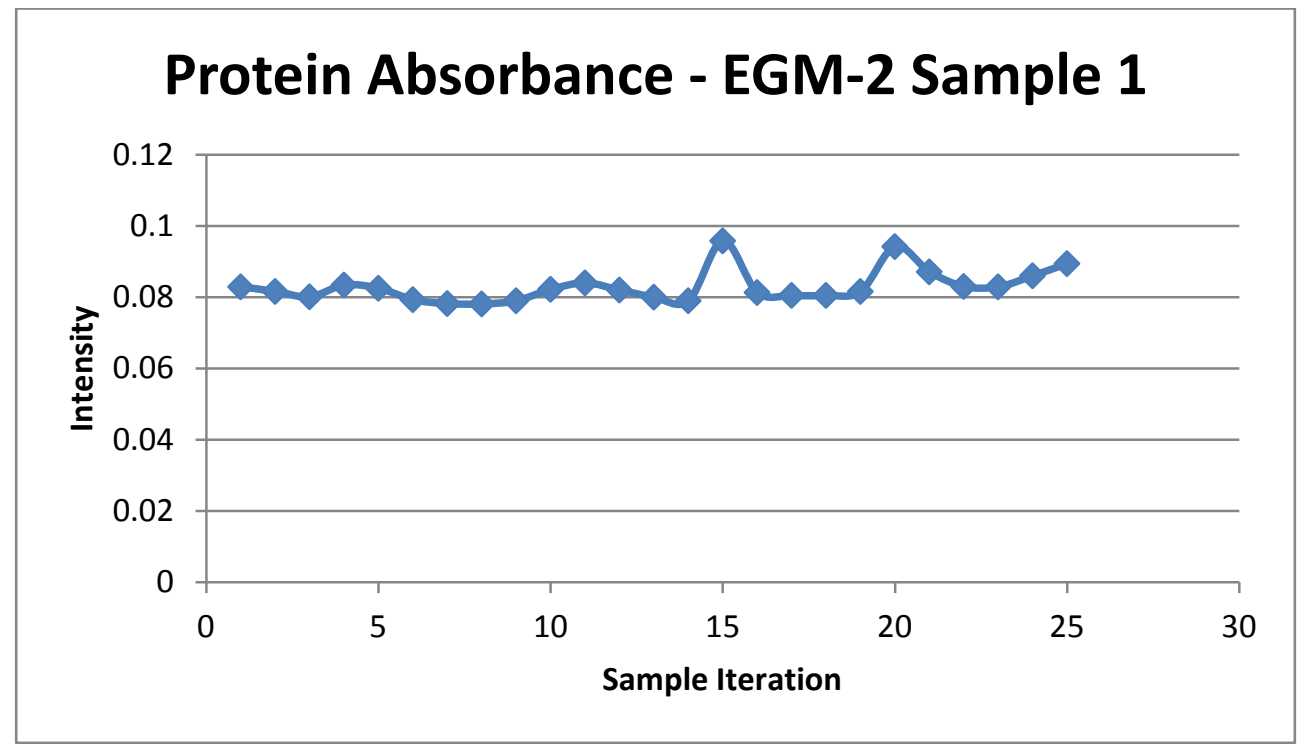

Figure 7: EGM-2 Media Sample 1 Protein Absorbance Curve

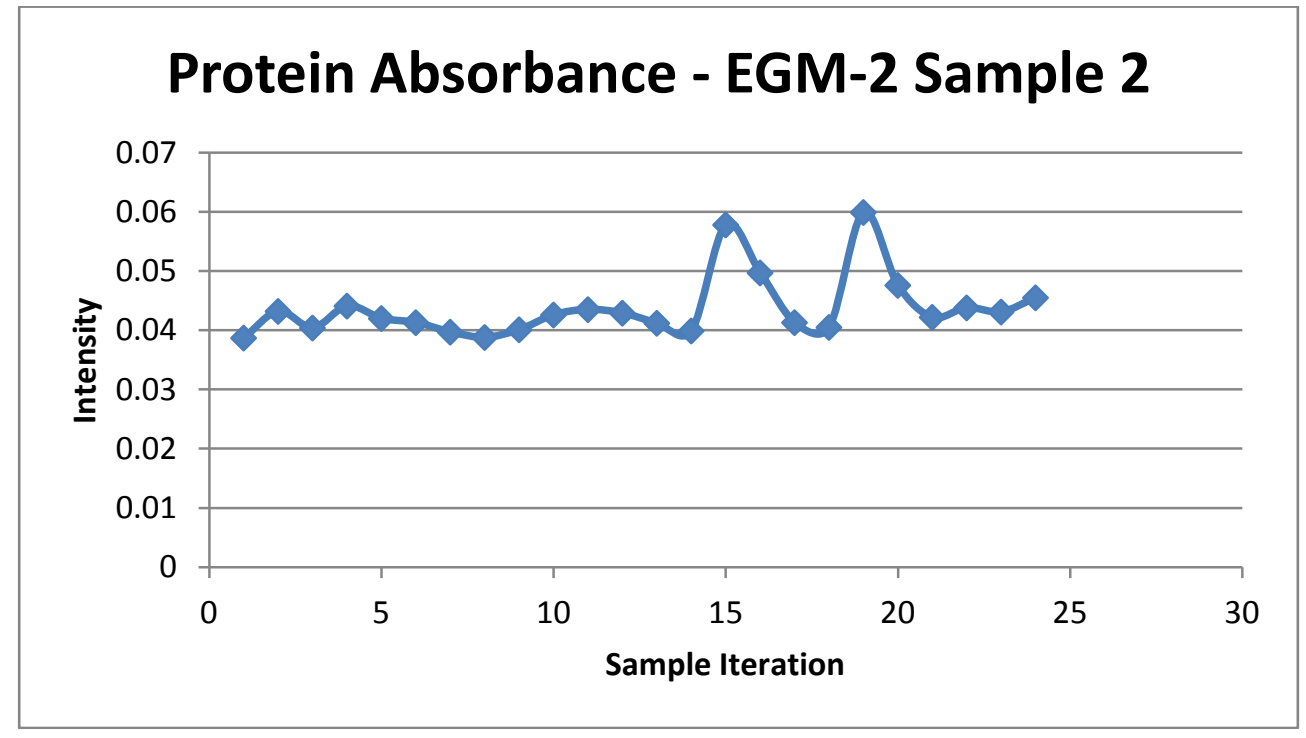

Figure 8: EGM-2 Media Sample 2 Protein Absorbance Curve 




Figure 9: EGM-2 Media Sample 3 Protein Absorbance Curve

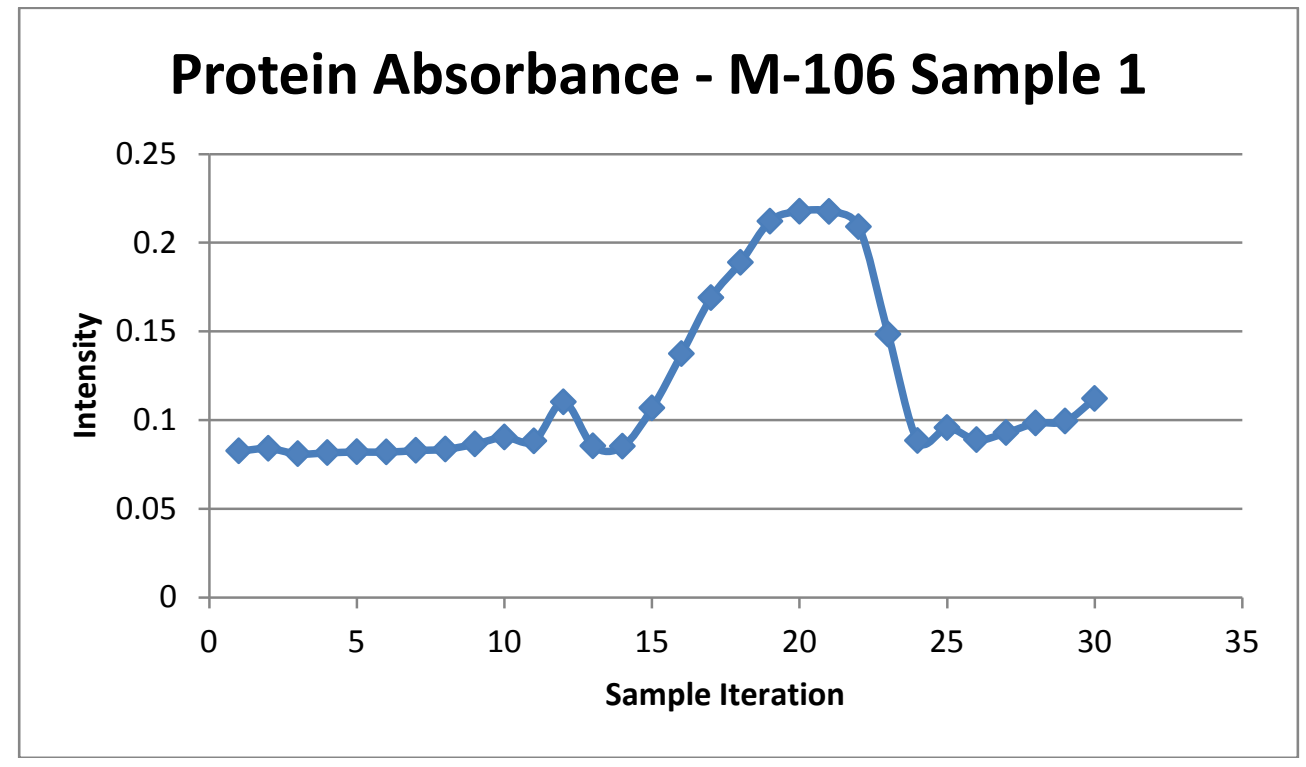

Figure 10: M-106 Media Sample 1 Protein Absorbance Curve 


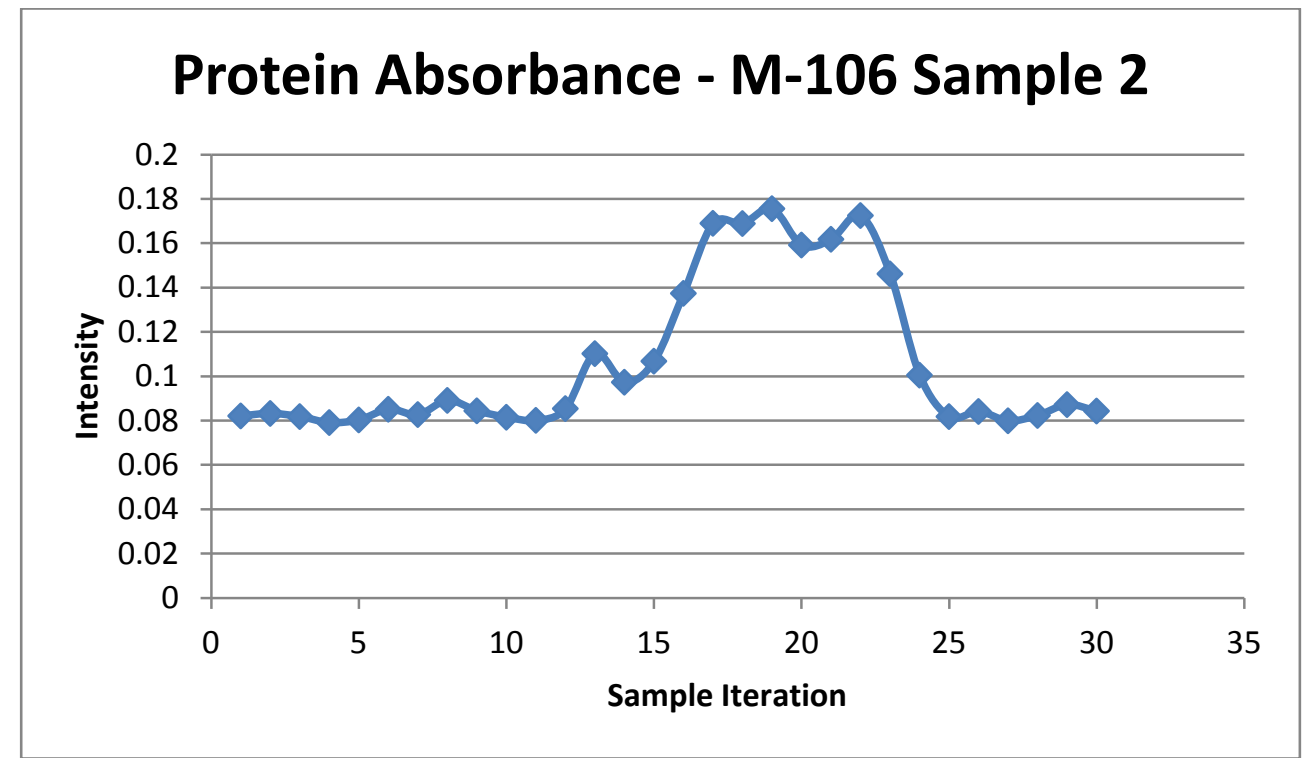

Figure 11: M-106 Media Sample 2 Protein Absorbance Curve

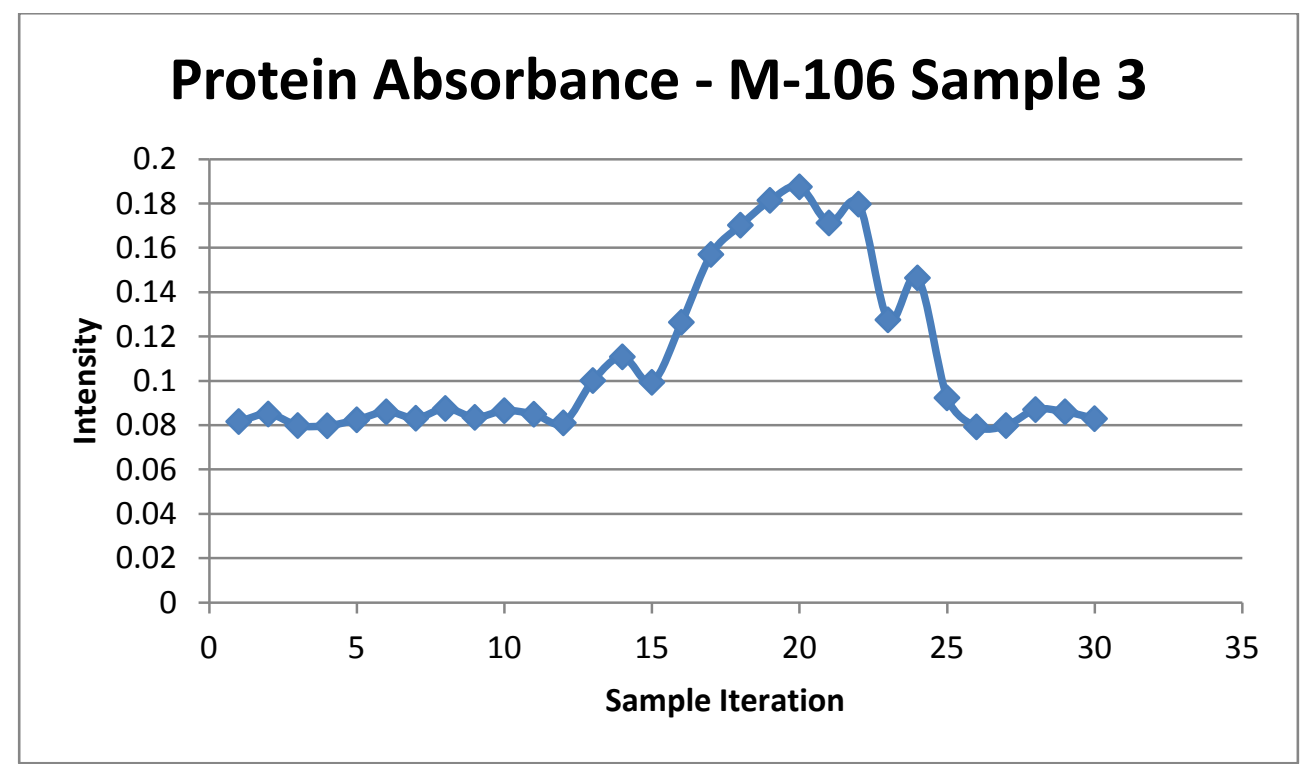

Figure 12: M-106 Media Sample 3 Protein Absorbance Curve 
EGM-2 Sample 1

Area under curve

Lipid and

$\begin{array}{lrr} & \text { Lipids } & \text { Proteins } \\ 1 & 6.3875 & 5.748\end{array}$

$2 \quad 19.261 \quad 11.1135$

$3 \quad 16.743 \quad 10.297$

$4 \quad 5.236 \quad 9.384$

$5 \quad 13.3085$

$6 \quad 12.378$

$7 \quad 6.38$

Total

$\begin{array}{lll}47.6275 & 68.609 & 116.2365\end{array}$

Proteins
EGM-2 Sample 2

Percent Vesicle Bound $=0.590253$

Percent Vesicle Free $=0.409747$
Area under curve



EGM-2 Sample 3

Area under curve

$\begin{array}{lrrl} & & & \text { Lipid and } \\ 1 & \text { Lipids } & \text { Proteins } & \text { Proteins } \\ 2 & 4.244 & 4.2815 & \\ 3 & 16.6405 & 9.81 & \\ 4 & 19.323 & 10.6615 & \\ 5 & 9.0845 & 9.6415 & \\ 6 & & 10.9395 & \\ 7 & & 9.184 & \\ \text { al } & 49.292 & 59.2755 & 108.5675\end{array}$

Percent Vesicle Bound $=0.545978$

Percent Vesicle Free $=0.454022$

Chart 1: Area Approximations under the EGM-2 Media Curve 
M-106 Sample 1

Area under curve

\begin{tabular}{rrrl} 
& \multicolumn{1}{c}{ Lipids } & Proteins & Lipid and \\
Proteins
\end{tabular}

Total

\section{$\begin{array}{lll}53.111 & 73.83 \quad 126.941\end{array}$}

M-106 Sample 2

Area under curve

$$
\text { Lipid and }
$$

$\begin{array}{lrrr} & \text { Lipids } & \text { Proteins } & \text { Proteins } \\ 1 & 4.568 & 5.9105 & \end{array}$

$2 \quad 12.8565 \quad 8.8015$

$3 \quad 20.7435 \quad 9.94$

$4 \quad 18.0495 \quad 9.526$

$\begin{array}{lll}5 & 9.838 & 9.9285\end{array}$

$\begin{array}{lll}6 & 5.808 \quad 10.402\end{array}$

$7 \quad 9.023$

$8 \quad 9.068$

$9 \quad 7.6955$

$10 \quad 6.9025$

$11 \quad 8.1015$

$12 \quad 8.4275$

$13 \quad 7.596$

$14 \quad 6.939$

$15 \quad 5.3315$

16

Total
M-106 Sample 3

Area under curve

\begin{tabular}{rrrl} 
& & & \multicolumn{1}{l}{ Lipid and } \\
& Lipids & Proteins & Proteins \\
1 & 4.8755 & 4.9335 & \\
2 & 13.5895 & 7.78 & \\
3 & 21.6365 & 9.4985 & \\
4 & 19.9465 & 9.165 & \\
5 & 10.827 & 8.586 & \\
6 & 4.9615 & 8.481 & \\
7 & & 8.5905 & \\
8 & & 8.2365 & \\
9 & & 8.441 & \\
10 & & 8.3545 & \\
11 & & 6.544 & \\
12 & & 6.588 & \\
13 & & 7.3065 & \\
14 & & 5.9375 & \\
15 & & 4.1305 & \\
16 & & 1.818 & \\
tal & 75.8365 & 114.391 & 190.2275
\end{tabular}

Percent Vesicle Bound $=0.581609$

Percent Vesicle Free $=0.418391$

$$
\begin{aligned}
\text { Percent Vesicle Bound }= & 0.637868 \\
\text { Percent Vesicle Free }= & 0.362132
\end{aligned}
$$$$
0.637868
$$

Percent Vesicle Bound $=0.601338$

Percent Vesicle Free $=0.398662$

Chart 2: Area Approximations under the M-106 Media Curve 


\begin{tabular}{ccccc} 
& \multicolumn{5}{c}{$\begin{array}{c}\text { Remaining Wound Percentage } \\
\text { Huvec }\end{array}$} \\
Time Minutes & $\begin{array}{c}\text { Huvec } \\
\text { Control }\end{array}$ & $\begin{array}{c}0.1 \mathrm{mg} / \mathrm{mL} \\
\text { VitaSol }\end{array}$ & $\begin{array}{c}\text { Huvec Flow } \\
\text { Huvew } \\
0.1 \mathrm{mg} / \mathrm{mL} \\
\text { VitaSol }\end{array}$ \\
0 & 100 & 100 & 100 & 100 \\
180 & - & - & 87.08283323 & 82.66307058 \\
360 & - & - & 74.66724515 & 69.81484197 \\
540 & - & - & 64.52112872 & 58.55846844 \\
720 & - & - & 55.85032968 & \\
1250 & 83.26424961 & 75.13798662 & & \\
1580 & 80.26479179 & 66.75377326 & & \\
2855 & 63.42235514 & 55.39735261 & & \\
3130 & 50.60951082 & 51.58012993 & & \\
4220 & 33.27561782 & 30.44741855 & & \\
4490 & 21.03643073 & 24.9938944 & & \\
5615 & 0 & 14.18209349 & & \\
5895 & & 5.966394764 & &
\end{tabular}

Chart 3: Data Used to Generate Wound Closure Curves for the HUVEC Cells

\begin{tabular}{ccccc} 
& \multicolumn{5}{c}{ Remaining Wound Percentage } \\
Time Minutes & HDFa & $\begin{array}{c}\text { HDFa } \\
0.1 \mathrm{mg} / \mathrm{mL} \\
\text { VitaSol }\end{array}$ & HDFa Flow & $\begin{array}{c}\text { HDFa Flow } \\
0.1 \mathrm{mg} / \mathrm{mL} \\
\text { VitaSol }\end{array}$ \\
0 & 100 & 100 & 100 & 100 \\
180 & - & - & 88.49115244 & 86.43940776 \\
275 & 85.41688766 & 84.63543526 & - & - \\
360 & - & - & 79.24206727 & 73.52470722 \\
540 & - & - & 68.98591408 & 62.97892903 \\
720 & - & - & 53.49474493 & 54.50450009 \\
900 & - & - & 42.50004177 & \\
1260 & 49.05855521 & 54.14554024 & & \\
1660 & 33.90527209 & 35.50132115 & & \\
2800 & 0 & 0 & &
\end{tabular}

Chart 4: Data Used to Generate Wound Closure Curves for the HDFa Cells 


$\begin{array}{ccccc}\text { Growth Rate at Each Sample } & \text { Huvec Control } & \begin{array}{c}\text { Huvec } \\ 0.1 \mathrm{mg} / \mathrm{mL} \\ \text { VitaSol }\end{array} & \text { Huvec Flow } & \begin{array}{c}\text { Huvec } \\ \text { Flow } \\ 0.1 \mathrm{mg} / \mathrm{mL} \\ \text { VitaSol }\end{array} \\ 1 & -0.013863736 & -0.019684724 & -0.071762038 & -0.096316 \\ 2 & -0.00795523 & -0.029870737 & -0.068975489 & -0.071379 \\ 3 & -0.013014089 & -0.009168305 & -0.056367313 & -0.051371 \\ 4 & -0.047633303 & -0.016363491 & -0.054288537 & -0.073022 \\ 5 & -0.016072551 & -0.015010376 & & \\ 6 & -0.045746476 & -0.017033163 & & \\ 7 & -0.018206536 & -0.01239481 & & \\ 8 & & -0.020031866 & & -0.073022 \\ & & & & 0.0183857\end{array}$

Chart 5: Closure Rate Measurements for the HUVEC Culture Model

$\begin{array}{ccccc}\text { Growth Rate at Each Sample } & \text { HDFa Control } & \begin{array}{c}\text { HDFa } \\ 0.1 \mathrm{mg} / \mathrm{mL} \\ \text { VitaSol }\end{array} & \text { HDFa Flow } & \begin{array}{c}\text { HDFa } \\ \text { Flow } \\ 0.1 \mathrm{mg} / \mathrm{mL} \\ \text { VitaSol }\end{array} \\ 1 & -0.05224799 & 0.014101792 & -0.070210305 & -0.075337 \\ 2 & -0.037030271 & -0.018881575 & -0.046564877 & -0.071748 \\ 3 & -0.038179228 & -0.029585663 & -0.058070382 & -0.058588 \\ 4 & -0.029723942 & -0.028141292 & -0.05500393 & -0.058754 \\ 5 & & & -0.068119618 & \\ & & & & \\ \text { Average } & -0.039295358 & -0.015626684 & -0.059593823 & -0.066107 \\ \text { STDEV } & 0.009412032 & 0.020378462 & 0.009728056 & 0.0087104\end{array}$

Chart 6: Closure Rate Measurements for the HDFa Culture Model 


\section{Statistical Tables:}

Wound Closure Rate Statistics:

F-Test Two-Sample for Variances

Huvec Control Vs. Huvec VitaSol

\begin{tabular}{lrr}
\hline & Variable 1 & Variable 2 \\
\hline Mean & - & - \\
Variance & 0.0232131 & 0.0174447 \\
Observations & 0.0002674 & $3.82 \mathrm{E}-05$ \\
df & 7 & 8 \\
F & 6 & 7 \\
P(F<=f) one-tail & 7.000409 & \\
F Critical one-tail & 0.0107815 & \\
\hline
\end{tabular}

$\mathrm{P}<0.05$ so assume unequal variance

t-Test: Two-Sample Assuming Unequal Variances

Huvec Control Vs. Huvec VitaSol

\begin{tabular}{lrr}
\hline & Variable 1 & Variable 2 \\
\hline & - & - \\
Mean & 0.0232131 & 0.0174447 \\
Variance & 0.0002674 & $3.82 \mathrm{E}-05$ \\
Observations & 7 & 8 \\
Hypothesized Mean Difference & 0 & \\
df & 7 & \\
& \multicolumn{2}{c}{-} \\
t Stat & 0.8799427 & \\
P(T<=t) one-tail & 0.2040411 & \\
t Critical one-tail & 1.8945786 & \\
P(T<=t) two-tail & 0.4080822 & \\
t Critical two-tail & 2.3646243 & \\
\hline
\end{tabular}

$\mathrm{P}>0.05$ so there is no significant difference between groups

Table 1: Statistical Table Huvec Control Vs. Huvec VitaSol

F-Test Two-Sample for Variances

Huvec Control Vs. Huvec Flow

\begin{tabular}{lrr}
\hline & Variable 1 & Variable 2 \\
\hline Mean & -0.0232131 & -0.0628483 \\
Variance & 0.0002674 & $7.742 \mathrm{E}-05$ \\
Observations & 7 & 4
\end{tabular}




\begin{tabular}{|c|c|c|}
\hline df & 6 & 3 \\
\hline $\mathrm{F}$ & 3.4537096 & \\
\hline$P(F<=f)$ one-tail & 0.1682448 & \\
\hline F Critical one-tail & 8.9406451 & \\
\hline \multicolumn{3}{|l|}{$P>0.05$ so assume equal variance } \\
\hline \multicolumn{3}{|c|}{ t-Test: Two-Sample Assuming Equal Variances } \\
\hline \multicolumn{3}{|l|}{ Huvec Control Vs. Huvec Flow } \\
\hline & Variable 1 & Variable 2 \\
\hline Mean & -0.0232131 & -0.0628483 \\
\hline Variance & 0.0002674 & $7.742 \mathrm{E}-05$ \\
\hline Observations & 7 & 4 \\
\hline Pooled Variance & 0.0002041 & \\
\hline Hypothesized Mean Difference & 0 & \\
\hline$d f$ & 9 & \\
\hline t Stat & 4.4266102 & \\
\hline $\mathrm{P}(\mathrm{T}<=\mathrm{t})$ one-tail & 0.0008276 & \\
\hline t Critical one-tail & 1.8331129 & \\
\hline $\mathrm{P}(\mathrm{T}<=\mathrm{t})$ two-tail & 0.0016553 & \\
\hline t Critical two-tail & 2.2621572 & \\
\hline
\end{tabular}

$\mathrm{P}<0.05$ so there is a statistically significant difference between groups

Table 2: Statistical Table Huvec Control Vs. Huvec Flow

F-Test Two-Sample for Variances

Huvec VitaSol Vs. Huvec Flow

\begin{tabular}{lrr}
\hline & \multicolumn{1}{c}{ Variable 1 } & \multicolumn{1}{c}{ Variable 2 } \\
\hline Mean & - & \\
Variance & 0.017444684 & -0.062848344 \\
Observations & $3.81974 \mathrm{E}-05$ & $7.74233 \mathrm{E}-05$ \\
df & 8 & 4 \\
F & 7 & 3 \\
P(F<=f) one-tail & 0.49335826 & \\
F Critical one-tail & 0.198800536 & \\
\hline
\end{tabular}

$P>0.05$ so assume equal variance

t-Test: Two-Sample Assuming Equal Variances

Huvec VitaSol Vs. Huvec Flow

\begin{tabular}{lcc}
\hline & Variable 1 & Variable 2 \\
\hline Mean & -0.062848344
\end{tabular}


0.017444684

\begin{tabular}{|c|c|c|}
\hline Variance & 3.81974E-05 & $7.74233 \mathrm{E}-05$ \\
\hline Observations & 8 & 4 \\
\hline Pooled Variance & 4.99652E-05 & \\
\hline Hypothesized Mean Difference & 0 & \\
\hline df & 10 & \\
\hline t Stat & 10.48917868 & \\
\hline $\mathrm{P}(\mathrm{T}<=\mathrm{t})$ one-tail & $5.12156 \mathrm{E}-07$ & \\
\hline t Critical one-tail & 1.812461102 & \\
\hline $\mathrm{P}(\mathrm{T}<=\mathrm{t})$ two-tail & $1.02431 \mathrm{E}-06$ & \\
\hline t Critical two-tail & 2.228138842 & \\
\hline $\begin{array}{l}\mathrm{P}<0.05 \text { so there is a statistically } \\
\text { groups } \\
\text { Table 3: Statistical Table Huv }\end{array}$ & $\begin{array}{l}\text { nificant difference b } \\
\text { VitaSol Vs. Huvec }\end{array}$ & $\begin{array}{l}\text { etween } \\
\text { Flow }\end{array}$ \\
\hline \multicolumn{3}{|l|}{ F-Test Two-Sample for Variances } \\
\hline \multicolumn{3}{|c|}{ Huvec Control Vs. Huvec Flow VitaSol } \\
\hline & Variable 1 & Variable 2 \\
\hline Mean & -0.02321 & -0.07302 \\
\hline Variance & 0.000267 & 0.000338 \\
\hline Observations & 7 & 4 \\
\hline df & 6 & 3 \\
\hline $\mathrm{F}$ & 0.791034 & \\
\hline$P(F<=f)$ one-tail & 0.367816 & \\
\hline F Critical one-tail & 0.210214 & \\
\hline
\end{tabular}

$P>0.05$ so assume equal variance

t-Test: Two-Sample Assuming Equal Variances

Huvec Control Vs. Huvec Flow VitaSol

\begin{tabular}{lrr}
\hline & Variable 1 & Variable 2 \\
\hline Mean & -0.02321 & -0.07302 \\
Variance & 0.000267 & 0.000338 \\
Observations & 7 & 4 \\
Pooled Variance & 0.000291 & \\
Hypothesized Mean Difference & 0 & \\
df & 9 & \\
t Stat & 4.658913 & \\
P(T<=t) one-tail & 0.000594 & \\
t Critical one-tail & 1.833113 & \\
P $(T<=t)$ two-tail & 0.001187 & \\
t Critical two-tail & 2.262157 & \\
\hline
\end{tabular}


$\mathrm{P}<0.05$ so there is a statistically significant difference between groups

Table 4: Statistical Table Huvec Control Vs. Huvec Flow VitaSol

F-Test Two-Sample for Variances

Huvec VitaSol Vs. Huvec Flow VitaSol

\begin{tabular}{lrr}
\hline & Variable 1 & Variable 2 \\
\hline Mean & -0.01744 & -0.07302 \\
Variance & $3.82 \mathrm{E}-05$ & 0.000338 \\
Observations & 8 & 4 \\
df & 7 & 3 \\
$F$ & 0.112998 & \\
P(F<=f) one-tail & 0.008839 & \\
F Critical one-tail & 0.230053 & \\
\hline
\end{tabular}

$\mathrm{P}<0.05$ so assume unequal variance

t-Test: Two-Sample Assuming Unequal Variances

Huvec VitaSol Vs. Huvec Flow VitaSol

\begin{tabular}{lrr}
\hline & Variable 1 & Variable 2 \\
\hline Mean & -0.01744 & -0.07302 \\
Variance & $3.82 \mathrm{E}-05$ & 0.000338 \\
Observations & 8 & 4 \\
Hypothesized Mean Difference & 0 & \\
df & 3 & \\
t Stat & 5.881816 & \\
$\mathrm{P}(\mathrm{T}<=\mathrm{t})$ one-tail & 0.004903 & \\
t Critical one-tail & 2.353363 & \\
$\mathrm{P}(\mathrm{T}<=\mathrm{t})$ two-tail & 0.009806 & \\
t Critical two-tail & 3.182446 & \\
\hline $\mathrm{P}<0.05$ so there is a statistically significant difference between &
\end{tabular}

Table 5: Statistical Table Huvec VitaSol Vs. Huvec Flow VitaSol

F-Test Two-Sample for Variances

Huvec Flow Vs. Huvec Flow VitaSol

\begin{tabular}{lrr}
\hline & Variable & \multicolumn{2}{c}{ Variable } \\
& \multicolumn{1}{c}{1} & \multicolumn{1}{c}{2} \\
\hline Mean & -0.06285 & -0.07302 \\
Variance & $7.74 \mathrm{E}-05$ & 0.000338 \\
Observations & 4 & 4 \\
df & 3 & 3 \\
F & 0.229039 &
\end{tabular}




\begin{tabular}{|c|c|c|}
\hline$P(F<=f)$ one-tail & 0.128663 & \\
\hline F Critical one-tail & 0.107798 & \\
\hline \multicolumn{3}{|l|}{$\mathrm{P}>0.05$ so assume equal variance } \\
\hline \multicolumn{3}{|c|}{ t-Test: Two-Sample Assuming Equal Variances } \\
\hline \multicolumn{3}{|l|}{ Huvec Flow Vs. Huvec Flow VitaSol } \\
\hline & $\begin{array}{c}\text { Variable } \\
1 \\
\end{array}$ & $\begin{array}{c}\text { Variable } \\
2 \\
\end{array}$ \\
\hline Mean & -0.06285 & -0.07302 \\
\hline Variance & 7.74E-05 & 0.000338 \\
\hline Observations & 4 & 4 \\
\hline Pooled Variance & 0.000208 & \\
\hline Hypothesized Mean Difference & 0 & \\
\hline df & 6 & \\
\hline t Stat & 0.998255 & \\
\hline $\mathrm{P}(\mathrm{T}<=\mathrm{t})$ one-tail & 0.178349 & \\
\hline t Critical one-tail & 1.94318 & \\
\hline $\mathrm{P}(\mathrm{T}<=\mathrm{t})$ two-tail & 0.356697 & \\
\hline t Critical two-tail & 2.446912 & \\
\hline
\end{tabular}

Table 6: Statistical Table Huvec Flow Vs. Huvec Flow VitaSol

F-Test Two-Sample for Variances

HDFa Control Vs. HDFa VitaSol

\begin{tabular}{lrr}
\hline & Variable 1 & Variable 2 \\
\hline Mean & -0.039295358 & 0.015626684 \\
Variance & $8.85864 \mathrm{E}-05$ & 0.000415282 \\
Observations & 4 & 4 \\
df & 3 & 3 \\
F & 0.213316284 & \\
P(F<=f) one-tail & 0.118324374 & \\
F Critical one-tail & 0.107797789 & \\
\hline
\end{tabular}

$\mathrm{P}>0.05$ so assume equal variance

t-Test: Two-Sample Assuming Equal Variances

HDFa Control Vs. HDFa VitaSol

\begin{tabular}{lrr}
\hline & Variable 1 & Variable 2 \\
\hline Mean & & - \\
Variance & -0.039295358 & 0.015626684 \\
& $8.85864 \mathrm{E}-05$ & 0.000415282
\end{tabular}


Observations

Pooled Variance

0.000251934

Hypothesized Mean Difference

0

df

6

t Stat

$-2.1088491$

$\mathrm{P}(\mathrm{T}<=\mathrm{t})$ one-tail

0.039749589

t Critical one-tail

1.943180274

$\mathrm{P}(\mathrm{T}<=\mathrm{t})$ two-tail

0.079499177

2.446911846

$\mathrm{P}>0.05$ so there is no statistically significant difference between groups

Table 7: Statistical Table HDFa Control Vs. HDFa VitaSol

F-Test Two-Sample for Variances

HDFa Control Vs. HDFa Flow

\begin{tabular}{lrr}
\hline & Variable 1 & Variable 2 \\
\hline Mean & -0.0392954 & -0.0595938 \\
Variance & $8.859 \mathrm{E}-05$ & $9.464 \mathrm{E}-05$ \\
Observations & 4 & 5 \\
df & 3 & 4 \\
$F$ & 0.9360837 & \\
P(F<=f) one-tail & 0.4983734 & \\
F Critical one-tail & 0.109683 & \\
\hline
\end{tabular}

$\mathrm{P}>0.05$ so assume equal variance

t-Test: Two-Sample Assuming Equal Variances

HDFa Control Vs. HDFa Flow

\begin{tabular}{lrr}
\hline & Variable 1 & Variable 2 \\
\hline Mean & -0.0392954 & -0.0595938 \\
Variance & $8.859 \mathrm{E}-05$ & $9.464 \mathrm{E}-05$ \\
Observations & 4 & 5 \\
Pooled Variance & $9.204 \mathrm{E}-05$ & \\
Hypothesized Mean Difference & 0 & \\
df & 7 & \\
t Stat & 3.154003 & \\
P(T<=t) one-tail & 0.008031 & \\
t Critical one-tail & 1.8945786 & \\
P $(T<=t)$ two-tail & 0.0160621 & \\
t Critical two-tail & 2.3646243 & \\
\hline
\end{tabular}

$\mathrm{P}<0.05$ so there is a statistically significant difference between groups

Table 8: Statistical Table HDFa Control Vs. HDFa Flow 
F-Test Two-Sample for Variances

HDFa VitaSol Vs. HDFa Flow

\begin{tabular}{|c|c|c|}
\hline & Variable 1 & Variable 2 \\
\hline & - & \\
\hline Mean & 0.015626684 & -0.059593823 \\
\hline Variance & 0.000415282 & $9.46351 E-05$ \\
\hline Observations & 4 & 5 \\
\hline$d f$ & 3 & 4 \\
\hline $\mathrm{F}$ & 4.38824309 & \\
\hline$P(F<=f)$ one-tail & 0.093531467 & \\
\hline F Critical one-tail & 6.591382117 & \\
\hline \multicolumn{3}{|l|}{$\mathrm{P}>0.05$ so assume equal variance } \\
\hline \multicolumn{3}{|c|}{ t-Test: Two-Sample Assuming Equal Variances } \\
\hline \multicolumn{3}{|l|}{ HDFa VitaSol Vs. HDFa Flow } \\
\hline & Variable 1 & Variable 2 \\
\hline & - & \\
\hline Mean & 0.015626684 & -0.059593823 \\
\hline Variance & 0.000415282 & $9.46351 \mathrm{E}-05$ \\
\hline Observations & 4 & 5 \\
\hline Pooled Variance & 0.000232055 & \\
\hline Hypothesized Mean Difference & 0 & \\
\hline df & 7 & \\
\hline t Stat & 4.302554925 & \\
\hline $\mathrm{P}(\mathrm{T}<=\mathrm{t})$ one-tail & 0.001777716 & \\
\hline t Critical one-tail & 1.894578604 & \\
\hline $\mathrm{P}(\mathrm{T}<=\mathrm{t})$ two-tail & 0.003555432 & \\
\hline t Critical two-tail & 2.364624251 & \\
\hline
\end{tabular}

$\mathrm{P}<0.05$ so there is a statistically significant difference between groups

Table 9: Statistical Table HDFa VitaSol Vs. HDFa Flow

F-Test Two-Sample for Variances

HDFa Control Vs. HDFa Flow VitaSol

\begin{tabular}{lrr}
\hline & Variable 1 & Variable 2 \\
\hline Mean & -0.0393 & -0.06611 \\
Variance & $8.86 \mathrm{E}-05$ & $7.59 \mathrm{E}-05$ \\
Observations & 4 & 4 \\
df & 3 & 3 \\
$F$ & 1.167591 & \\
$P(F<=f)$ one-tail & 0.450828 &
\end{tabular}




\begin{tabular}{|c|c|c|}
\hline \multicolumn{3}{|l|}{ F Critical one-tail } \\
\hline$P>0.05$ so assume equal varianc & & \\
\hline \multicolumn{3}{|c|}{ t-Test: Two-Sample Assuming Equal Variances } \\
\hline \multicolumn{3}{|c|}{ HDFa Control Vs. HDFa Flow VitaSol } \\
\hline & Variable 1 & Variable 2 \\
\hline Mean & -0.0393 & -0.06611 \\
\hline Variance & $8.86 \mathrm{E}-05$ & 7.59E-05 \\
\hline Observations & 4 & 4 \\
\hline Pooled Variance & $8.22 \mathrm{E}-05$ & \\
\hline Hypothesized Mean Difference & 0 & \\
\hline df & 6 & \\
\hline t Stat & 4.181407 & \\
\hline $\mathrm{P}(\mathrm{T}<=\mathrm{t})$ one-tail & 0.002902 & \\
\hline t Critical one-tail & 1.94318 & \\
\hline $\mathrm{P}(\mathrm{T}<=\mathrm{t})$ two-tail & 0.005804 & \\
\hline t Critical two-tail & 2.446912 & \\
\hline
\end{tabular}

$\mathrm{P}<0.05$ so there is a statistically significant difference between groups

Table 10: Statistical Table HDFa Control Vs. HDFa Flow VitaSol

F-Test Two-Sample for Variances

HDFa VitaSol Vs. HDFa Flow VitaSol

\begin{tabular}{lrr}
\hline & Variable 1 & Variable 2 \\
\hline Mean & -0.01563 & -0.06611 \\
Variance & 0.000415 & $7.59 \mathrm{E}-05$ \\
Observations & 4 & 4 \\
df & 3 & 3 \\
$F$ & 5.473522 & \\
P(F<=f) one-tail & 0.098154 & \\
F Critical one-tail & 9.276628 & \\
\hline
\end{tabular}

$\mathrm{P}>0.05$ so assume equal variance

t-Test: Two-Sample Assuming Equal Variances

HDFa VitaSol Vs. HDFa Flow VitaSol

\begin{tabular}{lrr}
\hline & Variable 1 & Variable 2 \\
\hline Mean & -0.01563 & -0.06611 \\
Variance & 0.000415 & $7.59 \mathrm{E}-05$ \\
Observations & 4 & 4 \\
Pooled Variance & 0.000246 & \\
Hypothesized Mean Difference & 0 &
\end{tabular}


df

t Stat

4.555557

$\mathrm{P}(\mathrm{T}<=\mathrm{t})$ one-tail

0.001935

t Critical one-tail

1.94318

$\mathrm{P}(\mathrm{T}<=\mathrm{t})$ two-tail

0.003869

$t$ Critical two-tail

2.446912

$\mathrm{P}<0.05$ so there is a statistically significant difference between groups

Table 11: Statistical Table HDFa VitaSol Vs. HDFa FlowVitaSol

F-Test Two-Sample for Variances

HDFa Flow Vs. HDFa Flow VitaSol

\begin{tabular}{lrr}
\hline & Variable 1 & Variable 2 \\
\hline Mean & -0.05959 & -0.06611 \\
Variance & $9.46 \mathrm{E}-05$ & $7.59 \mathrm{E}-05$ \\
Observations & 5 & 4 \\
df & 4 & 3 \\
$F$ & 1.247315 & \\
P(F<=f) one-tail & 0.44565 & \\
F Critical one-tail & 9.117182 & \\
\hline
\end{tabular}

$P>0.05$ so assume equal variance

t-Test: Two-Sample Assuming Equal Variances

HDFa Flow Vs. HDFa Flow VitaSol

\begin{tabular}{lrr}
\hline & Variable 1 & Variable 2 \\
\hline Mean & -0.05959 & -0.06611 \\
Variance & $9.46 \mathrm{E}-05$ & $7.59 \mathrm{E}-05$ \\
Observations & 5 & 4 \\
Pooled Variance & $8.66 \mathrm{E}-05$ \\
Hypothesized Mean Difference & 0 \\
df & 7 \\
t Stat & 1.043342 \\
P(T<=t) one-tail & 0.165738 \\
t Critical one-tail & 1.894579 \\
P(T<=t) two-tail & 0.331477 \\
t Critical two-tail & 2.364624 \\
\hline P $>0.05$ so there is no statistically significant difference between \\
groups & \multicolumn{2}{c}{} \\
Table 12: Statistical Table HDFa Flow Vs. HDFa FlowVitaSol & \\
\multicolumn{1}{c}{ MTT Assay Statistics: } \\
F-Test Two-Sample for Variances
\end{tabular}


Huvec Control Vs. Huvec VitaSol

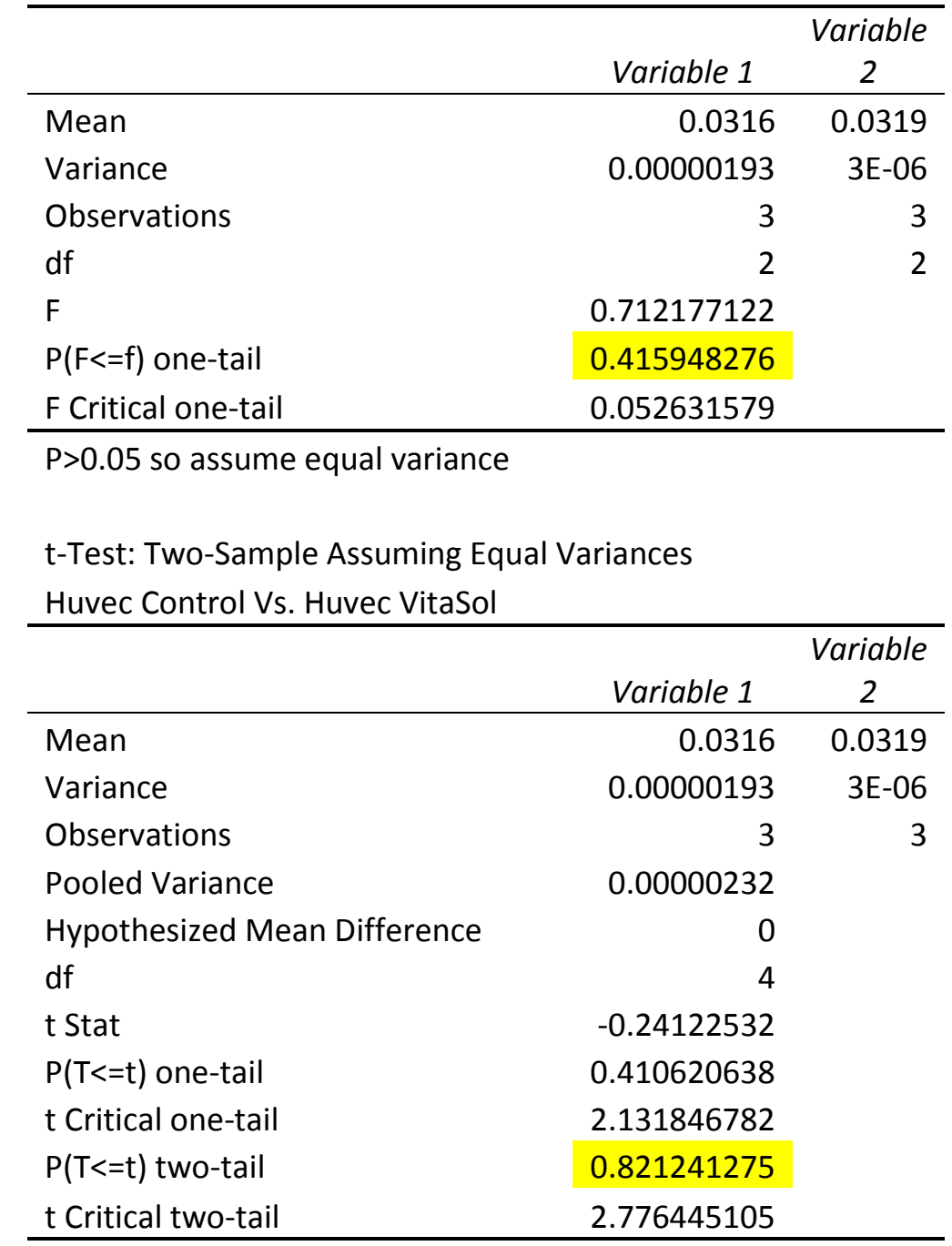

$\mathrm{P}>0.05$ so there is no significant difference between groups

Table 13: Statistical Table Huvec Control Vs. Huvec VitaSol

F-Test Two-Sample for Variances

Huvec Control Vs. Huvec Flow

\begin{tabular}{lrr}
\hline & Variable 1 & Variable 2 \\
\hline Mean & 0.0316 & 0.032766667 \\
Variance & 0.00000193 & $1.34333 \mathrm{E}-06$ \\
Observations & 3 & 3 \\
df & 2 & 2 \\
$F$ & 1.436724566 & \\
P(F<=f) one-tail & 0.410386965 & \\
F Critical one-tail & \multicolumn{2}{c}{19} \\
\hline P $>0.05$ so assume equal & \multicolumn{2}{|c}{}
\end{tabular}


variance

t-Test: Two-Sample Assuming Equal Variances

Huvec Control Vs. Huvec Flow

\begin{tabular}{lrr}
\hline & Variable 1 & Variable 2 \\
\hline Mean & 0.0316 & 0.032766667 \\
Variance & 0.00000193 & $1.34333 \mathrm{E}-06$ \\
Observations & 3 & 3 \\
Pooled Variance & $1.63667 \mathrm{E}-06$ & \\
Hypothesized Mean & \multicolumn{2}{|c}{0} \\
Difference & \multicolumn{2}{|c}{0} \\
df & \multicolumn{2}{|c}{-} \\
& 1.116894881 \\
t Stat & 0.163298694 \\
P(T<=t) one-tail & 2.131846782 \\
t Critical one-tail & 0.326597388 \\
P(T<=t) two-tail & 2.776445105 \\
t Critical two-tail & & \\
\hline
\end{tabular}

$\mathrm{P}>0.05$ so there is no significant difference between groups

Table 14: Statistical Table Huvec Control Vs. Huvec Flow

F-Test Two-Sample for Variances

Huvec Control Vs. Huvec Flow VitaSol

\begin{tabular}{lrr}
\hline & Variable & Variable \\
& \multicolumn{1}{c}{1} & \multicolumn{1}{c}{2} \\
\hline Mean & 0.0316 & 0.032567 \\
Variance & $1.93 \mathrm{E}-06$ & $1.29 \mathrm{E}-06$ \\
Observations & 3 & 3 \\
df & 2 & 2 \\
$F$ & 1.492268 & \\
$P(F<=f)$ one-tail & 0.401241 & \\
F Critical one-tail & \multicolumn{2}{c}{19} \\
\hline$P>0.05$ sO assume equal variance & \multicolumn{3}{|c}{} \\
\hline
\end{tabular}

$\mathrm{P}>0.05$ so assume equal variance

t-Test: Two-Sample Assuming Equal Variances

Huvec Control Vs. Huvec Flow VitaSol

\begin{tabular}{lrr}
\hline & \multicolumn{1}{c}{ Variable } & Variable \\
\hline Mean & \multicolumn{1}{c}{1} & \multicolumn{1}{c}{2} \\
\hline Variance & 0.0316 & 0.032567 \\
Observations & $1.93 \mathrm{E}-06$ & $1.29 \mathrm{E}-06$ \\
Pooled Variance & 3 & 3 \\
& $1.61 \mathrm{E}-06$ &
\end{tabular}




\begin{tabular}{lc} 
Hypothesized Mean Difference & 0 \\
df & 4 \\
$t$ Stat & -0.93258 \\
$P(T<=t)$ one-tail & 0.201916 \\
$t$ Critical one-tail & 2.131847 \\
$P(T<=t)$ two-tail & 0.403831 \\
$t$ Critical two-tail & 2.776445 \\
\hline P $>0.05$ so there is no significant difference between \\
groups
\end{tabular}

Table 15: Statistical Table Huvec Control Vs. Huvec Flow VitaSol

F-Test Two-Sample for Variances

Huvec VitaSol Vs. Huvec Flow

\begin{tabular}{lrr}
\hline & Variable & Variable \\
\hline Mean & \multicolumn{1}{c}{1} & \multicolumn{1}{c}{2} \\
Variance & 0.0319 & 0.032767 \\
Observations & $2.71 \mathrm{E}-06$ & $1.34 \mathrm{E}-06$ \\
df & 3 & 3 \\
F & 2 & 2 \\
P(F<=f) one-tail & 2.01737 & \\
F Critical one-tail & 0.331414 & \\
\hline
\end{tabular}

$\mathrm{P}>0.05$ so assume equal variance

t-Test: Two-Sample Assuming Equal Variances

Huvec VitaSol Vs. Huvec Flow

\begin{tabular}{lrr}
\hline & Variable & Variable \\
& \multicolumn{1}{c}{1} & \multicolumn{1}{c}{2} \\
\hline Mean & 0.0319 & 0.032767 \\
Variance & $2.71 \mathrm{E}-06$ & $1.34 \mathrm{E}-06$ \\
Observations & 3 & 3 \\
Pooled Variance & $2.03 \mathrm{E}-06$ & \\
Hypothesized Mean Difference & \multicolumn{2}{|c}{0} \\
df & \multicolumn{2}{|c}{4} \\
t Stat & -0.7456 \\
P(T<=t) one-tail & 0.248669 \\
t Critical one-tail & 2.131847 \\
$\mathrm{P}(\mathrm{T}<=\mathrm{t})$ two-tail & 0.497338 & \\
$\mathrm{t}$ Critical two-tail & 2.776445 & \\
\hline
\end{tabular}

$\mathrm{P}>0.05$ so there is no significant difference between

groups

Table 16: Statistical Table Huvec VitaSol Vs. Huvec Flow 
F-Test Two-Sample for Variances

Huvec VitaSol Vs. Huvec Flow VitaSol

\begin{tabular}{|c|c|c|}
\hline & $\begin{array}{c}\text { Variable } \\
1 \\
\end{array}$ & $\begin{array}{c}\text { Variable } \\
2 \\
\end{array}$ \\
\hline Mean & 0.0319 & 0.032567 \\
\hline Variance & 2.71E-06 & 1.29E-06 \\
\hline Observations & 3 & 3 \\
\hline df & 2 & 2 \\
\hline $\mathrm{F}$ & 2.095361 & \\
\hline$P(F<=f)$ one-tail & 0.323064 & \\
\hline F Critical one-tail & 19 & \\
\hline \multicolumn{3}{|l|}{$P>0.05$ so assume equal variance } \\
\hline \multicolumn{3}{|c|}{ t-Test: Two-Sample Assuming Equal Variances } \\
\hline \multicolumn{3}{|c|}{ Huvec VitaSol Vs. Huvec Flow VitaSol } \\
\hline & $\begin{array}{c}\text { Variable } \\
1\end{array}$ & $\begin{array}{c}\text { Variable } \\
2\end{array}$ \\
\hline Mean & 0.0319 & 0.032567 \\
\hline Variance & 2.71E-06 & 1.29E-06 \\
\hline Observations & 3 & 3 \\
\hline Pooled Variance & $2 \mathrm{E}-06$ & \\
\hline Hypothesized Mean Difference & 0 & \\
\hline$d f$ & 4 & \\
\hline t Stat & -0.57711 & \\
\hline $\mathrm{P}(\mathrm{T}<=\mathrm{t})$ one-tail & 0.297395 & \\
\hline t Critical one-tail & 2.131847 & \\
\hline$P(T<=t)$ two-tail & 0.59479 & \\
\hline t Critical two-tail & 2.776445 & \\
\hline
\end{tabular}

$\mathrm{P}>0.05$ so there is no significant difference between groups

Table 17: Statistical Table Huvec VitaSol Vs. Huvec Flow VitaSol

F-Test Two-Sample for Variances

Huvec Flow Vs. Huvec Flow VitaSol

\begin{tabular}{lrr}
\hline & Variable & Variable \\
Mean & \multicolumn{1}{c}{1} & \multicolumn{1}{c}{2} \\
\hline Variance & 0.032767 & 0.032567 \\
Observations & $1.34 \mathrm{E}-06$ & $1.29 \mathrm{E}-06$ \\
df & 3 & 3 \\
F & 2 & 2 \\
$P(F<=f)$ one-tail & 1.03866 & \\
& 0.490518 &
\end{tabular}


F Critical one-tail

19

$\mathrm{P}>0.05$ so assume equal variance

t-Test: Two-Sample Assuming Equal Variances

Huvec Flow Vs. Huvec Flow VitaSol

\begin{tabular}{lrr} 
& Variable & Variable \\
& 1 & \multicolumn{1}{c}{2} \\
\hline Mean & 0.032767 & 0.032567 \\
Variance & $1.34 \mathrm{E}-06$ & $1.29 \mathrm{E}-06$ \\
Observations & 3 & 3 \\
Pooled Variance & $1.32 \mathrm{E}-06$ \\
Hypothesized Mean Difference & \multicolumn{2}{|c}{0} \\
df & 4 \\
t Stat & 0.213335 \\
P(T<=t) one-tail & 0.420749 \\
t Critical one-tail & 2.131847 \\
P(T<=t) two-tail & 0.841498 \\
t Critical two-tail & 2.776445 \\
\hline P $>0.05$ so there is no significant difference between \\
groups
\end{tabular}

Table 18: Statistical Table Huvec Flow Vs. Huvec Flow VitaSol

F-Test Two-Sample for Variances

HDFa Control Vs. HDFa VitaSol

\begin{tabular}{lrr}
\hline & \multicolumn{2}{r}{ Variable } \\
\hline Mean & 0.031133333 & 0.0317 \\
Variance & $9.43333 \mathrm{E}-07$ & $2 \mathrm{E}-06$ \\
Observations & 3 & 3 \\
df & 2 & 2 \\
F & 0.43404908 & \\
P(F<=f) one-tail & 0.302673797 & \\
F Critical one-tail & 0.052631579 \\
\hline
\end{tabular}

$\mathrm{P}>0.05$ so assume equal variance

t-Test: Two-Sample Assuming Equal Variances

HDFa Control Vs. HDFa VitaSol

\begin{tabular}{lrr}
\hline & & Variable \\
& Variable 1 & \multicolumn{1}{c}{2} \\
\hline Mean & 0.031133333 & 0.0317 \\
Variance & $9.43333 \mathrm{E}-07$ & $2 \mathrm{E}-06$ \\
Observations & 3 & 3
\end{tabular}




\begin{tabular}{lr} 
Pooled Variance & $1.55833 \mathrm{E}-06$ \\
Hypothesized Mean Difference & 0 \\
df & 4 \\
& - \\
t Stat & 0.523255952 \\
$P(T<=t)$ one-tail & 0.314222195 \\
t Critical one-tail & 2.131846782 \\
$P(T<=t)$ two-tail & 0.628444391 \\
$t$ Critical two-tail & 2.776445105 \\
\hline
\end{tabular}

$\mathrm{P}>0.05$ so there is no significant difference between groups

Table 19: Statistical Table HDFa Control Vs. HDFa VitaSol

F-Test Two-Sample for Variances

HDFa Control Vs. HDFa Flow

\begin{tabular}{lrr}
\hline & Variable 1 & Variable 2 \\
\hline Mean & 0.031133333 & 0.032466667 \\
Variance & $9.43333 \mathrm{E}-07$ & $1.26333 \mathrm{E}-06$ \\
Observations & 3 & 3 \\
df & 2 & 2 \\
F & 0.746701847 & \\
P(F<=f) one-tail & 0.427492447 & \\
F Critical one-tail & 0.052631579 & \\
\hline$P>0.05$ so assume equat & &
\end{tabular}

$\mathrm{P}>0.05$ so assume equal

variance

t-Test: Two-Sample Assuming Equal Variances

HDFa Control Vs. HDFa Flow

\begin{tabular}{|c|c|c|}
\hline & Variable 1 & Variable 2 \\
\hline Mean & 0.031133333 & 0.032466667 \\
\hline Variance & 9.43333E-07 & 1.26333E-06 \\
\hline Observations & 3 & 3 \\
\hline Pooled Variance & 1.10333E-06 & \\
\hline \multicolumn{3}{|l|}{ Hypothesized Mean } \\
\hline Difference & 0 & \\
\hline \multirow[t]{2}{*}{ df } & 4 & \\
\hline & - & \\
\hline t Stat & 1.554644149 & \\
\hline $\mathrm{P}(\mathrm{T}<=\mathrm{t})$ one-tail & 0.09750143 & \\
\hline t Critical one-tail & 2.131846782 & \\
\hline $\mathrm{P}(\mathrm{T}<=\mathrm{t})$ two-tail & 0.195002861 & \\
\hline t Critical two-tail & 2.776445105 & \\
\hline
\end{tabular}


Table 20: Statistical Table HDFa Control Vs. HDFa Flow

F-Test Two-Sample for Variances HDFa Control Vs. HDFa Flow VitaSol

\begin{tabular}{|c|c|c|}
\hline & $\begin{array}{c}\text { Variable } \\
1\end{array}$ & $\begin{array}{c}\text { Variable } \\
2\end{array}$ \\
\hline Mean & 0.031133 & 0.0327 \\
\hline Variance & $9.43 \mathrm{E}-07$ & $1.72 \mathrm{E}-06$ \\
\hline Observations & 3 & 3 \\
\hline df & 2 & 2 \\
\hline $\mathrm{F}$ & 0.54845 & \\
\hline$P(F<=f)$ one-tail & 0.354193 & \\
\hline F Critical one-tail & 0.052632 & \\
\hline \multicolumn{3}{|l|}{$P>0.05$ so assume equal variance } \\
\hline \multicolumn{3}{|c|}{ t-Test: Two-Sample Assuming Equal Variances } \\
\hline \multicolumn{3}{|c|}{ HDFa Control Vs. HDFa Flow VitaSol } \\
\hline & $\begin{array}{c}\text { Variable } \\
1 \\
\end{array}$ & $\begin{array}{c}\text { Variable } \\
2 \\
\end{array}$ \\
\hline Mean & 0.031133 & 0.0327 \\
\hline Variance & $9.43 \mathrm{E}-07$ & $1.72 \mathrm{E}-06$ \\
\hline Observations & 3 & 3 \\
\hline Pooled Variance & $1.33 \mathrm{E}-06$ & \\
\hline Hypothesized Mean Difference & 0 & \\
\hline df & 4 & \\
\hline t Stat & -1.66274 & \\
\hline $\mathrm{P}(\mathrm{T}<=\mathrm{t})$ one-tail & 0.085849 & \\
\hline t Critical one-tail & 2.131847 & \\
\hline$P(T<=t)$ two-tail & 0.171699 & \\
\hline t Critical two-tail & 2.776445 & \\
\hline
\end{tabular}

Table 21: Statistical Table HDFa Control Vs. HDFa Flow VitaSol

F-Test Two-Sample for Variances

HDFa VitaSol Vs. HDFa Flow

\begin{tabular}{lrr}
\hline & Variable & Variable \\
Mean & \multicolumn{1}{c}{1} & \multicolumn{1}{c}{2} \\
\hline Variance & 0.031667 & 0.032467 \\
Observations & $2.17 \mathrm{E}-06$ & $1.26 \mathrm{E}-06$ \\
df & 3 & 3 \\
& 2 & 2
\end{tabular}




\begin{tabular}{|c|c|c|}
\hline $\mathrm{F}$ & 1.720317 & \\
\hline$P(F<=f)$ one-tail & 0.367604 & \\
\hline F Critical one-tail & 19 & \\
\hline \multicolumn{3}{|l|}{$P>0.05$ so assume equal variance } \\
\hline \multicolumn{3}{|c|}{ t-Test: Two-Sample Assuming Equal Variances } \\
\hline \multicolumn{3}{|l|}{ HDFa VitaSol Vs. HDFa Flow } \\
\hline & $\begin{array}{c}\text { Variable } \\
1\end{array}$ & $\begin{array}{c}\text { Variable } \\
2\end{array}$ \\
\hline Mean & 0.031667 & 0.032467 \\
\hline Variance & 2.17E-06 & $1.26 \mathrm{E}-06$ \\
\hline Observations & 3 & 3 \\
\hline Pooled Variance & $1.72 \mathrm{E}-06$ & \\
\hline Hypothesized Mean Difference & 0 & \\
\hline$d f$ & 4 & \\
\hline t Stat & -0.74745 & \\
\hline $\mathrm{P}(\mathrm{T}<=\mathrm{t})$ one-tail & 0.248169 & \\
\hline t Critical one-tail & 2.131847 & \\
\hline $\mathrm{P}(\mathrm{T}<=\mathrm{t})$ two-tail & 0.496337 & \\
\hline t Critical two-tail & 2.776445 & \\
\hline
\end{tabular}

$\mathrm{P}>0.05$ so there is no significant difference between groups

Table 22: Statistical Table HDFa VitaSol Vs. HDFa Flow

F-Test Two-Sample for Variances

HDFa VitaSol Vs. HDFa Flow VitaSol

\begin{tabular}{|c|c|c|}
\hline & $\begin{array}{c}\text { Variable } \\
1 \\
\end{array}$ & $\begin{array}{c}\text { Variable } \\
2 \\
\end{array}$ \\
\hline Mean & 0.031667 & 0.0327 \\
\hline Variance & 2.17E-06 & $1.72 \mathrm{E}-06$ \\
\hline Observations & 3 & 3 \\
\hline$d f$ & 2 & 2 \\
\hline $\mathrm{F}$ & 1.263566 & \\
\hline$P(F<=f)$ one-tail & 0.441781 & \\
\hline F Critical one-tail & 19 & \\
\hline \multicolumn{3}{|l|}{$P>0.05$ so assume equal variance } \\
\hline \multicolumn{3}{|c|}{ t-Test: Two-Sample Assuming Equal Variances } \\
\hline \multicolumn{3}{|l|}{ HDFa VitaSol Vs. HDFa Flow VitaSol } \\
\hline & $\begin{array}{c}\text { Variable } \\
1 \\
\end{array}$ & $\begin{array}{c}\text { Variable } \\
2 \\
\end{array}$ \\
\hline Mean & 0.031667 & 0.0327 \\
\hline
\end{tabular}




\begin{tabular}{|c|c|c|}
\hline Variance & 2.17E-06 & $1.72 \mathrm{E}-06$ \\
\hline Observations & 3 & 3 \\
\hline Pooled Variance & $1.95 \mathrm{E}-06$ & \\
\hline Hypothesized Mean Difference & 0 & \\
\hline df & 4 & \\
\hline t Stat & -0.90707 & \\
\hline $\mathrm{P}(\mathrm{T}<=\mathrm{t})$ one-tail & 0.207837 & \\
\hline t Critical one-tail & 2.131847 & \\
\hline $\mathrm{P}(\mathrm{T}<=\mathrm{t})$ two-tail & 0.415673 & \\
\hline t Critical two-tail & 2.776445 & \\
\hline \multicolumn{3}{|c|}{$\begin{array}{l}\mathrm{P}>0.05 \text { so there is no significant difference between } \\
\text { groups }\end{array}$} \\
\hline \multicolumn{3}{|c|}{ Table 23: Statistical Table HDFa VitaSol Vs. HDFa Flow VitaSol } \\
\hline \multicolumn{3}{|l|}{ F-Test Two-Sample for Variances } \\
\hline \multicolumn{3}{|l|}{ HDFa Flow Vs. HDFa Flow VitaSol } \\
\hline & $\begin{array}{c}\text { Variable } \\
1\end{array}$ & $\begin{array}{l}\text { Variable } \\
2\end{array}$ \\
\hline Mean & 0.032467 & 0.0327 \\
\hline Variance & $1.26 \mathrm{E}-06$ & $1.72 \mathrm{E}-06$ \\
\hline Observations & 3 & 3 \\
\hline df & 2 & 2 \\
\hline $\mathrm{F}$ & 0.734496 & \\
\hline$P(F<=f)$ one-tail & 0.423464 & \\
\hline F Critical one-tail & 0.052632 & \\
\hline \multicolumn{3}{|l|}{$P>0.05$ so assume equal variance } \\
\hline \multicolumn{3}{|c|}{ t-Test: Two-Sample Assuming Equal Variances } \\
\hline \multicolumn{3}{|l|}{ HDFa Flow Vs. HDFa Flow VitaSol } \\
\hline & $\begin{array}{l}\text { Variable } \\
1\end{array}$ & $\begin{array}{l}\text { Variable } \\
2\end{array}$ \\
\hline Mean & 0.032467 & 0.0327 \\
\hline Variance & $1.26 \mathrm{E}-06$ & $1.72 \mathrm{E}-06$ \\
\hline Observations & 3 & 3 \\
\hline Pooled Variance & 1.49E-06 & \\
\hline Hypothesized Mean Difference & 0 & \\
\hline df & 4 & \\
\hline t Stat & -0.23398 & \\
\hline $\mathrm{P}(\mathrm{T}<=\mathrm{t})$ one-tail & 0.413243 & \\
\hline t Critical one-tail & 2.131847 & \\
\hline $\mathrm{P}(\mathrm{T}<=\mathrm{t})$ two-tail & 0.826485 & \\
\hline t Critical two-tail & 2.776445 & \\
\hline
\end{tabular}


$\mathrm{P}>0.05$ so there is no significant difference between

groups

Table 24: Statistical Table HDFa Flow Vs. HDFa Flow VitaSol 
Appendix III: Representative Photos From Each Testing Group

\section{HUVEC Control Initial:}

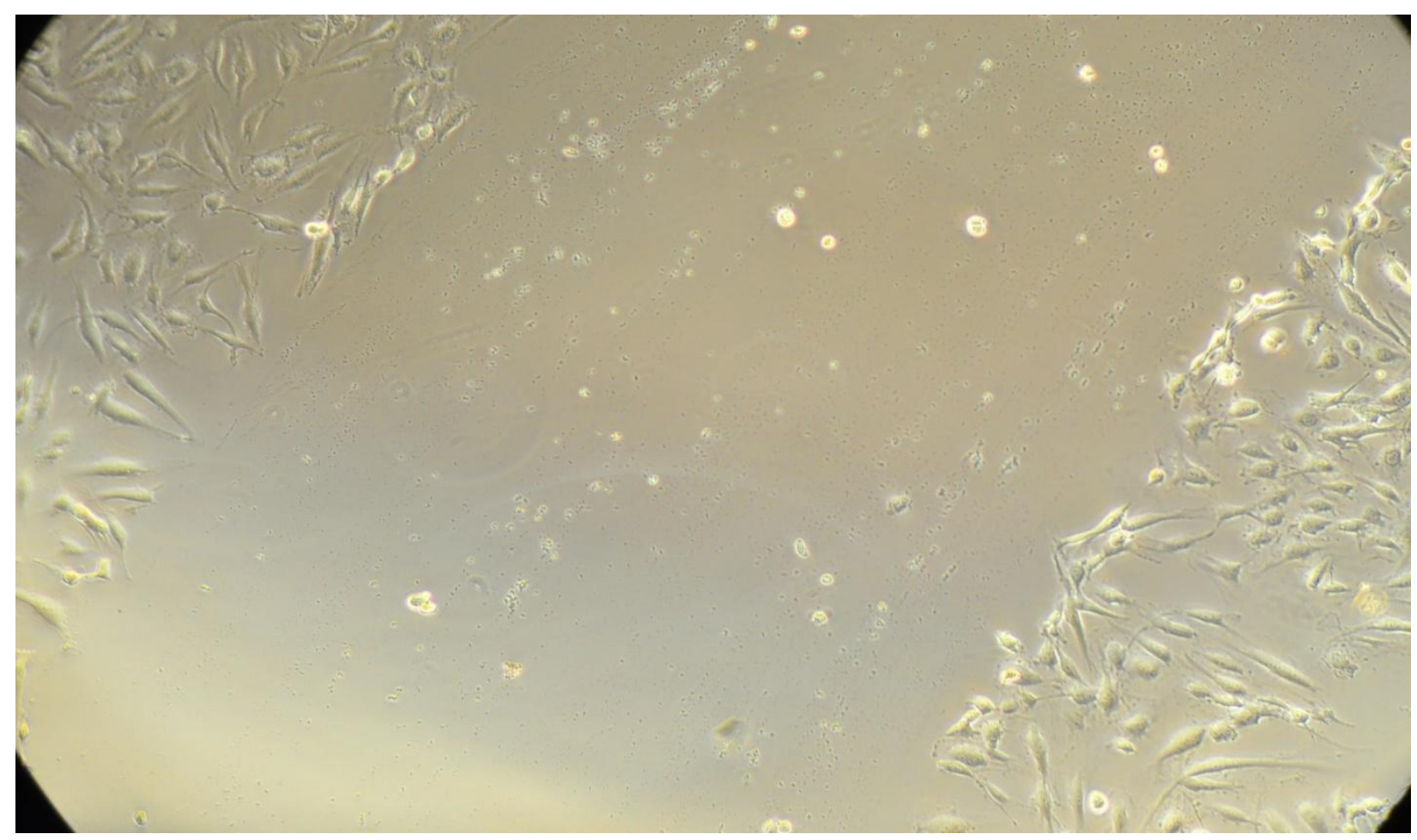

HUVEC Control Intermediate:

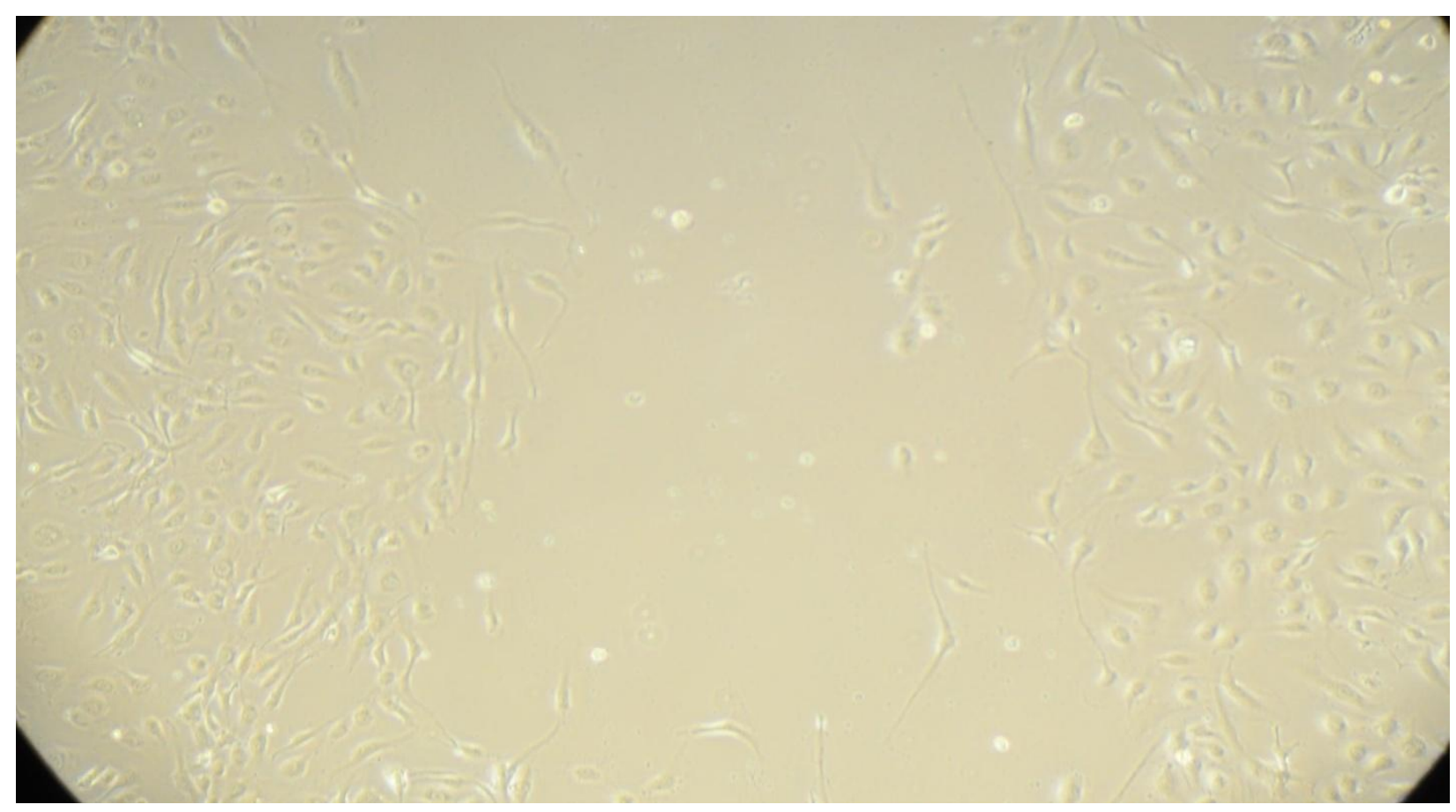




\section{HUVEC Control Final:}

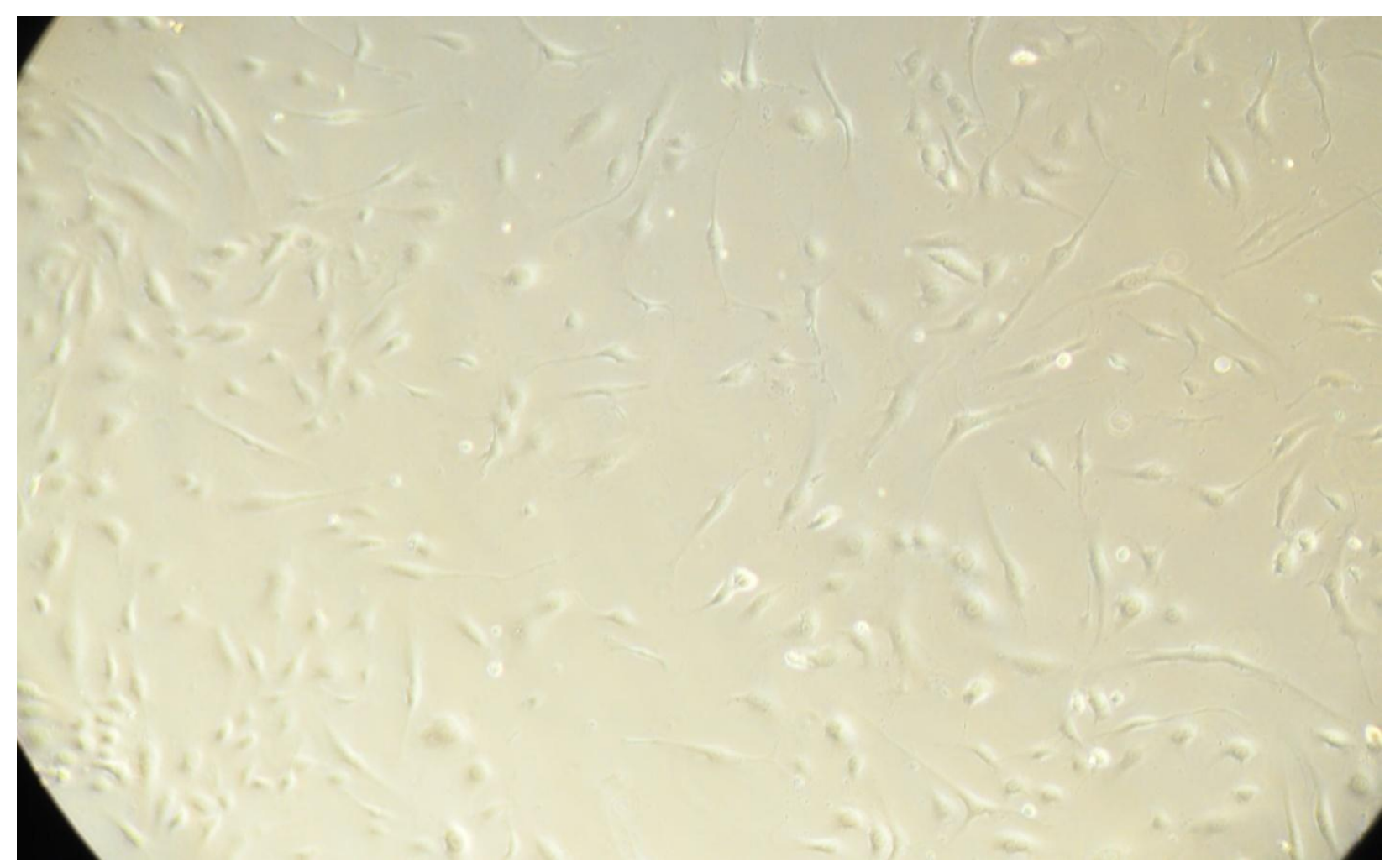

HUVEC VitaSol Initial:




HUVEC VitaSol Intermediate:

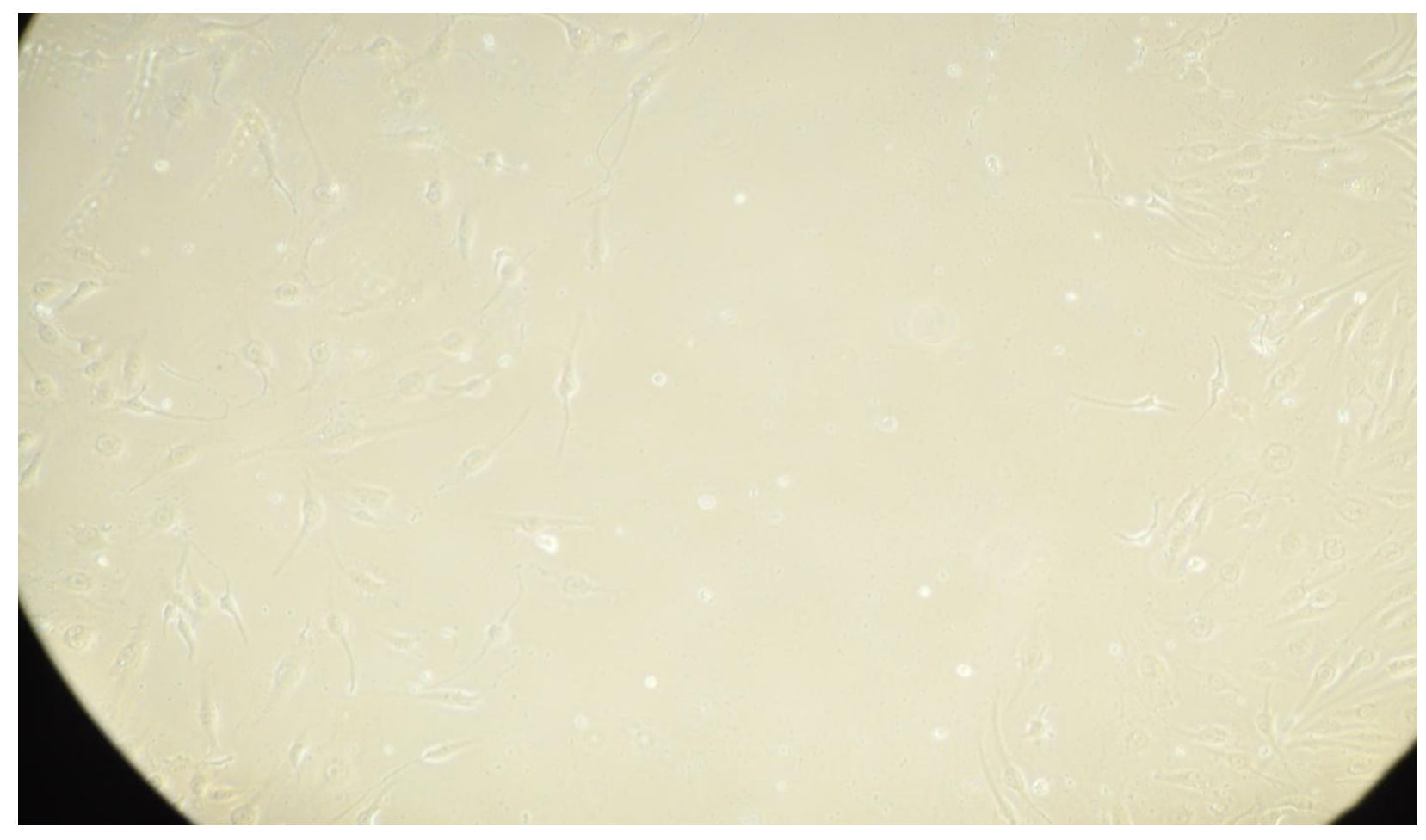

HUVEC VitaSol Final:

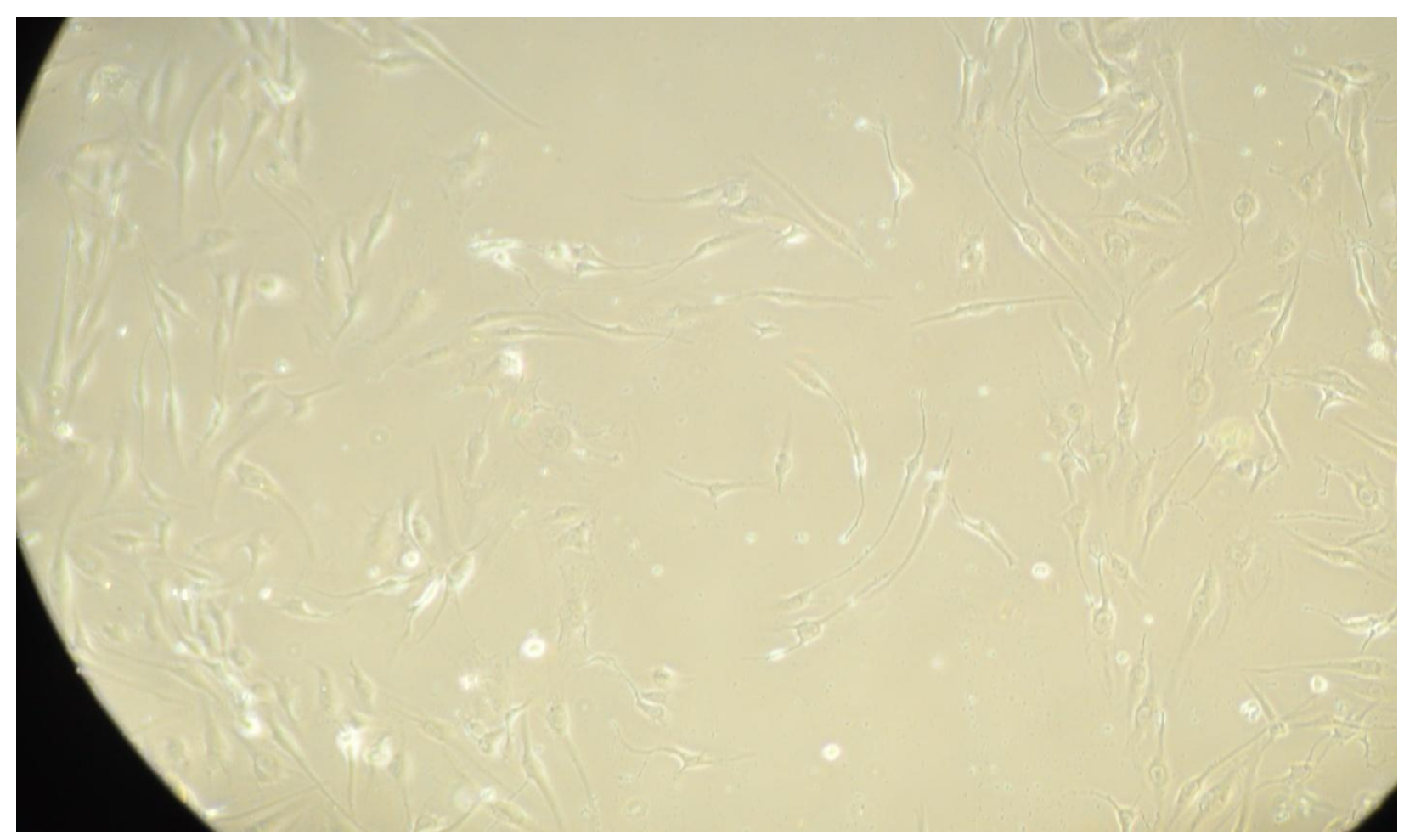


HUVEC Flow Initial:



HUVEC Flow Intermediate:

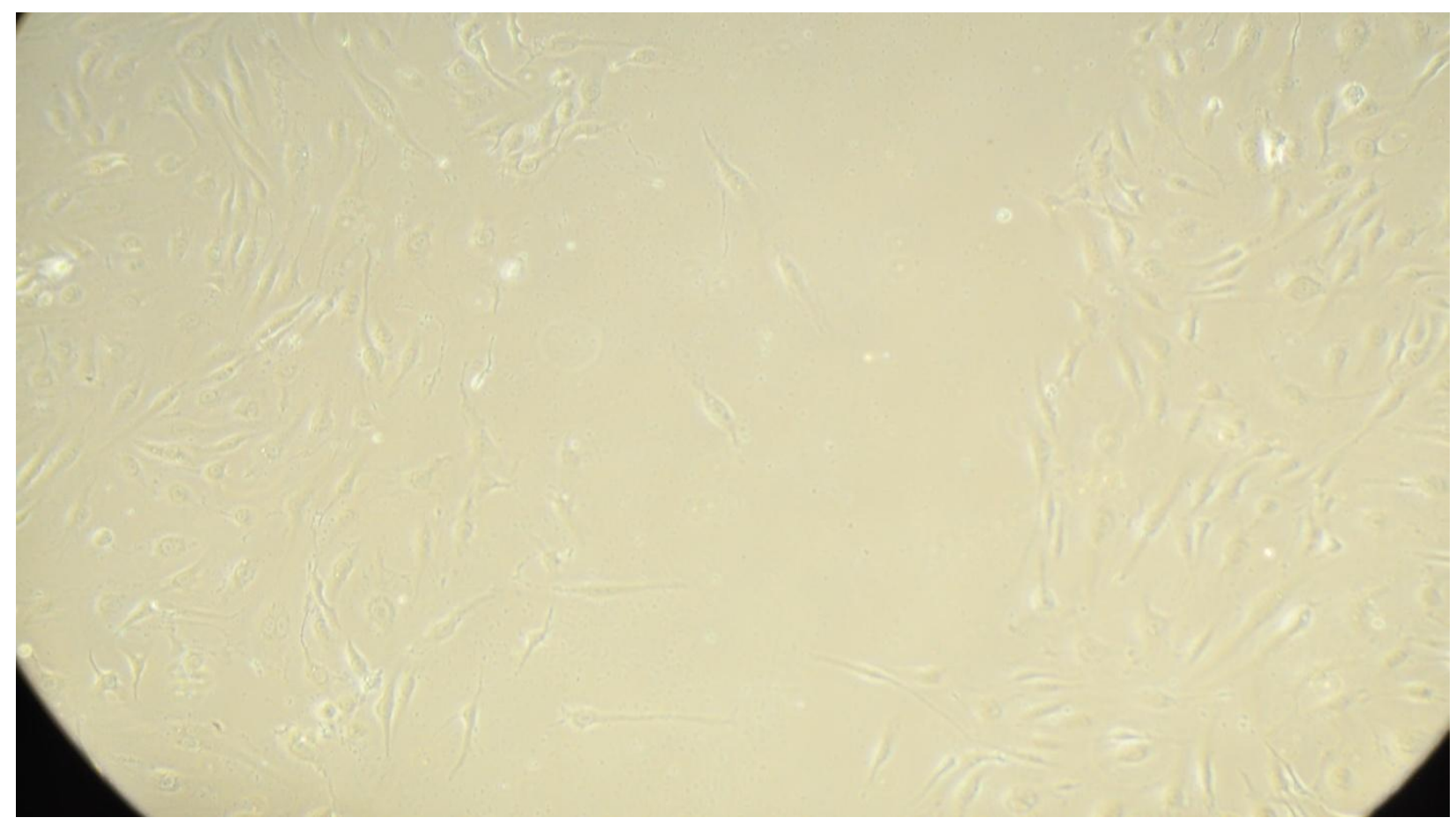




\section{HUVEC Flow Final:}

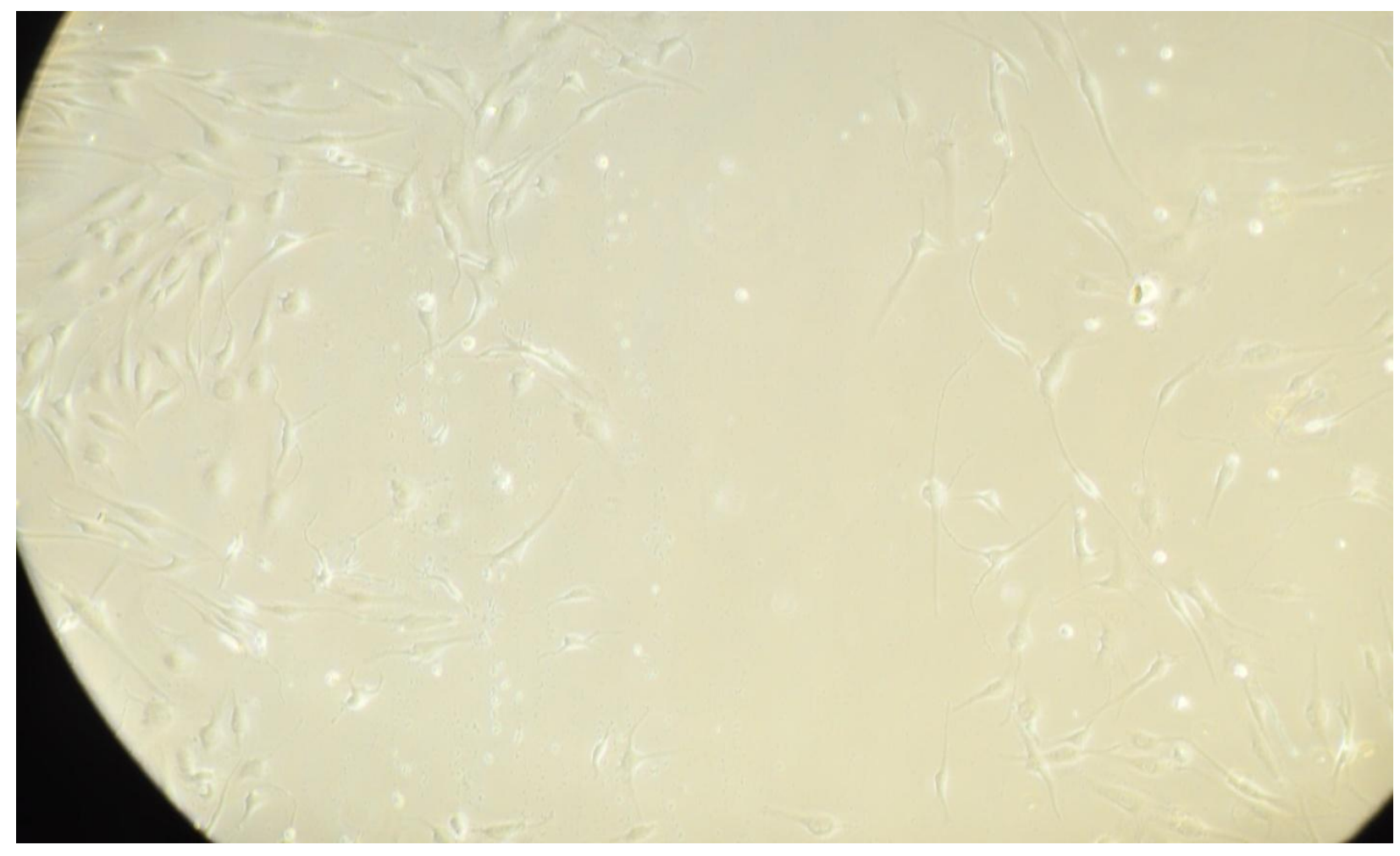

\section{HUVEC Flow VitaSol Initial:}




HUVEC Flow VitaSol Intermediate:

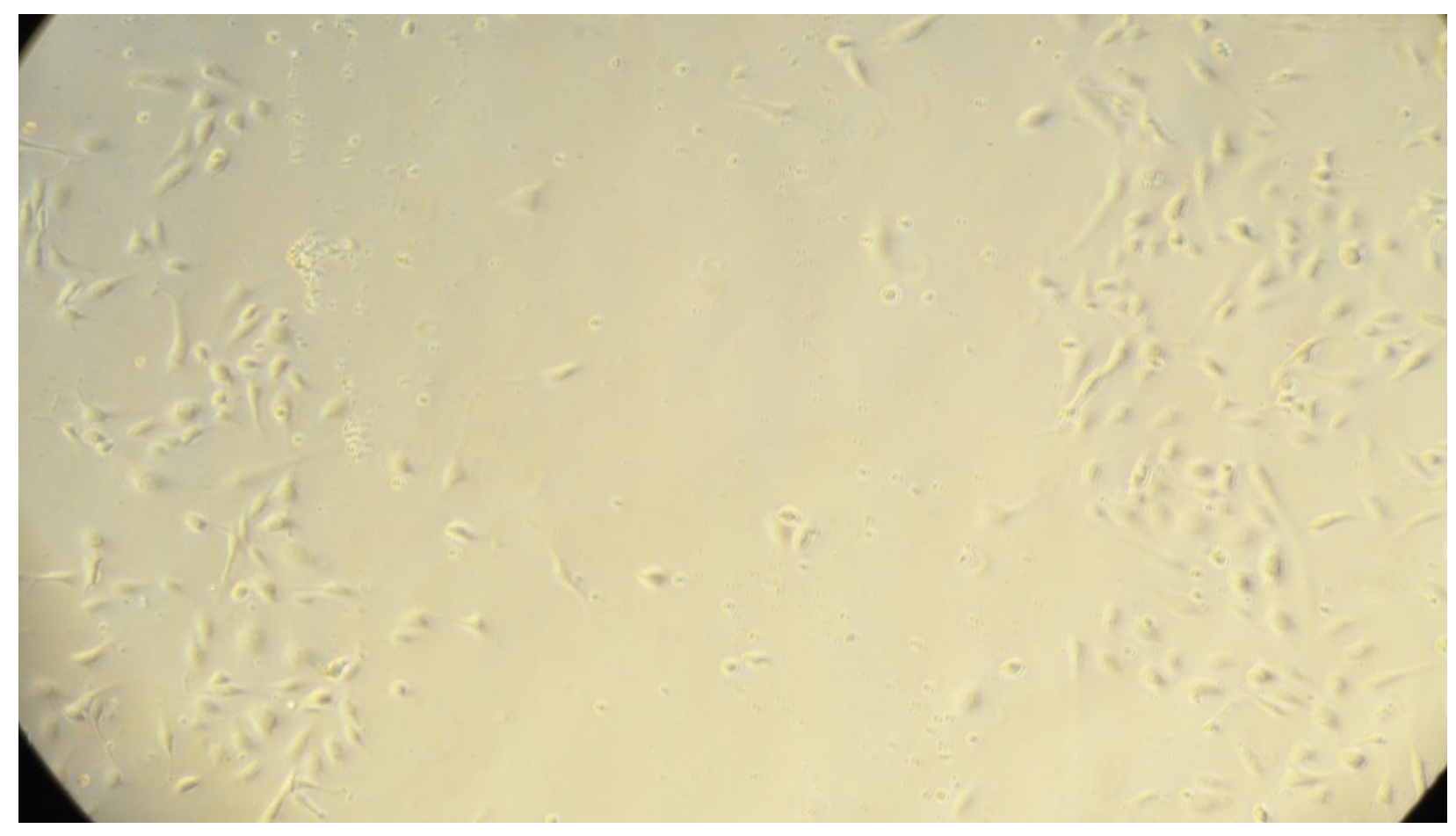

HUVEC Flow VitaSol Final:




HDFa Control Initial:



HDFa Control Intermediate:




HDFa Control Final:

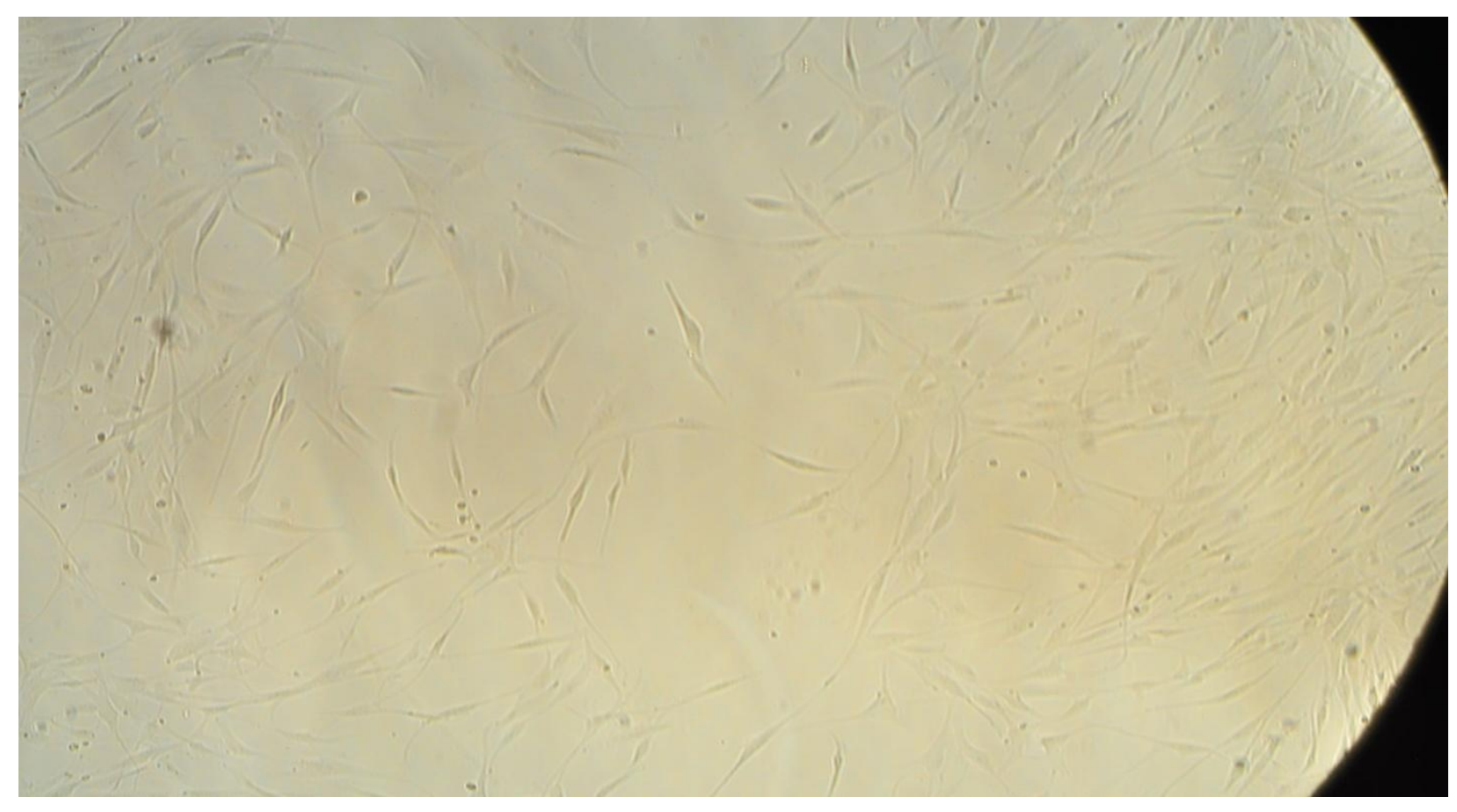

HDFa VitaSol Initial:

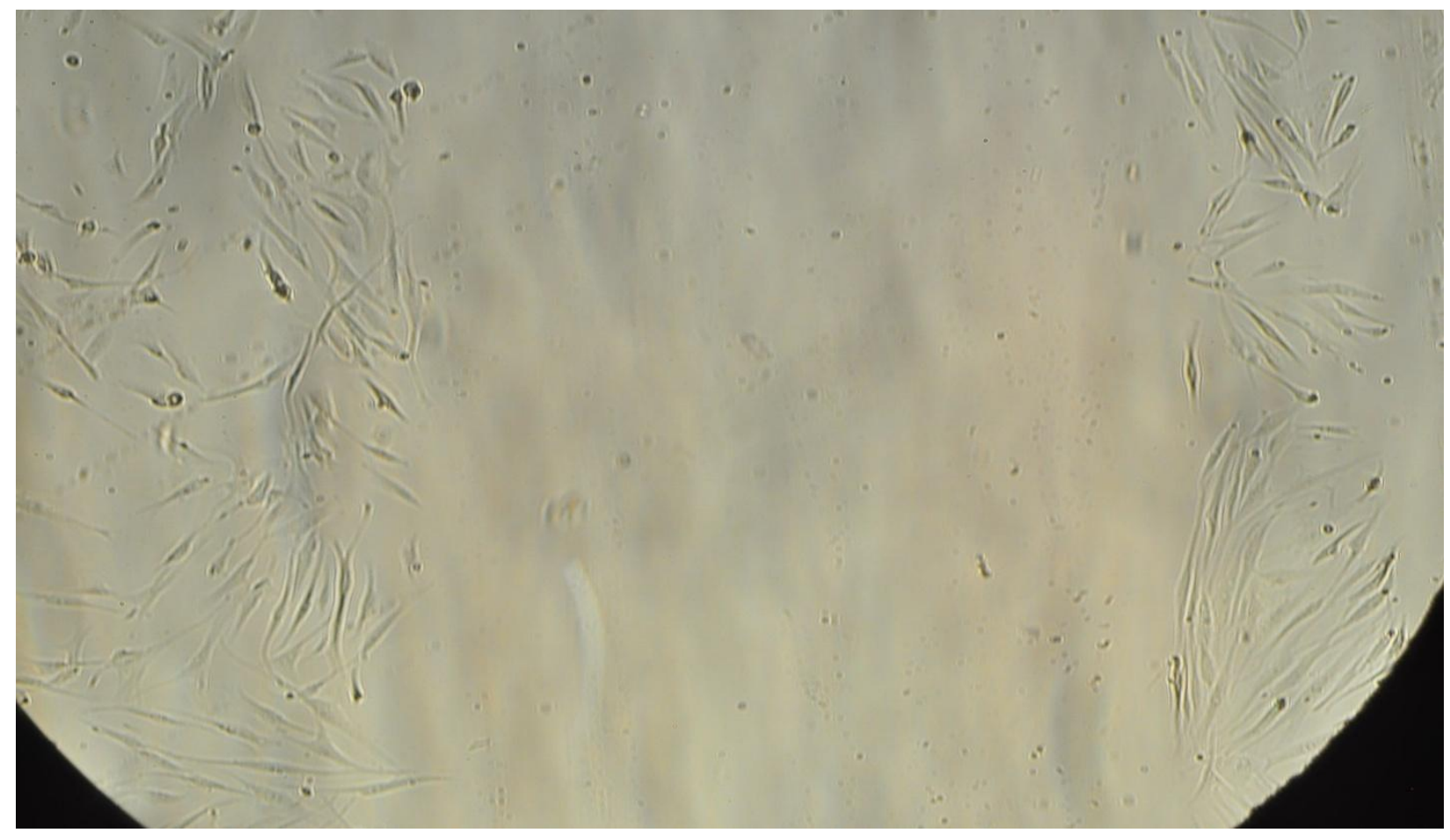


HDFa VitaSol Intermediate:

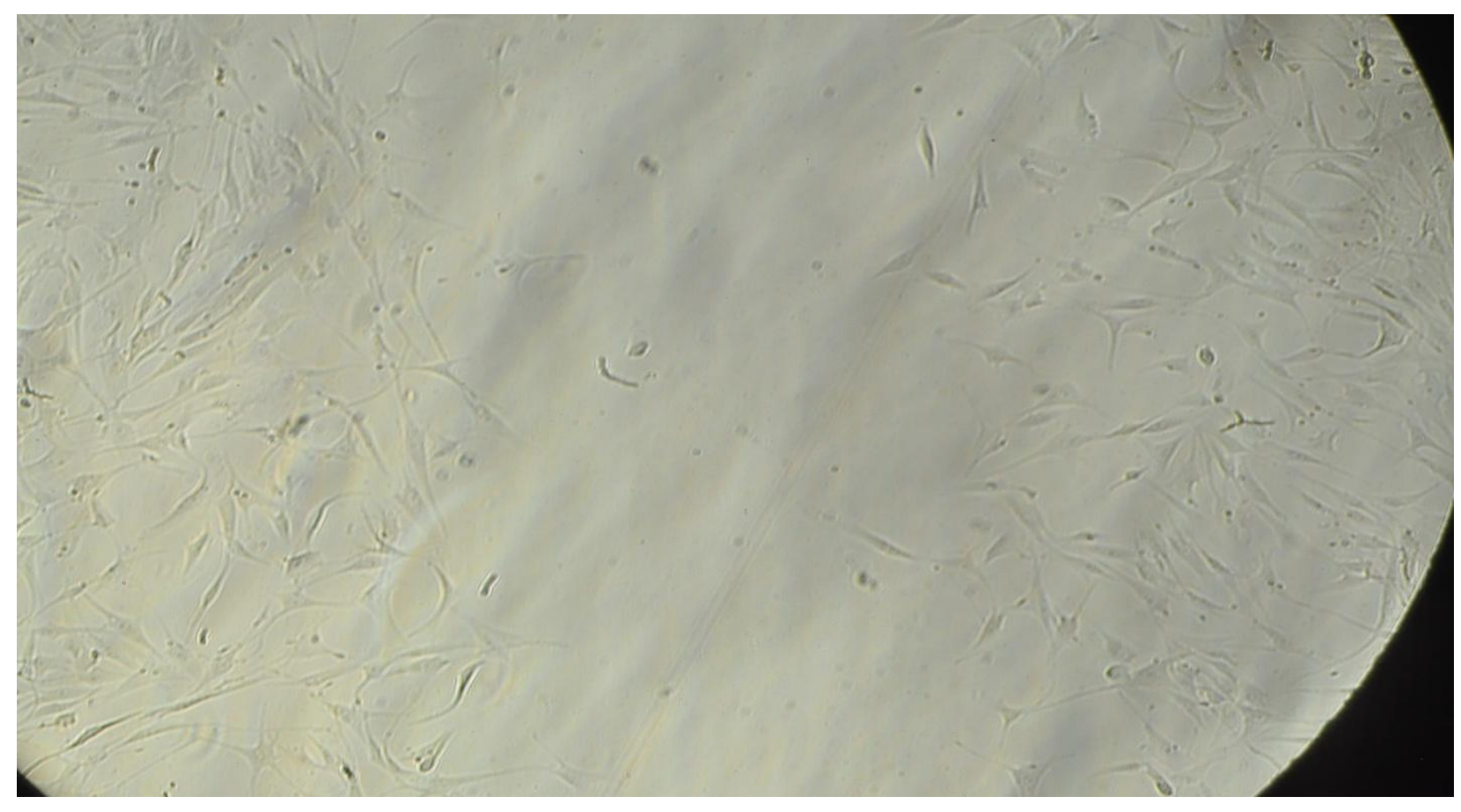

HDFa VitaSol Final:

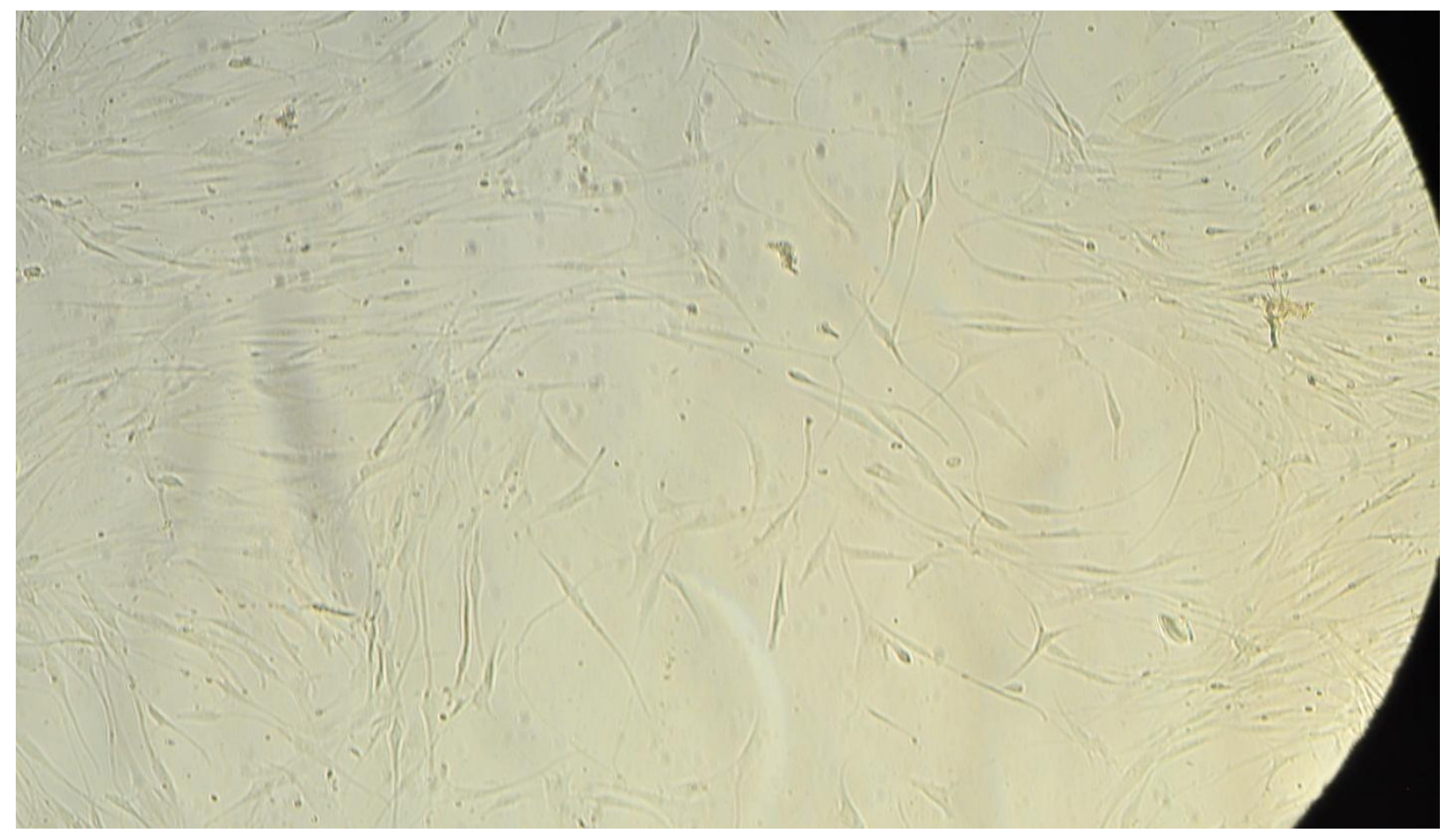


HDFa Flow Initial:

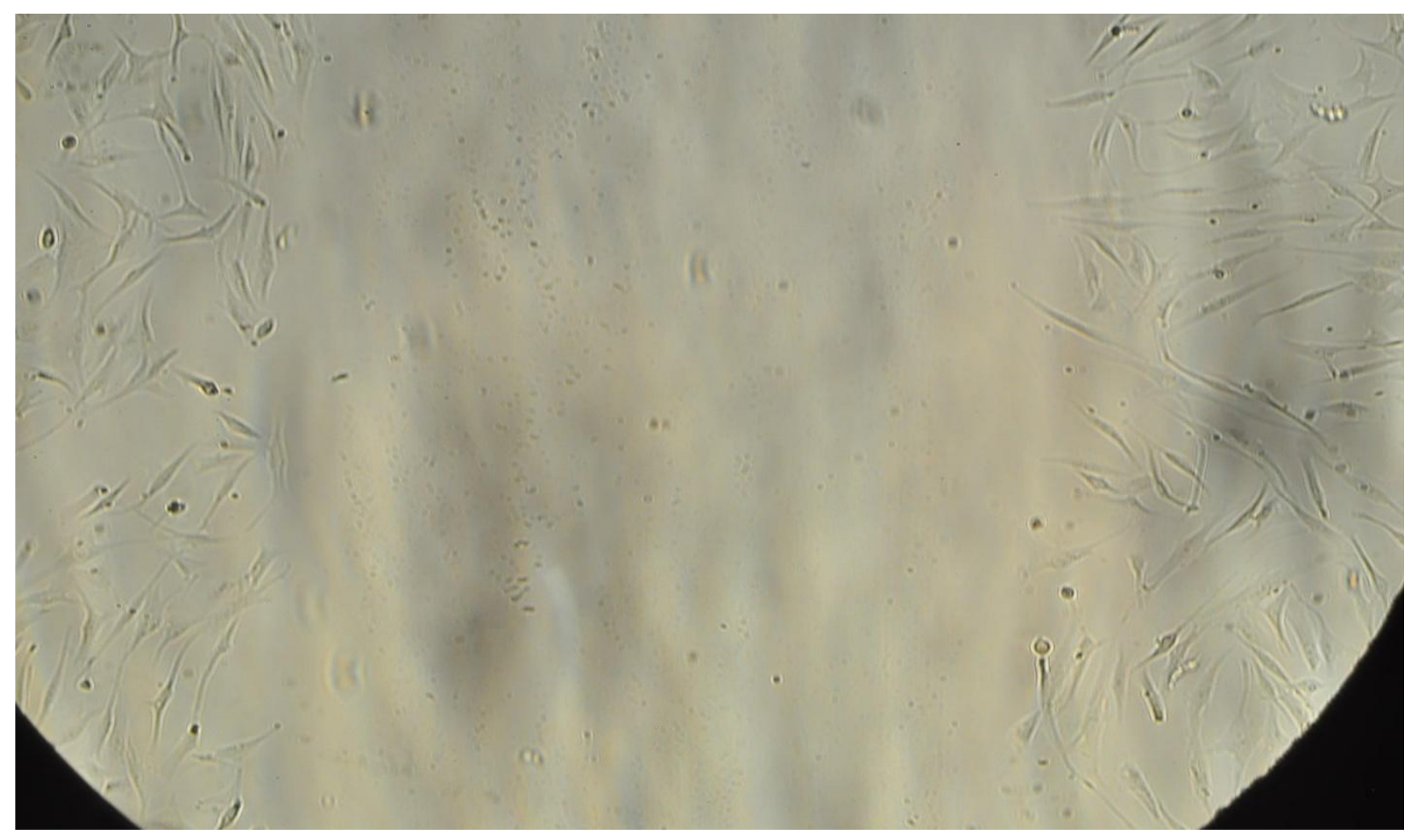

HDFa Flow Intermediate:

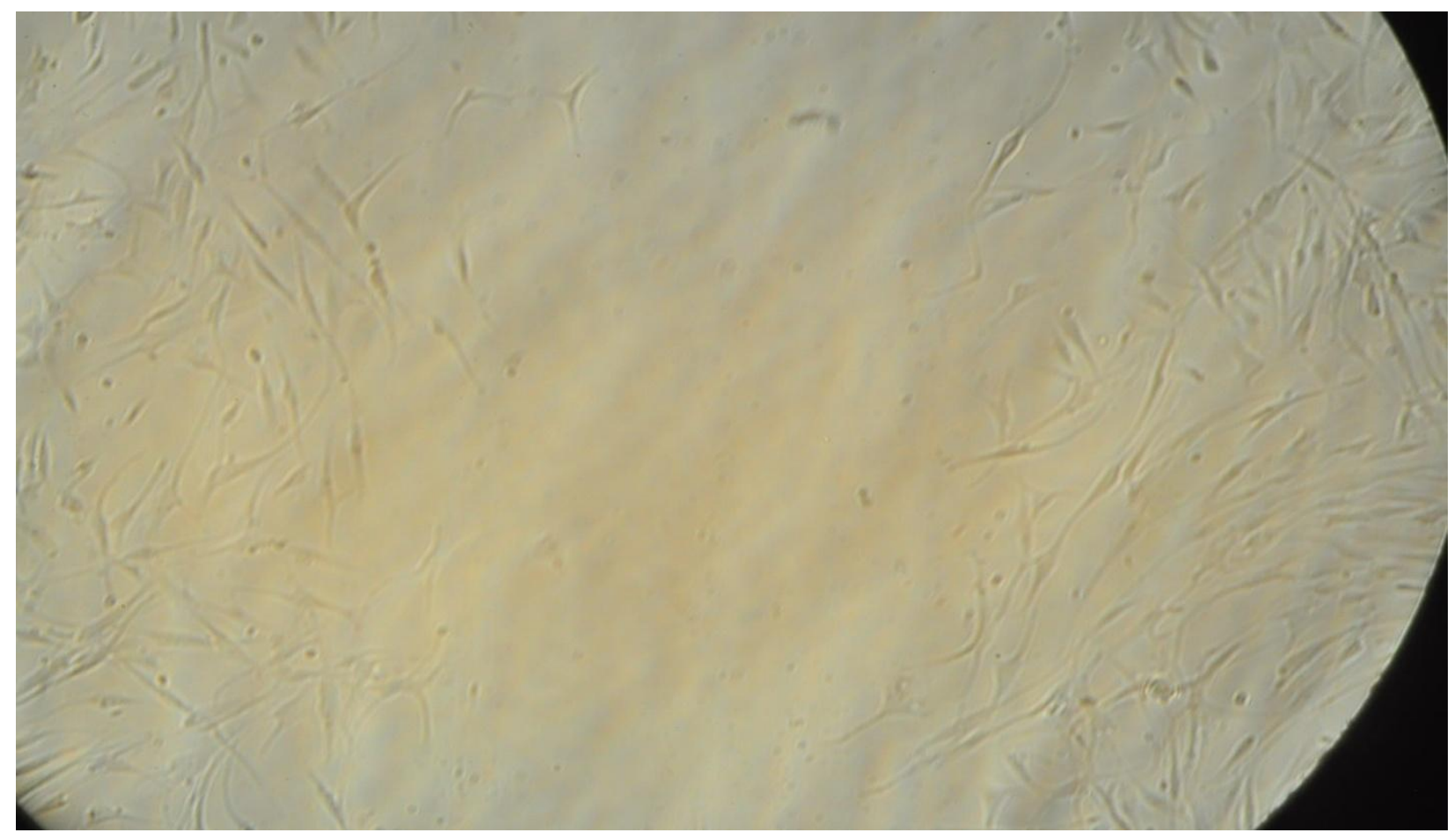


HDFa Flow Final:

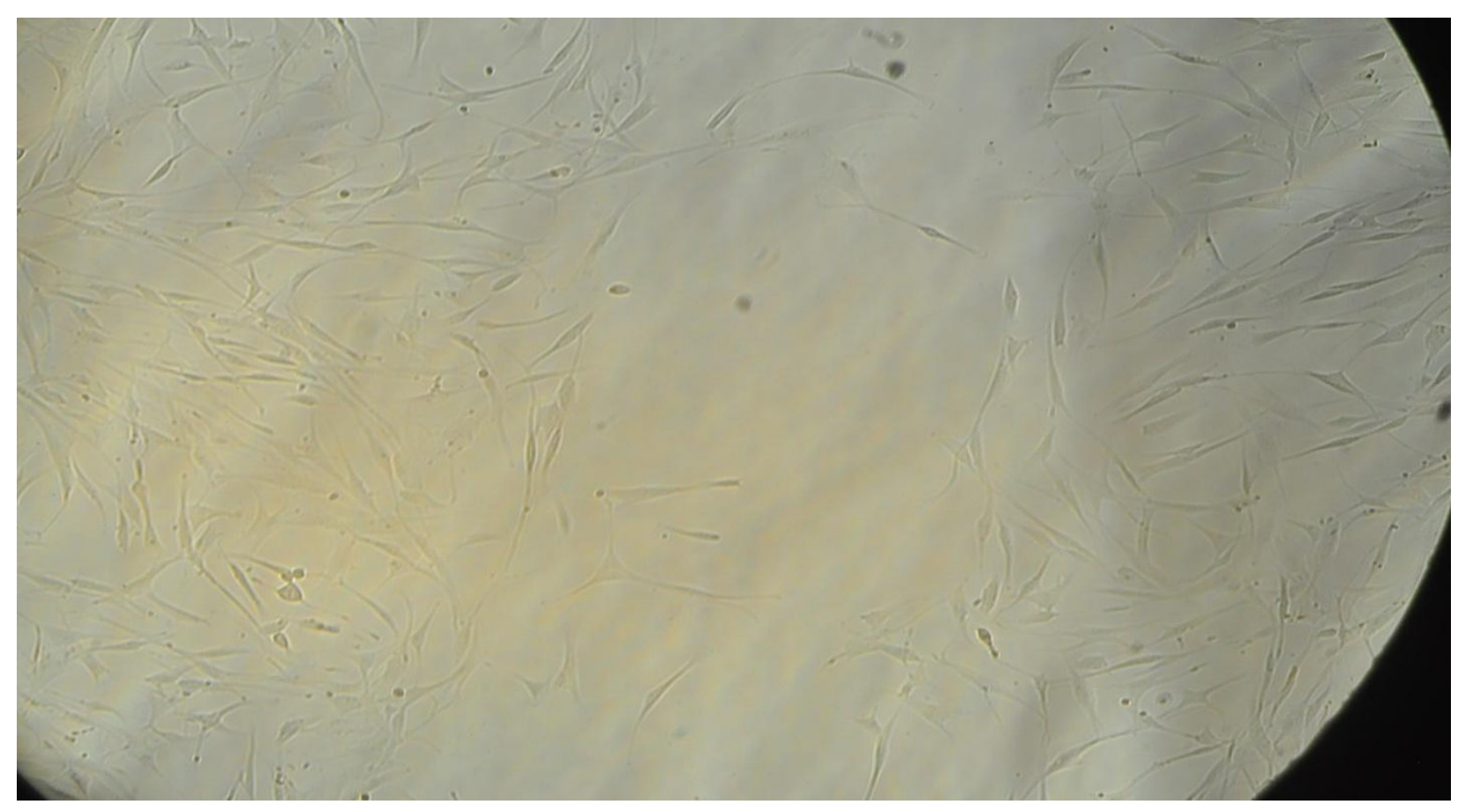

HDFa Flow VitaSol Initial:

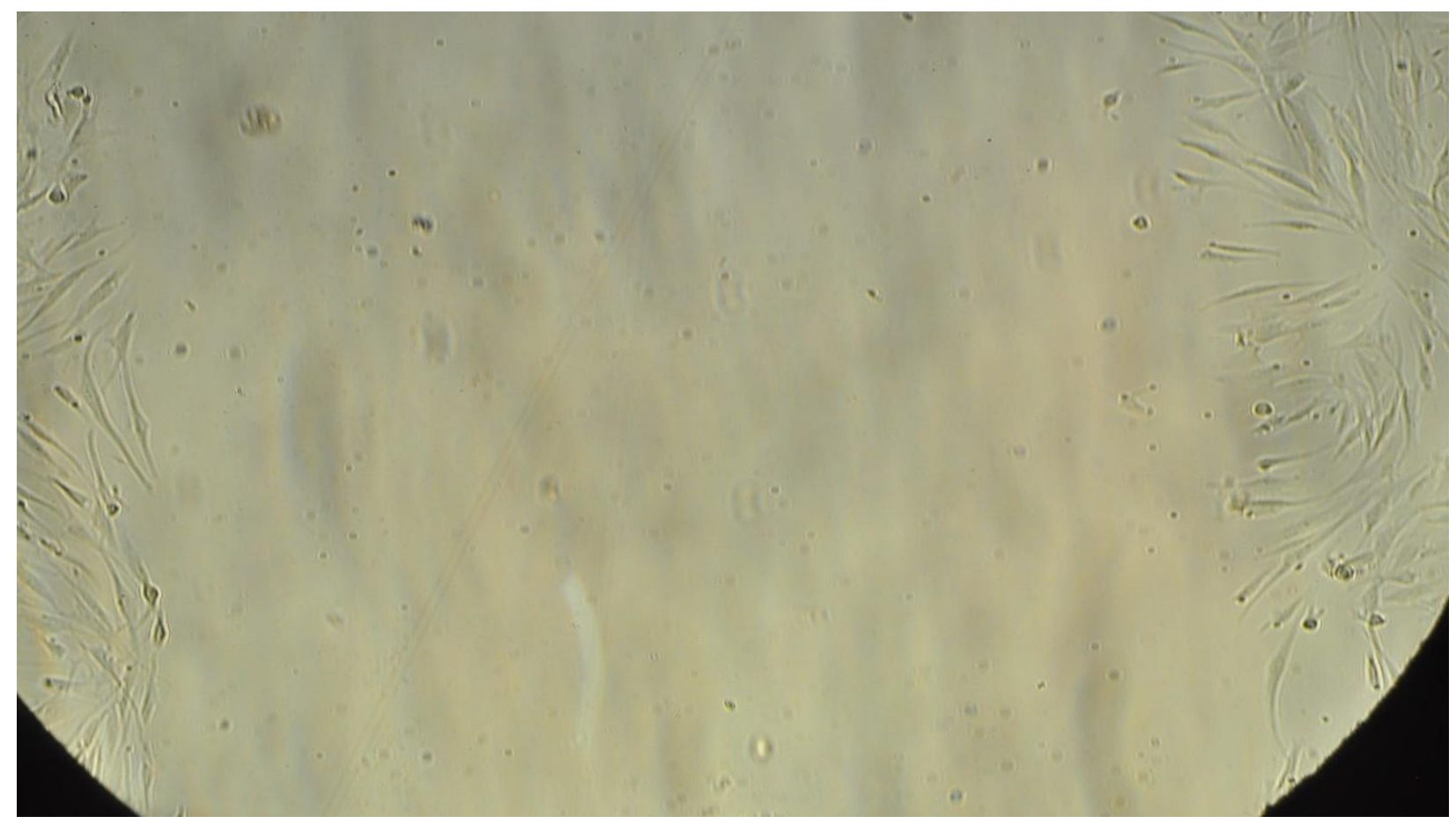


HDFa Flow VitaSol Intermediate:



HDFa Flow VitaSol Final:

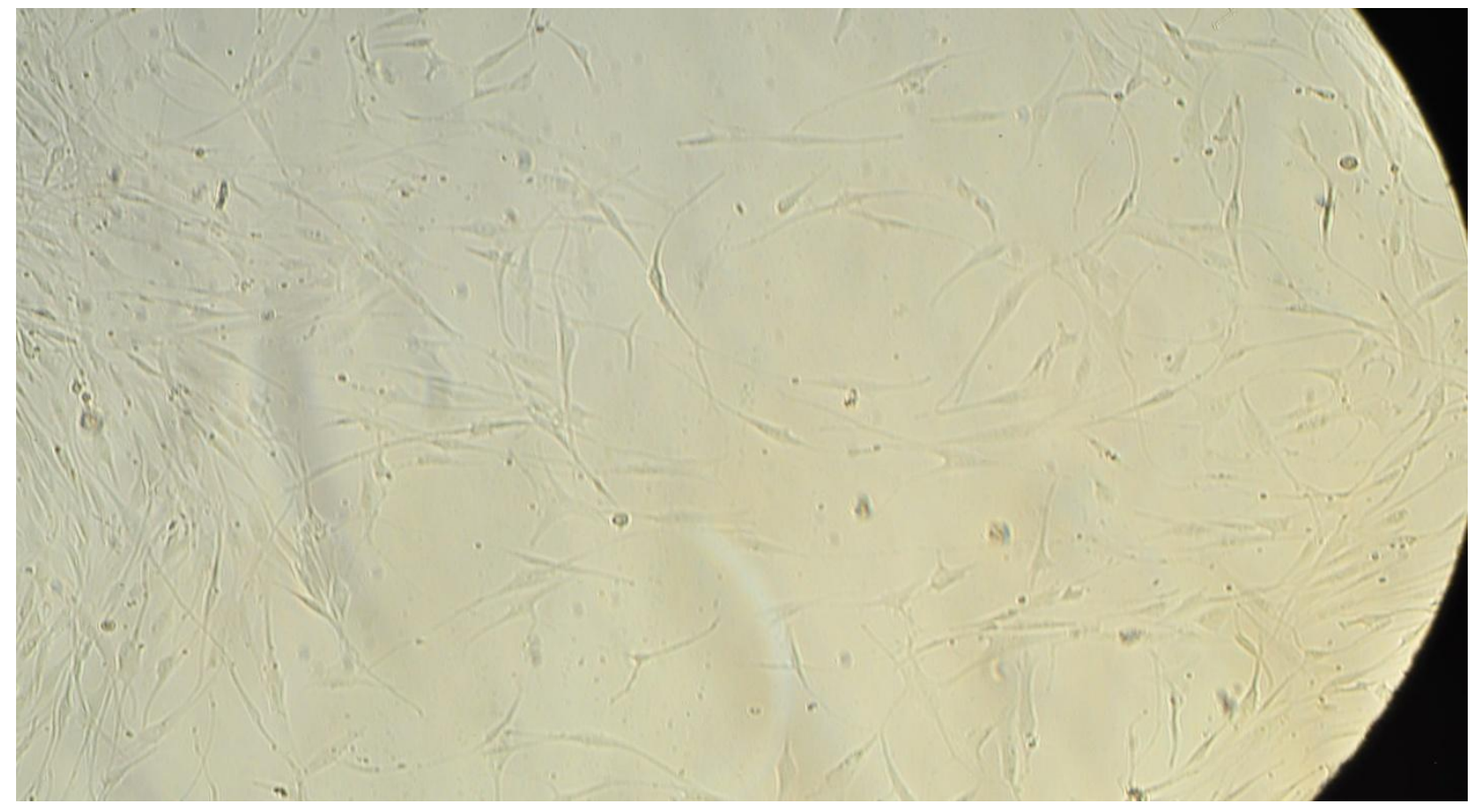




\section{VITA:}

Daniel Joseph Baumann is from the Northern Kentucky - Greater Cincinnati area and has lived in Louisville since first starting his Bioengineering Bachelors degree at University of Louisville in Fall of 2007. Upon completion of his master's degree, he plans to continue his education by starting medical school in Fall of 2013. He plans to make contributions to the medical field by utilizing his unique academic background that has fostered innovative and problem solving skill sets, as well as provide exceptional care for his patients. 